\title{
The Hendrickson 'POP' reagent and analogues thereof: synthesis, structure, and application in organic synthesis
}

\author{
Ziad Moussa \\ Department of Chemistry, Taibah University, P.O. Box 30002, \\ Almadinah Almunawarrah, Saudi Arabia \\ E-mail: zmousa@taibahu.edu.sa
}

\begin{abstract}
This comprehensive review discusses the synthesis, structure, and application of the Hendrickson 'POP' reagent and its analogues in organic synthesis. Specifically, the review describes applications of the preceding dehydrating agents in functional group interconversions, heterocycle synthesis, and total synthesis of natural products. Many examples are provided from the literature to show the scope and selectivity (regio and chemo) in these transformations.
\end{abstract}

Keywords: Hendrickson 'POP' reagent, functional group interconversions, heterocycle synthesis, total synthesis of natural products

\section{Table of Contents}

1. Introduction

2. The Hendrickson Reagent

2.1. Preparation of the Hendrickson reagent

2.2. Application of the Hendrickson reagent in functional group interconversions

2.2.1. Conversion of aldoximes into nitriles

2.2.2. Conversion of carboxylic acids to benzimidazole, benzoxazole, and benzthiazole heterocycles

2.2.3. Amide and amidine synthesis

2.2.4. Conversion of carboxylic acids into acid anhydrides

2.2.5. Ester formation from acid and alcohol

2.2.6. Conversion of activated ketones to alkynes

2.2.7. Cyclodehydrations of diols and amino alcohols

2.2.8. Conversion of epoxides to dienes

2.2.8.1 Mechanism of double elimination of epoxides to dienes

2.2.9. Conversion of sulfonic acids to sulfonamides and activated sulfonate esters 
2.2.10. Dehydrative glycosylation

2.3. Heterocycle synthesis

2.3.1. Synthesis of thiazolines

2.3.2. Synthesis of imidazolines

2.3.3. Solid-phase synthesis of hiazole- and imidazole-containing peptides

2.3.4. Synthesis of indolizino[1,2- $b]$ quinolin-9(11H)-ones

2.3.5. Synthesis of alkynyl imines as precursors to quinolines

2.3.5.1. Proposed mechanism for the reaction of $N$-arylbenzamides with bis(trimethylsilyl)acetylene in the presence of $\mathbf{1}$

2.3.6. Synthesis of isoquinolines and $\beta$-carbolines

2.3.7. Synthesis of phenanthridines

2.3.7.1. Proposed mechanism for Hendrickson reagent promoted intramolecular Friedel-Crafts reaction in the synthesis of phenanthridines

2.3.8 Synthesis of $11 H$-indolo[3,2-c] quinolines

2.3.8.1 Proposed mechanism for Hendrickson reagent promoted 6-endo cyclization in the synthesis of $11 H$-indolo[3,2-c]quinolines

2.3.9 Synthesis of quinoline-lactones and furoquinolinones

2.3.9.1 Proposed mechanism for Hendrickson reagent promoted cascade aza DielsAlder reaction

2.4 Application of the Hendrickson reagent in total synthesis of natural products

2.4.1 Total synthesis of dendroamide A

2.4.2 Total synthesis of bistratamides E-J

2.4.3 Total synthesis of didmolamides A and B

2.4.4 Total synthesis of (+)-largazole

2.4.5 Total synthesis of apratoxin A

2.4.6. Total synthesis of camptothecin

2.4.7. Total synthesis of 22-hydroxyacuminatine and luotonin A

2.4.8. Total synthesis of 14-azacamptothecin

2.4.9. Enantioselective total synthesis of 14-azacamptothecin

3. Analogues of the Hendrickson Reagent

3.1 Jenkins' cyclic analogues of the Hendrickson reagent

3.1.1 Application of Jenkins' cyclic reagents in the synthesis of esters and amides

3.1.2 Application of Jenkins' cyclic reagents in the synthesis of 2-oxazolines, 2thiazolines, and related derivatives

3.2 Jenkins' polymer-supported analogues of the Hendrickson reagent

3.2.1 Synthetic transformations using Jenkins' polymer-supported triphenylphosphine ditriflate 1

3.3 Mahdavi's polymer-supported analogue of the Hendrickson reagent

3.3.1 Synthesis 
3.3.2 Dehydration reactions with Mahdavi's polymer-supported analogue of the Hendrickson reagent

3.4 Moussa's analogues of the Hendrickson reagent

3.4.1 Moussa's triphenylphosphine /triflic anhydride dehydrating system

3.4.2 Moussa's cyclic aromatic analogues of the Hendrickson reagent

3.4.3. Synthesis and electrophilic properties

4. Conclusions

5. Acknowledgements

6. References

\section{Introduction}

One of the most fundamental and central reactions in organic synthesis involves activating oxygen with electrophilic species to induce its release as a nucleofuge by elimination or substitution reactions, with an overall net loss of water. In this regard, alkoxyphosphonium salts have attracted the interest of many research groups worldwide due to their intermediacy in various transformations such as the $\mathrm{Appel}^{1}$ and Mitsunobu ${ }^{2}$ reactions in which they selectively target and abstract oxygen. As such, phosphorus electrophiles are highly oxophilic and form unusually strong P-O bond which is considered to be the driving force for a fast first attack on oxygen and subsequent release of the oxygen as a phosphoryl group in the second step. Whereas the Appel reaction has been mainly used to convert alcohols to the corresponding halides, the Mitsunobu reaction has enjoyed a much more privileged role in synthetic chemistry because of its wider scope, stereospecificity, and mild reaction conditions. ${ }^{3}$ One of the drawbacks of such a reaction though from a safety perspective is the use of dialkyl azodicarboxylate reagents. In addition, the alkylation of the hydrazinedicarboxylate and other side reactions may occur. Desired characteristics of an effective dehydrating agent include ease of preparation, high selectivity toward attack on oxygen, preclusion of intrinsic nucleophiles, high reactivity to permit reactions to proceed rapidly at ambient conditions, and tolerance of a range of common solvents.

The Hendrickson 'POP' reagent, bis(triphenyl)oxodiphosphonium trifluoromethane-sulfonate (1) is an effective agent for dehydration reactions which appears to bring about dehydration in a manner analogous to the Mitsunobu reaction (an alkoxyphosphonium salt). ${ }^{4}$ The reagent was discovered over 30 years ago, preceding the Mitsunobu reaction by a few years. Surprisingly, the similarity between both reagents was overlooked for many years and, in contrast to the Mitsunobu reaction which has been extensively used over the years since its inception, further exploration of the full synthetic potential of the Hendrickson reagent or variations thereof was not aggressively pursued. However, lately the Hendrickson reagent and its analogues have emerged as powerful and selective dehydrating agents as demonstrated by the recent surge of papers published by various research groups on a wide range of transformations mediated by such reagents. This topic has not yet been reviewed in the literature. Thus, in this comprehensive 
review, an attempt to give an overall detailed picture has been made by taking examples from the literature during the last 36 years. The review will focus on the preparation of the Hendrickson reagent and analogues thereof and their utility in functional group interconversions, heterocyclic synthesis, and preparation of natural products.

\section{The Hendrickson reagent}

\subsection{Preparation of the Hendrickson reagent}

When the reagent was first reported, ${ }^{4}$ Hendrickson erroneously postulated that it was the monophosphonium triphenyl(trifluoromethylsulfonyloxy)phosphonium trifluoromethanesulfonate salt $\left(\mathrm{Ph}_{3} \mathrm{P}(\mathrm{OTf})_{2}\right)$ but was subsequently shown by Aaberg et al. to be the diphosphonium analogue $\left(\mathrm{Ph}_{3} \mathrm{P}^{+}\right)_{2} \mathrm{O} .2 \mathrm{OTf}$ (1) (Scheme 1). ${ }^{5}$ The molecular weight was determined by titration with aqueous sodium hydroxide and the elemental analysis data corroborated the proposed structure (Anal. calcd. for $\mathrm{C}_{38} \mathrm{H}_{30} \mathrm{O}_{7} \mathrm{~F}_{6} \mathrm{P}_{2} \mathrm{~S}_{2}$ : C, 54.42; H, 3.61; P, 7.39; S, 7.65\%, MW, 838.7). Found: C, 54.34; H, 3.81; P, 7.24; S, 7.02; MW, 837). Mindful of the new proposed structure, the initial procedure which called for the reaction of triphenylphosphine oxide $\left(\mathrm{Ph}_{3} \mathrm{PO}\right)$ with an equimolar amount of trifluoromethanesulfonic anhydride (triflic anhydride, $\mathrm{Tf}_{2} \mathrm{O}$ ) comprised an extra equivalent of triflic anhydride, an indiscriminate electrophile itself. Under these conditions, the remaining unreacted excess triflic anhydride masked the true identity of the electrophilic species responsible for dehydration. Thus, following the report of Aaberg et al., a new preparation protocol was advanced in which the new reagent may be formed instantly at $0{ }^{\circ} \mathrm{C}$ in $\mathrm{CH}_{2} \mathrm{Cl}_{2}$ from $2 \mathrm{Ph}_{3} \mathrm{P}=\mathrm{O}+\mathrm{Tf}_{2} \mathrm{O}$. Alternatively, the reagent can be prepared in 1,2-dichloroethane by briefly refluxing the mixture at $83{ }^{\circ} \mathrm{C}$. ${ }^{6}$ The first step in the reaction is believed to be the formation of the monophosphonium salt which gets rapidly attacked by the phosphoryl group of another molecule of $\mathrm{Ph}_{3} \mathrm{PO}$. The diphosphonium salt is very reactive as it contains two non-nucleophlic triflate groups. A base, often $\mathrm{Et}_{3} \mathrm{~N}$, is often used to neutralize the triflic acid formed during dehydration. The reagent is commonly used directly as prepared in $\mathrm{CH}_{2} \mathrm{Cl}_{2}$ without isolation. However, it may be precipitated as a white crystalline solid (mp 74-75 ${ }^{\circ} \mathrm{C}$ ) and re-dissolved in pyridine or THF for other applications by addition of diethyl ether and subsequent dry filtration (Schlenck or syringe decantation). Exposure of the complex to air or water causes rapid decomposition. However, it is stable for several months when stored under an inert atmosphere of nitrogen. The structure was conclusively determined by X-ray diffraction crystallography which revealed the anticipated O-bridged bis-phosphonium salt. ${ }^{7}$ Furthermore, in order to ensure that the solid-state structure was consistent with the reactive intermediates in solution, the ${ }^{31} \mathrm{P}$ NMR spectrum of the crystallized bis-phosphonium salt was compared to those of reagents prepared with various stoichiometric amounts of $\mathrm{Ph}_{3} \mathrm{PO}$ and $\mathrm{Tf}_{2} \mathrm{O}$. The study demonstrated that 1 was the sole species in solution $\left[{ }^{31} \mathrm{P} \delta\left(162 \mathrm{MHz}, \mathrm{CD}_{3} \mathrm{CN}\right) 77\right.$ ppm, $\mathrm{Ph}_{3} \mathrm{P}$ was used as an internal standard], regardless of whether one or two equivalents of $\mathrm{Tf}_{2} \mathrm{O}$ were used with two equivalents of $\mathrm{Ph}_{3} \mathrm{PO}$. 


$$
2 \mathrm{Ph}_{3} \mathrm{P}=\mathrm{O}+\mathrm{Tf}_{2} \mathrm{O} \stackrel{\mathrm{a}}{\longrightarrow} \underset{\mathbf{1}}{\left(\mathrm{Ph}_{3} \mathrm{P}^{+}\right)_{2} \mathrm{O} .2 \mathrm{OTf}^{-}} \begin{gathered}
\text { Hendrickson's } \\
\text { 'POP' reagent }
\end{gathered}
$$

Scheme 1. Preparation of the Hendrickson reagent 1. Reagents and conditions: (a) $\mathrm{Ph}_{3} \mathrm{PO}: \mathrm{Tf}_{2} \mathrm{O}$ (2:1 stoichiometry), $0{ }^{\circ} \mathrm{C}, \mathrm{CH}_{2} \mathrm{Cl}_{2}$.

\subsection{Application of the Hendrickson reagent in functional group interconversions}

Although preliminary studies on the application of the Hendrickson reagent $\mathbf{1}$ in the one-step synthesis of amides and their dehydrations to nitriles were reported in 1975 in the same paper that disclosed the reagent, ${ }^{4}$ incorrect stoichiometry of $\mathrm{Ph}_{3} \mathrm{PO}$ and $\mathrm{Tf}_{2} \mathrm{O}$ was used $(1: 1)$, casting doubt on the true identity of the electrophilic dehydrating species because the reaction contained excess and deleterious triflic anhydride. Thus, the dehydration reactions reported in this early publication will not be reviewed. However, reexamination of the preceding reactions (vide infra) using the correct stoichiometry consistently gave superior result than previously reported.

2.2.1. Conversion of aldoximes into nitriles. One of the initial brief assessments of the efficacy of reagent $\mathbf{1}$ involved dehydrating aldoximes into nitriles as shown in Table $1 .^{6}$ The reagent was prepared in situ in 1,2-dichloroethane and treated with the aldoxime and $\mathrm{Et}_{3} \mathrm{~N}$ to afford the products in yields over $93 \%$. The conversion occurred rapidly at room temperature in most cases (complete conversion within 5 minutes) and produced high yields with alkyl, aryl, and heterocyclic aldoximes.

Table 1. Dehydration of aldoximes into nitriles

Entry


2.2.2. Conversion of carboxylic acids to benzimidazole, benzoxazole, and benzthiazole heterocycles. In an initial effort to prepare 2-arylbenzimidazoles, the cyclodehydration of monoamides, produced by the monoacylation of diamines with aroyl chlorides, proceeded in an excellent fashion. ${ }^{6}$ In this transformation, the amide function of the amino amide substrate is activated with the reagent (1) at oxygen to give a phosphonium imino ether, which is readied for a second nucleophilic substitution and elimination of $\mathrm{Ph}_{3} \mathrm{PO}$. Thus, the nucleophilic amine tether reacts with the phosphonium imino ether intermediate in an addition-elimination sequence to afford the cyclodehydrated product. However, apart from requiring two steps, selective monoacylation of diamines was very difficult due to the concomitant formation of the diamide byproduct. Pleasingly, it was found that using 2 moles of reagent 1 produced the same 2 arylbenzimidazoles by directly reacting the carboxylic acid with the diamine (Table 2). The reaction comprises two successive dehydration steps of the parent carboxylic acid. Surprisingly, this protocol transcends typical procedures which require elevated temperatures and afford much lower yields of similar heterocycles. Thus, with reagent $\mathbf{1}$, most reactions proceeded to completion within $1 \mathrm{~h}$ at $0{ }^{\circ} \mathrm{C}$ or room temperature (Entries 1-5). However, with naphthalene-1,8diamine as a substrate (Entry 6), the reaction was refluxed at $83{ }^{\circ} \mathrm{C}$ for 100 minutes. Finally, in addition to diamines, other nucleophilic substrates (o-aminophenol and $o$-aminothiophenol) reacted successfully with the acids to produce benzoxazole and benzthiazole heterocycles (Entries 7 and 8, respectively). ${ }^{8}$

Table 2. Double dehydration of carboxylic acids with various bis-nucleophiles

Entry


Table 2. Continued

Entry Acid

2.2.3. Amide and amidine synthesis. The reaction of an equimolar amount of acid with primary or secondary amines in the presence of $\mathbf{1}$ (1 equiv.) undergoes immediate dehydration to yield amides cleanly and in high yields (78-90\%) (Table 3). ${ }^{8}$ It is noted that, while most common methods for amide synthesis require prior activation of the acid, in the current coupling protocol both components may be mixed with the reagent. Although amines react preferentially with $\mathbf{1}$ due to their enhanced nucleophilicity, the resulting intermediate $\left(\mathrm{Ph}_{3} \mathrm{P}^{+} \mathrm{NR}_{2}\right)$ undergoes rapid exchange in order to form the stronger phosphorus-oxygen bond and eventually eliminates $\mathrm{Ph}_{3} \mathrm{PO}$, which is a more thermodynamically favored process. In addition, selectivity for oxygen may arise from the presence of two electron pairs on oxygen as opposed to one electron pair on nitrogen that can back-donate into the p-orbitals of phosphorus. Primary and secondary amines were also successfully coupled with amides (Table 3 ) to afford amidines in high yields (Entries 6 and 7 ; 86-94\%).

Table 3. Amide ${ }^{a}$ and amidine ${ }^{b}$ synthesis

Entry Acid or Amide


Table 3. Continued

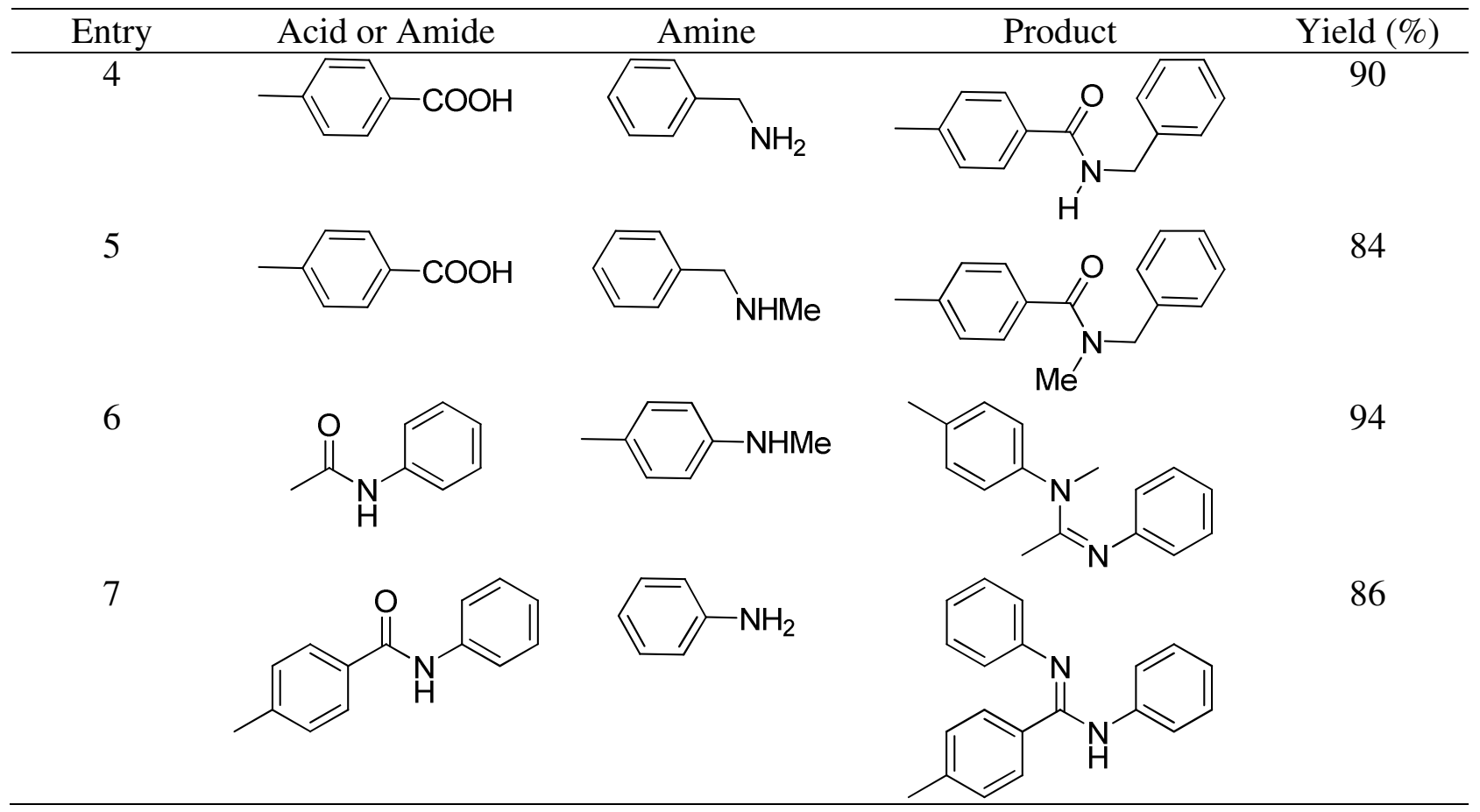

${ }^{a}$ Reagents and conditions: 2:1:1:1:2 molar ratios of $\mathrm{Ph}_{3} \mathrm{PO}: \mathrm{Tf}_{2} \mathrm{O}: \mathrm{RCOOH}$ or amide:amine: $\mathrm{Et}_{3} \mathrm{~N}$ in $\mathrm{C}_{2} \mathrm{H}_{4} \mathrm{Cl}_{2} / 25^{\circ} \mathrm{C} / 15 \mathrm{~min} ;{ }^{\mathrm{b}} 8 \mathrm{~h}$ time for amidines was required at $25^{\circ} \mathrm{C}$.

2.2.4. Conversion of carboxylic acids into acid anhydrides. Carboxylic acids may be activated by reagent 1 , forming an $\mathrm{RCOO}^{+} \mathrm{PPh}_{3}$ intermediate and eliminating $\mathrm{Ph}_{3} \mathrm{PO}$. The activated carboxylic acid may be envisaged to either undergo elimination from the $\alpha-\mathrm{CH}$ to give a ketene, or displacement by a nucleophile. If no external nucleophile is present and the acid is used in excess, substitution by a carboxylate should produce the corresponding anhydride by eliminating a second molecule of $\mathrm{Ph}_{3} \mathrm{PO}$. Indeed, when 2 moles of carboxylic acid in dichloromethane were mixed with 1 mole of reagent 1 and 2 moles of $\mathrm{Et}_{3} \mathrm{~N}$ at room temperature, the corresponding anhydride formed immediately in high yield (Table 4). ${ }^{8}$ The base was used, not only to neutralize the generated triflic acid, but to facilitate removal of $\mathrm{Ph}_{3} \mathrm{PO}$. When no base was used, the reaction between the acid and reagent was very sluggish at room temperature as copious amount of acid remained unreacted after several hours. When acid substrates bearing $\alpha$-hydrogen with higher acidity were utilized, preferential formation of the ketene was observed. For instance, diphenylacetic acid underwent immediate and quantitative conversion to diphenylketene (Entry 5), whereas phenylacetic acid formed the anhydride as the sole product (Entry 3). Interestingly, this protocol provides a simpler and more effective approach to prepare ketenes than known methods as simple removal of the solvent, followed by extraction with hexane produced pure ketenes, rendering distillation unnecessary. 
Table 4. Dehydration of carboxylic acids ${ }^{\mathrm{a}}$

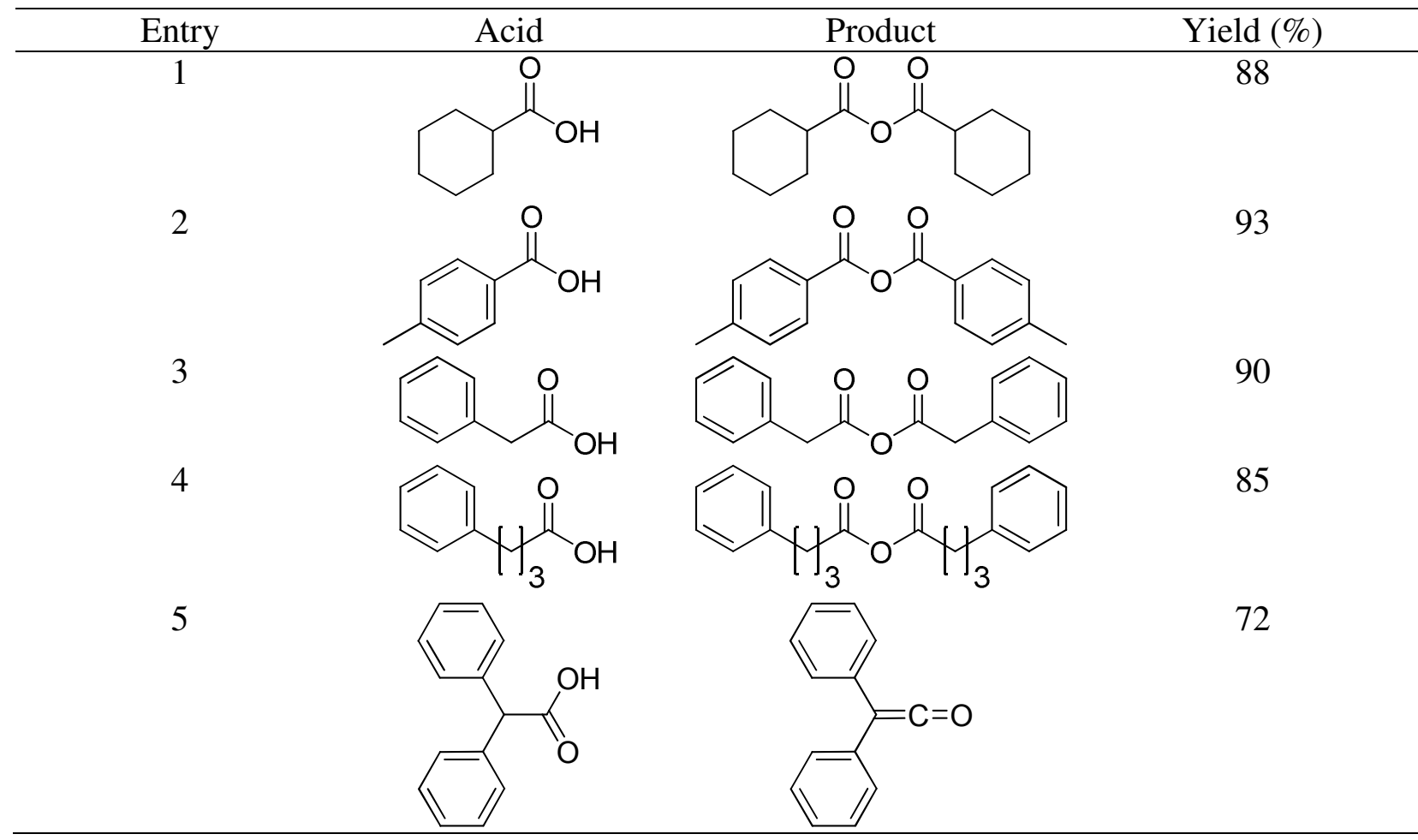

${ }^{\mathrm{a} C o n d i t i o n s: ~ 2: 1: 2: 2 ~ m o l a r ~ r a t i o s ~ o f ~} \mathrm{Ph}_{3} \mathrm{PO}: \mathrm{Tf}_{2} \mathrm{O}: \mathrm{RCOOH}: \mathrm{Et}_{3} \mathrm{~N}$ in $\mathrm{C}_{2} \mathrm{H}_{4} \mathrm{Cl}_{2} / 25^{\circ} \mathrm{C} / 15$ min.

2.2.5. Ester formation from acid and alcohol. It can be envisaged that reagent 1 may activate either oxygen when added to a mixture of acid and alcohol in the presence of $\mathrm{Et}_{3} \mathrm{~N}$. This is inconsequential as both pathways would lead to the formation of an ester. Hence, if the carboxylic acid is activated first, it becomes a strong acylating agent and the ester is consequently formed by acylating the alcohol. Alternatively, if the alcohol is activated first, the carboxylate can react with the phosphonium complex $\left(\mathrm{RO}^{+} \mathrm{PPh}_{3}\right)$ to afford the ester via $O$ alkylation. The latter pathway, however, may prove detrimental in the case of hindered alcohols (secondary and tertiary) and phenols where substitution may not be possible. Fortunately, a third pathway involving fast exchange of phosphonium between activated alcohol and acid may be in operation. As shown in Table 5, a variety of alcohols were successfully coupled to carboxylic acids by adding a dichloromethane solution of a 1:1:2 mixture of acid, alcohol, and $\mathrm{Et}_{3} \mathrm{~N}$ to the reagent. ${ }^{8}$ While yields obtained with primary and secondary alcohols were high, the yield of ester generated form 2-methyl-2-propanol was only $42 \%$ (Entry 4).

This was attributed to the concurrent elimination pathway of the activated alcohol to isobutene. Interestingly, while this result suggests some degree of alcohol activation, preferential activation of alcohol may inhibit ester formation unless there is a subsequent transfer of the phosphonium group. Indeed when $p$-cresol was deliberately activated with reagent 1 (Entry 5), followed by the addition of $p$-toluic acid, the ester formed rapidly, underscoring free exchange of the phosphonium group. 
Table 5. Ester formation ${ }^{\mathrm{a}}$ from acid and alcohol

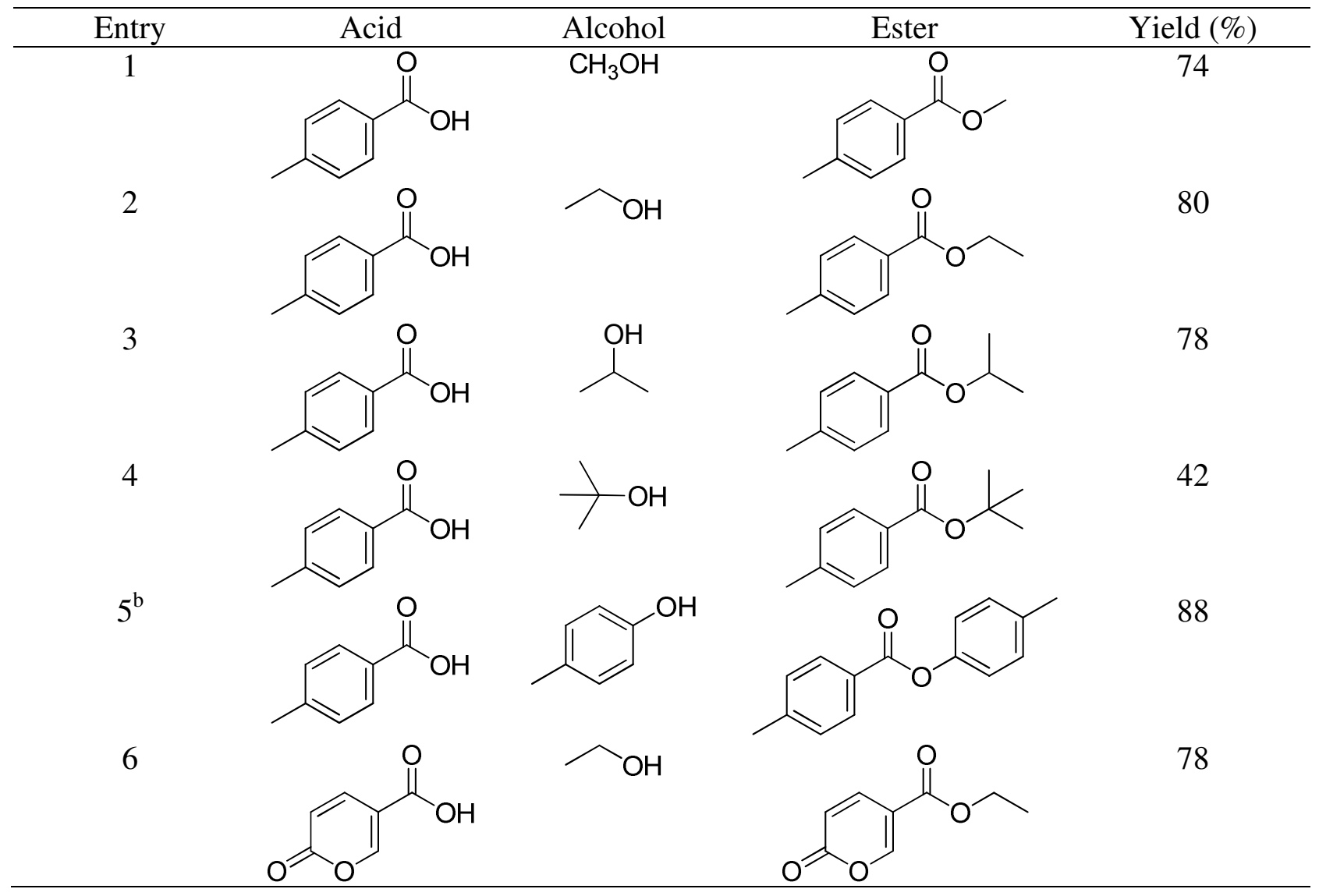

${ }^{\mathrm{a}}$ Reagents and conditions: 2:1:1:1:2 molar ratios of $\mathrm{Ph}_{3} \mathrm{PO}: \mathrm{Tf}_{2} \mathrm{O}: \mathrm{RCOOH}: \mathrm{R}^{\prime} \mathrm{OH}: \mathrm{Et}_{3} \mathrm{~N}$ in $\mathrm{C}_{2} \mathrm{H}_{4} \mathrm{Cl}_{2} / 25^{\circ} \mathrm{C} / 15 \mathrm{~min}$. Reagent 1 was first made in $\mathrm{CH}_{2} \mathrm{Cl}_{2}$ or $\mathrm{C}_{2} \mathrm{H}_{4} \mathrm{Cl}_{2}$ and subsequently treated with a mixture of acid-alcohol-base in the same solvent, ${ }^{\mathrm{b}}$ Addition of cresol and $\mathrm{Et}_{3} \mathrm{~N}$ to reagent 1 first, followed by acid.

2.2.6. Conversion of activated ketones to alkynes. Not only has the phosphonium anhydride reagent 1 proven successful in activating $-\mathrm{OH}$ moieties into leaving groups, Hendrickson extended this activation to the enols of activated ketones in order to convert them into alkynes by an elimination reaction (Table 6). ${ }^{9}$ The reagent was prepared in situ as usual in 1,2dichloroethane and treated with an equimolar amount of the ketone and two equivalents of $\mathrm{Et}_{3} \mathrm{~N}$ and the mixture refluxed for an hour. When the ketone was activated by an adjacent carbonyl in $\mathrm{R}_{2}$, the reaction proceeded to completion within an hour (Entries 1-4). However, with less activating groups in $\mathrm{R}_{2}(\mathrm{Ph})$ (Entry 5), 10 hours of reflux time were required for complete conversion. Finally, unactivated ketones $\left(\mathrm{R}_{2}=\mathrm{H}\right.$ or aliphatic) were completely unreactive as the enol-phosphonium intermediate was not formed as demonstrated by ${ }^{1} \mathrm{H}-\mathrm{NMR}$. The yields ranged from 53-98\% and the reactions proceeded cleanly in one step and did not require the isolation and an intermediate enol species. In the case of unsymmetrical $\beta$-dicarbonyl compounds (2b-d), 
the more reactive one underwent conversion to the corresponding alkyne. The products were easily isolated by passage through a plug of silica gel to remove $\mathrm{Ph}_{3} \mathrm{PO}$, followed by removal of solvent under vacuo.

Table 6. Dehydration of activated ketones to alkynes

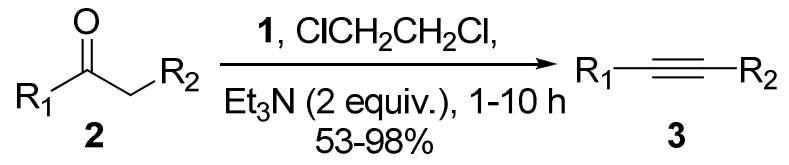

\begin{tabular}{ccccc}
\hline Entry & $\mathbf{2 , 3}$ & $\mathrm{R}_{1}$ & $\mathrm{R}_{2}$ & Yield (\%) \\
\hline 1 & $\mathrm{a}$ & $\mathrm{Ph}$ & $\mathrm{COPh}$ & 93 \\
2 & $\mathrm{~b}$ & $\mathrm{Me}$ & $\mathrm{COPh}$ & 53 \\
3 & $\mathrm{c}$ & $\mathrm{Ph}$ & $\mathrm{CO}_{2} \mathrm{Et}$ & 98 \\
4 & $\mathrm{~d}$ & $\mathrm{Me}$ & $\mathrm{CO}_{2} \mathrm{CH}_{2} \mathrm{Ph}$ & 89 \\
5 & $\mathrm{e}$ & $\mathrm{Ph}$ & $\mathrm{Ph}$ & 87 \\
\hline
\end{tabular}

2.2.7. Cyclodehydrations of diols and amino alcohols. The triphenylphosphonium anhydride 1 has been found to react rapidly with diols or amino alcohols to effect the formation of cyclic ethers (Table 7, Entries 1-5) and amines (Table 7, Entries 6 and 7) with 3-, 5-, and 6-membered rings. ${ }^{10}$ When a diol or an amino alcohol is added to the reagent $(\mathbf{1})$, the hydroxyl group in the latter and one alcohol group in the former get converted to the corresponding phosphonium ether, where ring formation ensues cyclic nucleophilic displacement of $\mathrm{Ph}_{3} \mathrm{PO}$ by the attached nucleophilic tether. Whereas the formation of the 3-membered ring is fastest (epoxide) (Entries 1 and 2), the 4-membered ring could not be formed presumably due to ring strain and 1,3-diol cleavage. For instance, attempted formation of 2,4-diphenyloxetane from 1,3-diphenylpropane1,3-diol resulted in the conclusive formation of styrene and benzaldehyde as the decomposition products (Scheme 2). It is noted that amino alcohols comprise two nucleophilic groups which are reactive toward $\mathbf{1}$, but apparently the formation of the cyclic amines is fast. This suggests a free transfer of the phosphonium group from the nitrogen atom to the hydroxyl group, indicating a preference for oxygen and for the pathway that leads to the elimination of the very stable $\mathrm{Ph}_{3} \mathrm{PO}$ leaving group.

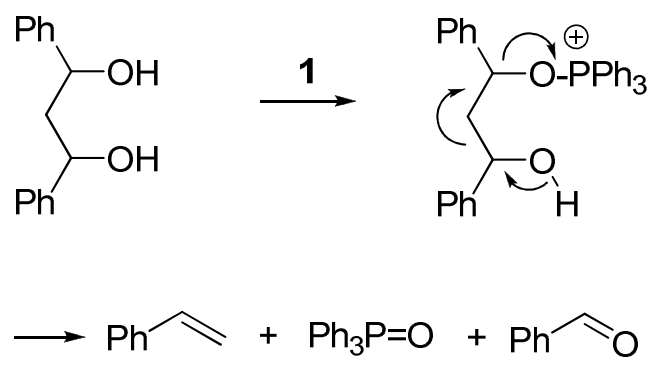

Scheme 2. Decomposition of 1,3-diphenylpropane-1,3-diol. 
Table 7. Cyclodehydrations of diols and amino alcohols

Entry

2.2.8. Conversion of epoxides to dienes. A variety of acyclic, 1,2-di-, and trisubstituted, and cis-disubstituted epoxides were shown to react smoothly and cleanly with reagent $\mathbf{1}$ and $\mathrm{Et}_{3} \mathrm{~N}$ in boiling 1,2-dichloroethane to afford the dienes shown in Table 8 in yields ranging from 50$85 \%$. ${ }^{11}$ The elimination reactions were performed in one pot where a prepared suspension of the phosphonium anhydride reagent $\mathbf{1}$ was treated with an equimolar amount of the epoxide, followed by five equivalents of $\mathrm{Et}_{3} \mathrm{~N}$ at $0{ }^{\circ} \mathrm{C}$. The white precipitate was immediately discharged and the mixtures were heated at reflux from 6-48 hrs. Table 8 shows a selection of examples that illustrate the range of substrates that were converted successfully to the corresponding dienes. It is noted that cyclododecene oxide (Entry 3) was a mixture of cis and trans isomers (2:1), but the product was a clean mixture of $(1 E, 3 Z)$-diene and unreacted trans epoxide. It appears that the formation of the sterically-demanding complexes (vide infra) makes such a conversion not feasible. 
Table 8. Elimination of epoxides to dienes

Entry

2.2.8.1. Mechanism of double elimination of epoxides to dienes. ${ }^{31} \mathrm{P}-\mathrm{NMR}$ studies on the reaction of cyclododecene oxide with $\mathbf{1}$ indicated that the signal for the latter immediately disappears and gets replaced by three signals at $\delta 43$ (br s), 62.2 (s), and 62.8 (s) ppm. Following the addition of $\mathrm{Et}_{3} \mathrm{~N}$, the peak at $\delta 43 \mathrm{ppm}$ disappears instantly, whereas the other two diminish progressively and are accompanied by peak enhancement for $\mathrm{Ph}_{3} \mathrm{PO}$ at $\delta 29.3 \mathrm{ppm}$. The proposed mechanism (Scheme 3 ) involves the addition of the epoxide oxygen to 1 to produce a pentacoordinated complex $\mathbf{4}$, which undergoes ring opening to a bis-phosphonium ether $\mathbf{5}$ and subsequently eliminates two molecules of $\mathrm{Ph}_{3} \mathrm{PO}$ in the presence of a base to produce the corresponding diene. It appears that the equilibration of $\mathbf{4}$ is fast on the NMR time scale, causing the signals of the two different phosphorus atoms to coalesce into a single broad singlet ( $\delta 43$ ppm) which immediately vanishes in the presence of a base due to rapid elimination. The remaining two sharp peaks at 62.2 and $62.8 \mathrm{ppm}$ for $\mathbf{5}$ suggest that a mixture of cis and trans isomers may exist. 


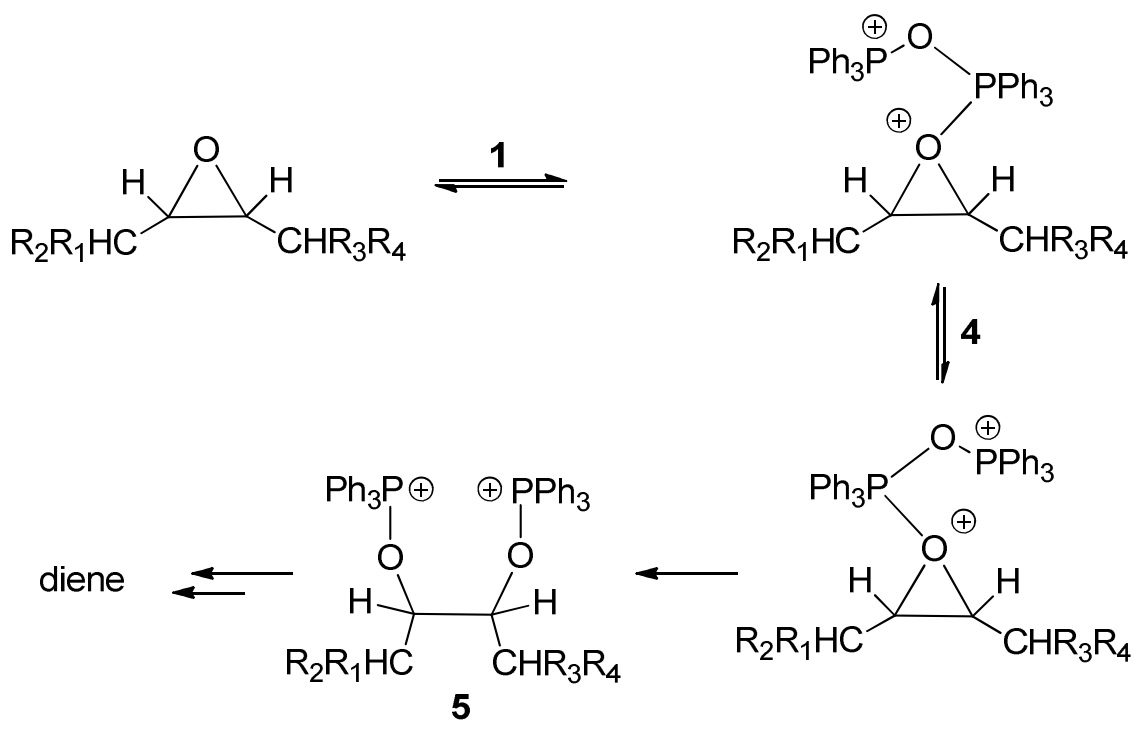

Scheme 3. Mechanism of epoxide elimination to dienes.

2.2.9. Conversion of sulfonic acids to sulfonamides and activated sulfonate esters. The sulfonamide moiety is the basis of several groups of drugs and is of tremendous importance to medicinal chemistry. ${ }^{12}$ It comprises the largest class of antimicrobial agents and is found in other drugs including thiazide diuretics (including hydrochlorothiazide, metolazone, and indapamide, among others), loop diuretics (including furosemide, bumetanide, and torsemide), sulfonylureas (including glipizide, glyburide, among others), some COX-2 inhibitors (e.g., celecoxib), and acetazolamide. The group acts as a transition state mimetic of peptide hydrolysis and has been shown to be the critical pharmacophore for potent inhibitors of cysteine proteases. ${ }^{13}$ These enzymes have been implicated in the degradative processing of peptides and proteins, and play key roles in a number of physiological processes including arthritis, Alzheimer's disease, and apoptosis. Traditional methods for the generation of sulfonamides have used sulfonyl chlorides and nucleophiles such as amines. Unfortunately, sulfonyl chlorides are not amenable to longterm storage and are often difficult to handle. As an alternative route, Caddick described a general method for the preparation of sulfonamides whereby a sulfonic acid or its salt undergo activation with 1 (Table 9, Entries 1-6), followed by a rapid reaction with amines. ${ }^{14}$ The method also proved successful for the preparation of activated pentafluorophenol-sulfonate esters which have been established as stable replacement to sulfonyl chlorides. Thus, as depicted in Table 9, the exposure of various aromatic, aliphatic, and heterocyclic sulfonic acid salts $\mathbf{6}$ to reagent $\mathbf{1}$, followed by reaction of the resulting activated $\mathrm{RSO}_{2} \mathrm{O}^{+} \mathrm{PPh}_{3}$ complex with either allylamine or pentafluorophenol (PFPOH), afforded the coupled sulfonamides $\mathbf{7}$ and PFP sulfonate esters 8 in high yields. In addition, a number of functional groups are tolerated under the reaction conditions It is noted that metal salts of sulfonic acids are unsuitable substrates for this reaction as they lack good solubility and are generally hygroscopic. However, pyridine, tetrabutylammonium, or 
triethylamine salts of sulfonic acids are better alternatives since they are easily prepared from the acid, are not hygroscopic, and are soluble in organic solvents.

The generality of the above approach was also extended to the synthesis of a wide range of sulfonamides by varying the amine substrate. It this regards, 3-nitrobenzene sulfonic acid pyridine salt was reacted with primary and secondary amines, and amino acid derivatives to produce most sulfonamides in nearly quantitative yield (61-92\%). Even electron-deficient anilines underwent successful coupling under the reaction conditions used earlier.

Table 9. Conversion of sulfonic acids to sulfonamides and activated sulfonate esters

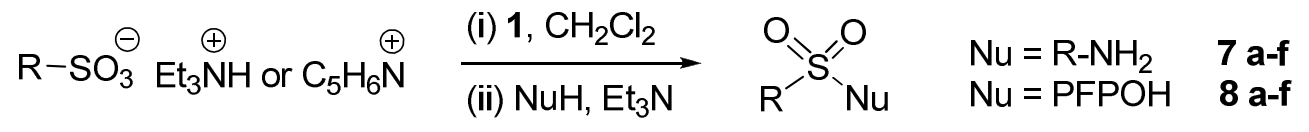

Entry Sulfonic acid salt

2.2.10. Dehydrative glycosylation. The importance of the glycosylation reaction can not be overstated because of the many biological functions of oligosaccharides and related sugars. ${ }^{15}$ The term refers to a reaction in which a carbohydrate (a glycosyl donor) gets attached to a hydroxyl 
or other functional group of another molecule (a glycosyl acceptor). The equivalent phenomenon in biological systems describes an enzymatic process that attaches glycans to proteins and lipids. Glycans serve a variety of structural and functional roles in cellular membranes and recognition events. The glycosylation process also produces one of the fundamental biopolymers found in cells (along with DNA, RNA, and proteins). The majority of proteins synthesized in the rough endoplasmic reticulum undergo glycosylation and the process is also present in the cytoplasm and cell nucleus. Because of the biological relevance of glycosylation, several procedures for the synthesis of glycosides have been disclosed. For instance, dehydrative glycosylation is such method where the hydroxyl group of a hemiacetal sugar is transformed to a leaving group in situ and consequently displaced to effect glycosidic bond formation. Dehydrative glycosylation has been traditionally carried out by the classical Fischer glycosylation method, and more recently by the method of Garcia and Gin, ${ }^{16}$ where 1-hydroxyglycosyl donors underwent dehydrative glycosylations employing a reagent combination of triflic anhydride and diphenyl sulfoxide. Others like Shingu et al. exploited the Appel reagent to develop a one-pot practical $\alpha$ glycosylation reaction, converting 1-hydroxy sugars into $\alpha$-glycosyl-bromides under dehydrative conditions, followed by glycosylation. ${ }^{17}$ Very recently, the 'POP' reagent $\mathbf{1}$ has been used in an efficient dehydrative glycosylation of 1-hydroxyglycosyl donors. ${ }^{18}$ The reactions involved the activation of the hemiacetal donor 9a with the POP reagent (1.1 equiv) without addition of a base, followed by treatment with 1 equiv. of 2,3,4,6-tetra- $O$-benzylgalactopyranose as a donor, gave exclusively the self-condensation product (perbenzylated galacto trehaloses). It appears that self-condensation between the activated donor and the 1-OH sugar is faster than the reaction of 1-OH with reagent $\mathbf{1}$. As a result, the order of addition of the donor and acceptor was modified, where the latter was added first to the POP reagent, followed by the donor. Under such conditions, the glycoside formed in modest yield, but the acidic conditions were unsuitable for acid labile protecting groups. The optimized glycosylation conditions involved adding a mixture of DIPEA and donor 9a to reagent $\mathbf{1}$ at $0{ }^{\circ} \mathrm{C}$ and stirring for $2 \mathrm{~h}$ to form the alkoxyphosphonium ion. Subsequent addition of the donor gave the expected glycosides (10-13) in good yields, completely suppressing the formation of the galacto trehalose (Table 10). The stereoselectivity was poor in most cases as indicated by the observed $\alpha / \beta$ ratios. Mechanistic studies demonstrated that the reaction proceeds through an alkoxyphosphonium intermediate as indicated by NMR studies and ${ }^{18} \mathrm{O}$ labeling experiments. 
Table 10. Glycosylation of tetrabenzylglucosyl donors with various acceptors

\begin{tabular}{|c|c|c|c|c|}
\hline Entry & Donor & Acceptor $(\mathrm{ROH})$ & Product & $\begin{array}{l}\text { Yield }(\%) \\
(\alpha: \beta \text { ratio) }\end{array}$ \\
\hline 1 & $\begin{array}{l}\text { a: } \mathrm{R}_{1}=\mathrm{OBn}, \mathrm{R}_{2}=\mathrm{H} \\
\text { b: } \mathrm{R}_{1}=\mathrm{H}, \mathrm{R}_{2}=\mathrm{OBn}\end{array}$ & & $\mathbf{a}, \mathbf{b}$ & $\begin{array}{l}\text { 10a: } 98 \\
(44: 56) \\
\text { 10b: } 97 \\
(25: 75)\end{array}$ \\
\hline 2 & $9 a, b$ & $\begin{array}{r}\mathrm{BnC} \\
\mathrm{Br}\end{array}$ & $\mathrm{Bn}$ & $\begin{array}{l}\text { 11a: } 98 \\
(60: 40) \\
\text { 11b: } 96 \\
(37: 63)\end{array}$ \\
\hline 3 & $9 a, b$ & TBDPS & & $\begin{array}{c}\text { 12a: } 75(\alpha \\
\text { only) } \\
\text { 12b: } 72(\alpha \\
\text { only) }\end{array}$ \\
\hline 4 & $9 a, b$ & & $3 a, b$ & $\begin{array}{l}\text { 13a: } 95 \\
(42: 58) \\
\text { 13b: } 95 \\
(27: 73)\end{array}$ \\
\hline
\end{tabular}

\subsection{Heterocycle synthesis}

2.3.1. Synthesis of thiazolines. Thiazoline heterocycles are part of many macrolactams isolated from marine sources and and are also present in many biologically active natural products of peptide origin. ${ }^{19}$ They are known to fulfill several functions such as providing conformational rigidity and serving as a recognition site for protein, DNA, and RNA binding. This motif is biosynthesized from peptides whereby the amide carbonyl function of cysteine undergoes nucleophilic attack by its thiol tether, followed by dehydration. ${ }^{20}$ Interestingly, traditional preparation methods of thiazolines could not biomimic its synthesis. However, Kelly et al. showcased the utility of the POP reagent $\mathbf{1}$ by reporting a biomimetic synthesis of thiazolines by reacting trityl-protected $\mathrm{N}$-acylated cysteines with the reagent (Scheme 4$){ }^{7}$ In this context, dehydrocyclization required activation of the amide group with concurrent deprotection of the trityl protecting group to unveil the nucleophilic thiol group. The thiazoline ring would then form by nucleophilic attack of the free cysteine thiol on the phosphonium-activated amide carbonyl group of the former residue, followed by dehydration via the elimination of $\mathrm{Ph}_{3} \mathrm{PO}$. It was envisaged that the strong oxophilicity of the oxydiphosphonium salt $\mathbf{1}$ and the generation of triflic acid during the course of the reaction should enable generation of the imidate, cleavage of 
the trityl protecting group, and finally cyclization to the thiazoline with concomitant elimination of $\mathrm{Ph}_{3} \mathrm{PO}$ (Scheme 4).

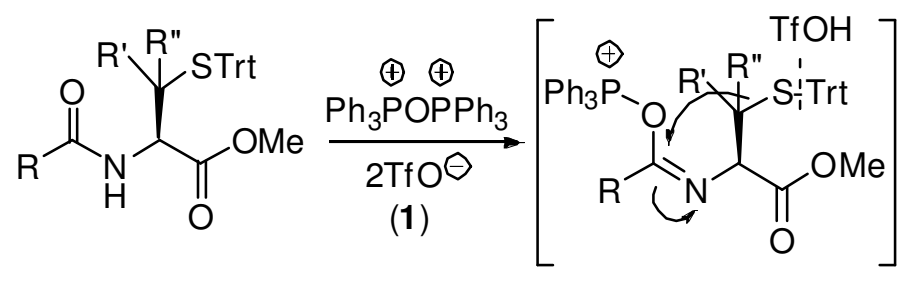<smiles>[R]C1=N[C@@H](C(=O)OC)C([R])([R])S1</smiles>

Scheme 4. Proposed mechanism for the synthesis of thiazolines with reagent 1.

Pleasingly, among the many phosphonium salts and phosphoranes evaluated, reagent $\mathbf{1}$ was the only one that converted fully Cbz-protected cysteine-containing dipeptides to thiazolines in high chemical yields (84-98\%) and excellent chemo- and enantiospecificity ( $>99.5 \%$ ee), without epimerization of the exocyclic stereocenter (Table 11). The reactions were carried out at $-20{ }^{\circ} \mathrm{C}$ using 1.5 equivalent of $\mathbf{1}$ and were complete within $3 \mathrm{~h}$. The one-pot tandem cyclodehydration method was also applied to a fully protected cysteine-cysteine dipeptide to give the corresponding thiazole-thiazoline product in $63 \%$ yield and $99.5 \%$ optical purity.

Table 11. Synthesis of thiazolines from Cbz-protected cysteine-containing dipeptides

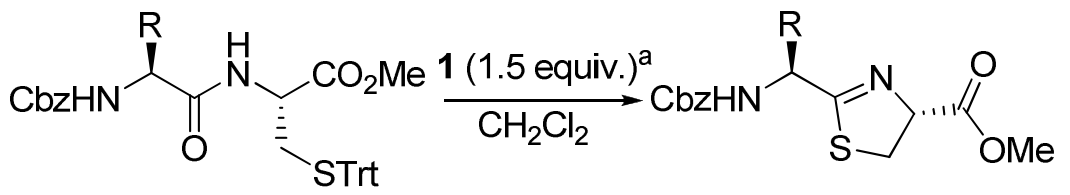

\begin{tabular}{cccccc}
\hline Entry & $\mathrm{R}$ & $\begin{array}{c}\text { Cysteine } \\
(\text { d.r. })^{\mathrm{b}}\end{array}$ & $\begin{array}{c}\text { Thiazoline } \\
(\text { d.r. })\end{array}$ & ee (\%) & Yield (\%) \\
\hline 1 & $\mathrm{Bn}$ & $99: 1$ & $97: 3$ & $>99.5$ & 98 \\
2 & $\mathrm{Me}$ & $99: 1$ & $91: 9$ & $>99.5$ & 84 \\
3 & $i \mathrm{Pr}$ & $98: 2$ & $97: 3$ & $>99.5$ & 86 \\
4 & $s \mathrm{Bu}$ & $96: 4$ & $96: 4$ & $>99.5$ & 95 \\
\hline
\end{tabular}

a Prepared from 3 equiv. $\mathrm{Ph}_{3} \mathrm{PO}$ and 1.5 equiv. $\mathrm{Tf}_{2} \mathrm{O}$ in $\mathrm{CH}_{2} \mathrm{Cl}_{2}$. ${ }^{\mathrm{b}}$ Diastereomeric ratio was determined by HPLC on a Chiralcel OD or OD-H column; ee is that of the major product.

The above cyclization methodology with 1 was later applied by Jew et al. to prepare a thiazoline methyl ester which served as a key substrate in enantioselective phase-transfer catalytic alkylation reactions. $^{21}$ 
2.3.2. Synthesis of imidazolines. Imidazolines are useful synthetic intermediates ${ }^{22}$ and serve as chiral auxiliaries, ${ }^{23}$ chiral catalysts, ${ }^{24}$ and ligands for asymmetric catalysis. ${ }^{25}$ In addition, derivatives of these heterocycles have attracted substantial attention because of their interesting biological activities. ${ }^{26}$ Consequently, the design of enantiospecific routes to imidazolines and their derivatives constitutes an important step toward the construction and biological evaluation of macrolactam natural product analogues containing these heterocycles. Building on their early success of the biomimetic synthesis of thiazolines using $\mathbf{1},{ }^{7}$ Kelly and You showcased the versatility of the 'POP' reagent in the highly efficient enantiospecific synthesis of imidazolines. ${ }^{27}$ Therefore, starting from $N$-acylated $\beta$-tosylamino- $\alpha$-acylamino esters, the proposed formation of imidazolines by the diphosphonium salt 1 was examined under the conditions shown in Table 12. Generally, the imidazoline products formed in high chemical and optical yields with excellent retention of stereochemistry at the starting stereogenic center except with the 3-CF - phenylsubstituted substrate (Table 12, Entry 6).

Table 12. Synthesis of imidazolines from $N$-acylated $\beta$-tosylamino- $\alpha$-acylamino esters

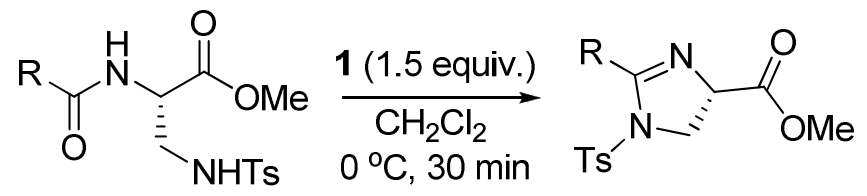

\begin{tabular}{cccc}
\hline Entry & $\mathrm{R}$ & Yield $(\%)$ & ee $(\%)$ \\
\hline 1 & $\mathrm{Ph}$ & 96 & 97 \\
2 & $\mathrm{Ph}$ & 95 & 98 \\
3 & $\mathrm{Tol}$ & 97 & 98 \\
4 & $4-\mathrm{MeO}-\mathrm{Ph}$ & 95 & 97 \\
5 & $\mathrm{Bn}$ & 94 & 99 \\
6 & $3-\mathrm{CF}_{3}-\mathrm{Ph}$ & 90 & 86 \\
\hline
\end{tabular}

The preceding protocol was also utilized for the synthesis of enantiopure imidazoline-based amino acids starting from $\alpha-N$-protected dipeptides with a tosylated $\beta$-amino group. In addition, several of the prepared imidazoline-based amino acids were converted to imidazoles by using $\mathrm{BrCCl}_{3} / \mathrm{DBU}$ and activated $\mathrm{MnO}_{2}$, respectively. Finally, these heterocyclic amino acids were exploited as building blocks for the synthesis of a macrolactam related to bistratamide $\mathrm{H}$ (Scheme 5). Thus, coupling of amine 14 to the carboxyl acid group of the imidazoline-based amino acid 15, prepared according to the aforementioned protocol afforded diamide 16 in $93 \%$ yield. Subsequent removal of the protecting groups and PyBOP-DMAP promoted macrolactamization afforded the macrolactam analogue of bistratamide $H$ (17) (64\% yield) without loss of stereochemical integrity. 


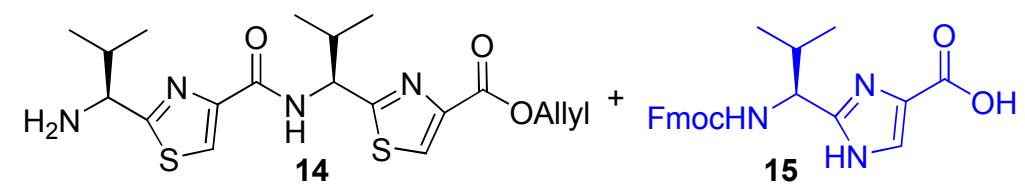<smiles>C[13CH2]C=CN[C@H](c1nc(C(=O)N[C@H](c2nc(C(=O)NC(c3nc(C(=O)O[Na])cs3)C(C)C)cs2)C(C)C)cs1)C(C)C</smiles><smiles>CC(C)c1nc(C(=O)NC(c2nc(C(=O)N[C@H](c3nc(C(=O)N[C@@H](C(C)C)C(F)(F)F)cs3)C(C)C)cs2)C(C)C)cs1</smiles>

Scheme 5. Synthesis of a macrolactam related to bistratamide $\mathrm{H}$. (a) $\mathrm{HBTU}, \mathrm{CH}_{3} \mathrm{CN}, \mathrm{DIEA}$, 93\%; (b) DEA/CH $3 \mathrm{CN}$; (c) $\mathrm{Pd}(\mathrm{OAc})_{2}, \mathrm{PS}-\mathrm{Ph}-\mathrm{PPh}_{2}, \mathrm{PhSiH}_{3}, \mathrm{CH}_{2} \mathrm{Cl}_{2}$; (c) PyBOP, DMAP, DMF, $\mathrm{CH}_{2} \mathrm{Cl}_{2}, 64 \%$.

Very recently, Du et al. exploited the preceding protocol of imidazoline ${ }^{18}$ formation to prepare diphenyl sulfide linked bis(imidazoline) chiral ligands $\mathbf{1 8}$ (Table 13) for use in asymmetric allylic alkylations. ${ }^{28}$ The $N$-Ts precursors were reacted with $\mathbf{1}$ (1 equiv.) in $\mathrm{CH}_{2} \mathrm{Cl}_{2}$ at $0{ }^{\circ} \mathrm{C}$ to afford the desired ligands in moderate to good yields (53-82\%). The methodology was also recently used by Shi et al. to prepare chiral $N$-tosyl imidazoline-phosphine ligands with a $1,1^{\prime}$-binaphthalene framework for use in palladium-catalyzed asymmetric allylic substitutions. ${ }^{29}$

Table 13. Synthesis of $N$-Ts-substituted diphenyl sulfide linked bis(imidazoline) ligands

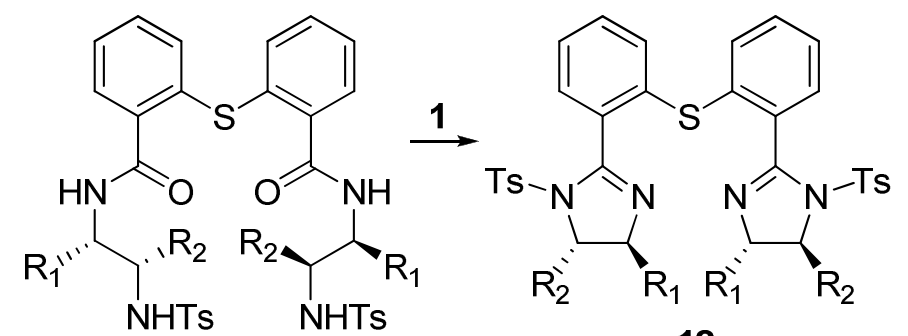

18

\begin{tabular}{cccc}
\hline Entry & $\mathrm{R}_{1}$ & $\mathrm{R}_{2}$ & Yield (\%) \\
\hline 1 & $\mathrm{Ph}$ & $\mathrm{H}$ & 66 \\
2 & $\mathrm{Bn}$ & $\mathrm{H}$ & 79 \\
3 & $i \mathrm{Pr}$ & $\mathrm{H}$ & 71 \\
4 & $t \mathrm{Bu}$ & $\mathrm{H}$ & 53 \\
5 & $\mathrm{Ph}$ & $\mathrm{Ph}$ & 82 \\
6 & $\left(\mathrm{CH}_{2}\right)_{4}$ & $\left(\mathrm{CH}_{2}\right)_{4}$ & 71 \\
\hline
\end{tabular}


2.3.3. Solid-phase synthesis of thiazole- and imidazole-containing peptides. As indicated earlier, marine natural products bearing thiazole and imidazole rings are abundant in nature. These species have shown broad spectrum of biological activities, including anticancer, antiviral, and antibacterial activities, and the inhibition of plasma membrane efflux pump. ${ }^{30}$ In particular, 1,3 azoles have proved useful in combinatorial chemistry and as peptidomimetics. ${ }^{31}$ Because of the unique attributes these heterocycles confer on bioactive compounds, simple and efficient synthetic routes to prepare such intermediates are always in high demand. Thus, building on the methodology reported earlier by You and Kelly for the biomimetic synthesis of thiazolines ${ }^{7}$ and imidazolines $^{27}$ from $N$-acylated cysteines or $\beta$-tosylamino- $\alpha$-acylamino esters using $\mathbf{1}$, Kessler et al. reported a highly efficient two-step protocol for the solid phase synthesis of 1,3-thiazole- and imidazole-containing peptides and peptidomimetics. ${ }^{32}$ As shown in Scheme 6, the solid phase synthesis of thiazole-based peptides started from Cbz- and Fmoc-protected dipeptides 19 (Entries 1 and 2) supported on Wang resin and consisting of phenylalanine and $S$-trityl-cysteine. The key step involving cyclodehydration with 1 proceeded remarkably well, giving the Cbz- and Fmocprotected thiazolines 20 in high overall yields. Subsequent oxidation to 21 with $\mathrm{BrCCl}_{3} / \mathrm{DBU}$ and cleavage from the resin with TFA afforded the free thiazole-based peptides 22 in high yields, which were calculated based on loading of the first amino acid on the resin. The same strategy employing the oxodiphosphonium salt procedure with 1 was applied to prepare imidazole-based amino acids from dipeptides. Hence, Cbz- and Fmoc-protected dipeptides (Entries 3 and 4) consisting of phenylalanine and $\beta$-tosylamino- $\alpha$-aminopropionic acid were bound on Wang resin and cyclodehydrated with 1 , followed by $\mathrm{BrCCl}_{3} / \mathrm{DBU}$ oxidation and resin cleavage with TFA to give the $N$-tosyl imidazole peptides.

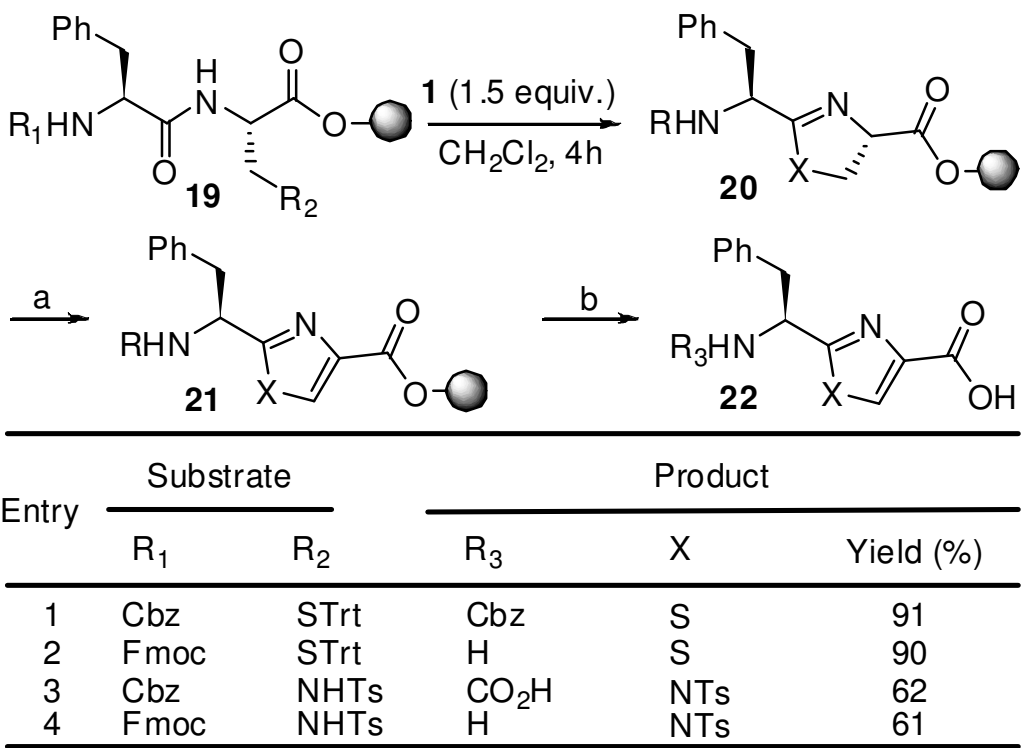

Scheme 6. Solid-phase synthesis of thiazole- and imidazole-containing peptides. Reagents and conditions: (a) DBU, $\mathrm{BrCCl}_{3}, \mathrm{CH}_{2} \mathrm{Cl}_{2}, 12 \mathrm{~h}$; (b) TFA, $\mathrm{H}_{2} \mathrm{O}$, TIS, 2 h. 
2.3.4. Synthesis of indolizino[1,2-b]quinolin-9(11H)-ones. Quinoline alkaloids containing the indolizino[1,2- $b$ ]quinolin-9(11H)-one scaffold have attracted the interest of several research groups worldwide because of their potent antitumor activities. For example, camptothecin (vide infra), a cytotoxic quinoline alkaloid which inhibits the covalent binary complex formed between DNA and the enzyme topoisomerase I (topo I), ${ }^{33}$ showed remarkable anticancer activity in preliminary clinical trials. Consequently, the search for imaginative syntheses of such heterocycles remains an active area of research. In this regard, Yao et al. reported a cascade methodology triggered by reagent 1 to construct variously substituted indolizino[1,2- $b$ ]quinolin$9(11 H)$ )-ones 24 starting from the amide-alkyne substrate 23 (Table 14). ${ }^{34}$

Table 14. Synthesis of indolizino[1,2-b]quinolin-9(11H)-ones

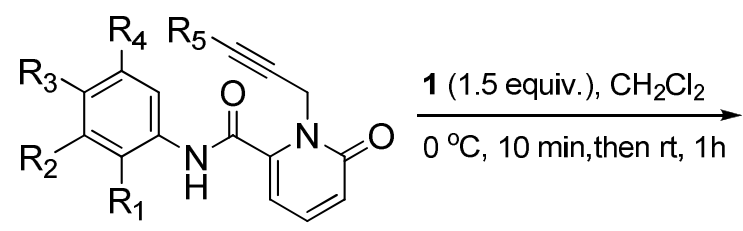

23 (1 mmol)

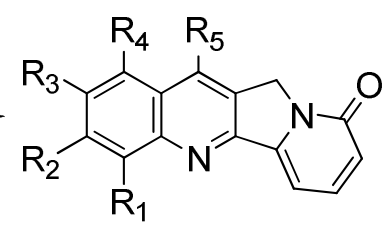

24

\begin{tabular}{|c|c|c|c|}
\hline Entry & Starting material & Product & Yield (\%) \\
\hline 1 & $\begin{array}{c}\mathrm{R}_{1}=\mathrm{R}_{2}=\mathrm{R}_{4}= \\
\mathrm{R}_{5}=\mathrm{H}, \mathrm{R}_{3}=\mathrm{OMe}\end{array}$ & $\begin{array}{c}\mathrm{R}_{1}=\mathrm{R}_{2}=\mathrm{R}_{4}= \\
\mathrm{R}_{5}=\mathrm{H}, \mathrm{R}_{3}=\mathrm{OMe}\end{array}$ & 90 \\
\hline 2 & $\mathrm{R}_{1}-\mathrm{R}_{5}=\mathrm{H}$ & $\mathrm{R}_{1}-\mathrm{R}_{5}=\mathrm{H}$ & 98 \\
\hline 3 & $\begin{array}{c}\mathrm{R}_{1}=\mathrm{R}_{2}=\mathrm{R}_{4}= \\
\mathrm{R}_{5}=\mathrm{H}, \mathrm{R}_{3}=\mathrm{NMe}_{2}\end{array}$ & $\begin{array}{c}\mathrm{R}_{1}=\mathrm{R}_{2}=\mathrm{R}_{4}= \\
\mathrm{R}_{5}=\mathrm{H}, \mathrm{R}_{3}=\mathrm{NMe}_{2}\end{array}$ & 95 \\
\hline 4 & $\begin{array}{c}\mathrm{R}_{1}=\mathrm{R}_{2}=\mathrm{R}_{4}= \\
\mathrm{R}_{5}=\mathrm{H}, \mathrm{R}_{3}=\mathrm{Me}\end{array}$ & $\begin{array}{c}\mathrm{R}_{1}=\mathrm{R}_{2}=\mathrm{R}_{4}= \\
\mathrm{R}_{5}=\mathrm{H}, \mathrm{R}_{3}=\mathrm{Me}\end{array}$ & 98 \\
\hline 5 & $\begin{array}{l}\mathrm{R}_{1}=\mathrm{R}_{2}=\mathrm{R}_{4}= \\
\mathrm{R}_{5}=\mathrm{H}, \mathrm{R}_{3}=\mathrm{Br}\end{array}$ & $\begin{array}{l}\mathrm{R}_{1}=\mathrm{R}_{2}=\mathrm{R}_{4}= \\
\mathrm{R}_{5}=\mathrm{H}, \mathrm{R}_{3}=\mathrm{Br}\end{array}$ & 95 \\
\hline 6 & $\begin{array}{l}\mathrm{R}_{1}=\mathrm{R}_{2}=\mathrm{R}_{4}= \\
\mathrm{R}_{5}=\mathrm{H}, \mathrm{R}_{3}=\mathrm{F}\end{array}$ & $\begin{array}{l}\mathrm{R}_{1}=\mathrm{R}_{2}=\mathrm{R}_{4}= \\
\mathrm{R}_{5}=\mathrm{H}, \mathrm{R}_{3}=\mathrm{F}\end{array}$ & 95 \\
\hline 7 & $\begin{array}{c}\mathrm{R}_{1}=\mathrm{R}_{2}=\mathrm{R}_{4}= \\
\mathrm{R}_{5}=\mathrm{H}, \mathrm{R}_{3}= \\
\mathrm{CO}_{2} \mathrm{Me}\end{array}$ & $\begin{array}{c}\mathrm{R}_{1}=\mathrm{R}_{2}=\mathrm{R}_{4}= \\
\mathrm{R}_{5}=\mathrm{H}, \mathrm{R}_{3}= \\
\mathrm{CO}_{2} \mathrm{Me}\end{array}$ & 91 \\
\hline 8 & $\begin{array}{c}\mathrm{R}_{1}=\mathrm{R}_{2}=\mathrm{R}_{4}= \\
\mathrm{R}_{5}=\mathrm{H}, \mathrm{R}_{3}=\mathrm{CN}\end{array}$ & $\begin{array}{c}\mathrm{R}_{1}=\mathrm{R}_{2}=\mathrm{R}_{4}= \\
\mathrm{R}_{5}=\mathrm{H}, \mathrm{R}_{3}=\mathrm{CN}\end{array}$ & 99 \\
\hline 9 & $\begin{array}{c}\mathrm{R}_{2}=\mathrm{R}_{3}=\mathrm{R}_{4}= \\
\mathrm{R}_{5}=\mathrm{H}, \mathrm{R}_{1}=\mathrm{Me}\end{array}$ & $\begin{array}{c}\mathrm{R}_{2}=\mathrm{R}_{3}=\mathrm{R}_{4}= \\
\mathrm{R}_{5}=\mathrm{H}, \mathrm{R}_{1}=\mathrm{Me}\end{array}$ & 94 \\
\hline 10 & $\begin{array}{c}\mathrm{R}_{1}=\mathrm{R}_{3}=\mathrm{R}_{5}= \\
\mathrm{H}, \mathrm{R}_{2}=\mathrm{R}_{4}=\mathrm{Me}\end{array}$ & $\begin{array}{c}\mathrm{R}_{1}=\mathrm{R}_{3}=\mathrm{R}_{5}= \\
\mathrm{H}, \mathrm{R}_{2}=\mathrm{R}_{4}=\mathrm{Me}\end{array}$ & 98 \\
\hline
\end{tabular}

Initially, a range of amide-activating reagents were screened using the substrate shown in Entry 1 (Table 14). Unfortunately, after extensive optimization, the product could only be isolated in $32 \%$ yield. On the contrary, reagent $\mathbf{1}$ triggered a mild and efficient cascade reaction at ambient temperature, where imidate formation promoted a subsequent intramolecular aza- 
Diels-Alder annulation, converting the aniline-amide precursors into variously substituted indolizino[1,2-b]quinolin-9(11H)-ones (Table 14). Optimized reaction conditions were realized with 3 equivalents of $\mathrm{Ph}_{3} \mathrm{PO}$ and 1.5 equivalents of $\mathrm{Tf}_{2} \mathrm{O}$ in $\mathrm{CH}_{2} \mathrm{Cl}_{2}$ from $0{ }^{\circ} \mathrm{C}$ to room temperature. The generality of the reaction was examined on various substituted aniline-amides (Entries 1-10), affording the corresponding products in nearly quantitative yields (90-99\%). Because this strategy proved to be the most efficient in constructing the $\mathrm{B}$ and $\mathrm{C}$ rings of camptothecin-family alkaloids, subsequent mechanistic investigations were carried out by $\mathrm{Yu}$ et al. in order to rationalize why reagent 1 was a superior amide-activating agent. ${ }^{35}$ Overall, the reaction proceeds in three consecutive steps: (a) in situ formation of an $\mathrm{N}$-arylimidate through activation of the corresponding amide, (b) intramolecular aza-Diels-Alder (IADA) reaction between the $N$-arylimidate and the alkyne group, and (c) aromatization to the quinoline. The FMO computational studies indicated that the key IADA proceeds via a $\left[4^{+}+2\right]$ reaction and that the amide-activating reagent is critical to the success of the ensuing cascade reaction. Reagent $\mathbf{1}$ was found to form a more electron-deficient cationic $N$-phenyl $O$-trifluoromethylsulfonylimidate, which participates more efficiently in the rate-determining $\left[4^{+}+2\right]$ reaction, and consequently, leads to a milder reaction condition and a higher reaction yield.

2.3.5 Synthesis of alkynyl imines as precursors to quinolines. $N$-Aryl $\alpha$-alkynyl imines have been frequently used as precursors in the synthesis of quinolines, which comprise an important class of heterocycles found in many natural products, drug candidates, and functional polymers. ${ }^{36}$ However, due to the low acidity of the $\alpha$-proton of imines, the preparation of $N$-aryl $\alpha$-alkynyl imines often requires the use of reactive and sensitive organometallic reagents, rendering current methods impractical in the laboratory. Therefore, there is a need to develop simple and more efficient metal-free protocols for the synthesis of $N$-aryl $\alpha$-alkynyl imines. Building on their early success in converting an amide into the corresponding imidate with oxophosphonium 1, ${ }^{34}$ Yao et al. capitalized on the efficiency of such a transformation and attempted to add mono- and di-substituted aliphatic alkynes to the imidate intermediate in hope of generating the $\alpha$-alkynyl imines exclusively. ${ }^{37}$ However, all reactions produced an almost 1:1 mixture of the $\alpha$-alkynyl imine and quinoline derivative, pointing to the presence of two competitive reaction pathways. In one pathway, an intermolecular Diels-Alder reaction between the alkyne and imidate, followed by eliminative aromatization gives the quinoline heterocycle.

The other pathway involves a cationic process, leading to the $\alpha$-alkynyl imines (vide infra). Apparently, electronic property of the alkyne is critical and judicial choice of the alkyne is required. For instance, the reaction failed to produce either product when trimethylsilylacetylene was used. Therefore, bis(trimethylsilylacetylene), which is a better electron donor, was chosen and reacted with a variety of aniline amides 25 in the presence of $\mathbf{1}$ (Table 15). Amides with electron-donating substituents (Entries 1, 2, 4, and 6) afforded the corresponding $\alpha$-alkynyl imines 26 in higher yields than those bearing electron-withdrawing groups (Entries 3, 5, and 1012). Interestingly, the methylated amine (Entry 13) also gave a lower yield, possibly because it gets converted to the electron-withdrawing ammonium salt. 
Table 15. Synthesis of alkynyl imines

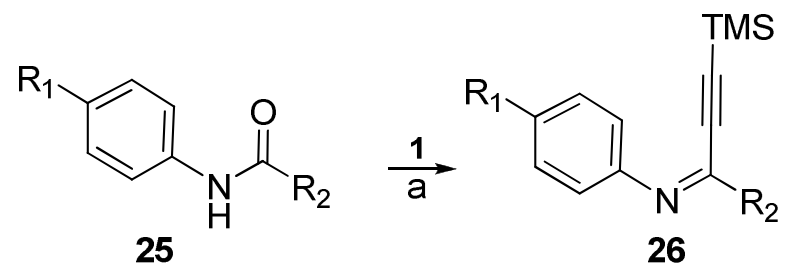

\begin{tabular}{ccc}
\hline Entry & $\mathrm{R}$ & Product yield (\%) \\
\hline 1 & $\mathrm{R}_{1}=\mathrm{OMe} ; \mathrm{R}_{2}=\mathrm{Ph}$ & 71 \\
2 & $\mathrm{R}_{1}=\mathrm{OMe} ; \mathrm{R}_{2}=\mathrm{Ph}-4-\mathrm{OMe}$ & 86 \\
3 & $\mathrm{R}_{1}=\mathrm{OMe} ; \mathrm{R}_{2}=\mathrm{Ph}-4-\mathrm{Cl}$ & 44 \\
4 & $\mathrm{R}_{1}=\mathrm{OMe} ; \mathrm{R}_{2}=\mathrm{Ph}-4-\mathrm{Bu}$ & 81 \\
5 & $\mathrm{R}_{1}=\mathrm{OMe} ; \mathrm{R}_{2}=\mathrm{Ph}-4-\mathrm{NO}_{2}$ & 28 \\
6 & $\mathrm{R}_{1}=\mathrm{Me} ; \mathrm{R}_{2}=\mathrm{Ph}-4-\mathrm{OMe}$ & 80 \\
7 & $\mathrm{R}_{1}=\mathrm{Cl} ; \mathrm{R}_{2}=\mathrm{Ph}-4-\mathrm{OMe}$ & 69 \\
8 & $\mathrm{R}_{1}=\mathrm{H} ; \mathrm{R}_{2}=\mathrm{Ph}-4-\mathrm{OMe}$ & 65 \\
9 & $\mathrm{R}_{1}=\mathrm{F} ; \mathrm{R}_{2}=\mathrm{Ph}-4-\mathrm{OMe}$ & 59 \\
10 & $\mathrm{R}_{1}=\mathrm{NO} \mathrm{R}_{2}=\mathrm{Ph}-4-\mathrm{OMe}$ & 50 \\
11 & $\mathrm{R}_{1}=\mathrm{CN} ; \mathrm{R}_{2}=\mathrm{Ph}-4-\mathrm{OMe}$ & 57 \\
12 & $\mathrm{R}_{1}=\mathrm{CO}_{2} \mathrm{Me}_{2} \mathrm{R}_{2}=\mathrm{Ph}-4-\mathrm{OMe}$ & 65 \\
13 & $\mathrm{R}_{1}=\mathrm{NMe}_{2} ; \mathrm{R}_{2}=\mathrm{Ph}-4-\mathrm{OMe}$ & 50 \\
\hline
\end{tabular}

Reagents and conditions: 25 ( $1 \mathrm{mmol}), \mathbf{1}$ (1.5 mmol; prepared from $\mathrm{Tf}_{2} \mathrm{O}$ (1.5 equiv.) and $\mathrm{Ph}_{3} \mathrm{PO}$ (3 equiv.), $\mathrm{CH}_{2} \mathrm{Cl}_{2}, 0{ }^{\circ} \mathrm{C}, 10 \mathrm{~min}$; (a) bis(trimethylsilylacetylene) (1.2 mmol), rt, $6 \mathrm{~h}$.

\subsubsection{Proposed mechanism for the reaction of $N$-arylbenzamides with} bis(trimethylsilyl)acetylene in the presence of 1 . As noted earlier, product distribution favoring the formation of the desired $N$-aryl $\alpha$-alkynyl imines was realized by using bis(trimethylsilylacetylene). Under these conditions, the cationic pathway becomes competitive. From a mechanistic prospective (Scheme 7), following the fast formation of the imidate intermediate 27, an addition-elimination sequence involving the reaction of the acetylene with 27 and concomitant removal of $\mathrm{Ph}_{3} \mathrm{PO}$ produces the cationic intermediate 28. The final step, which involves cationic elimination of TMSOTf (as opposed to $\mathrm{TfOH}$ ), is believed to be the driving force rendering the alkynyl imine as the exclusive product. 

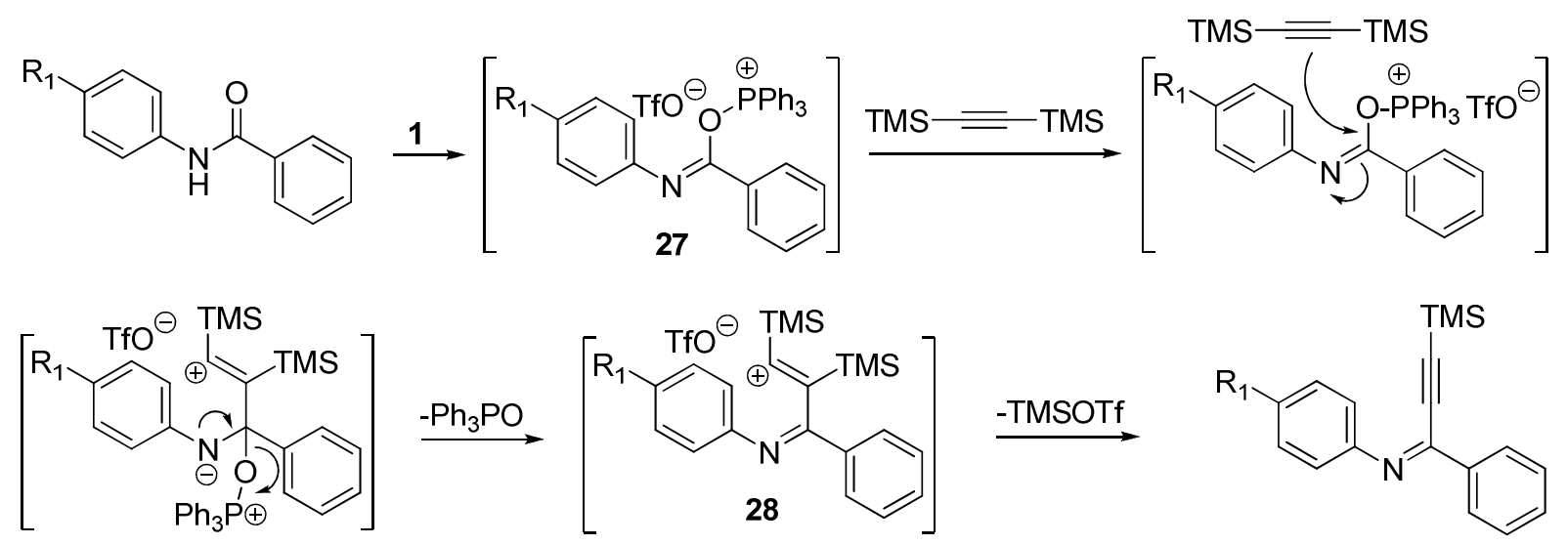

Scheme 7. Proposed mechanism of $N$-aryl $\alpha$-alkynyl imine formation

2.3.6. Synthesis of isoquinolines and $\boldsymbol{\beta}$-carbolines. The isoquinoline ${ }^{38}$ and $\beta$-carboline ${ }^{39}$ structural skeletons are found in various bioactive alkaloids and pharmaceutical agents. Because of their extensive bioactivities, considerable effort has been directed in the past few decades to the construction of the skeletal framework of isoquinoline and $\beta$-carboline heterocycles. The Pictet-Gams isoquinoline synthesis is one such synthetic approach which utilizes cascade cyclization and dehydration of $\beta$-hydroxy- $\beta$-arylethylamides driven by $\mathrm{POCl}_{3}$ or $\mathrm{P}_{2} \mathrm{O}_{5}{ }^{40}$ Building on the concept of cascade cyclization, $\mathrm{Wu}$ and Wang investigated the assembly of isoquinoline and $\beta$-carboline cores beginning from $\beta$-arylethylamides devoid of the hydroxyl group. ${ }^{41}$ In this context, they observed that under the action of 1 (1.5 equiv.), amide 29 gets converted into 1phenyl-3,4-dihydroisoquinoline $\mathbf{3 2}$ in $95 \%$ yield within 30 minutes at ambient temperature. The proposed mechanism for the intramolecular cyclization triggered by Hendrickson reagent is depicted in Scheme 8. As shown, the reaction of $\mathbf{1}$ with the amide function of $\mathbf{2 9}$ forms the corresponding activated imidate 30, then intramolecular nucleophilic addition by the phenyl ring accompanied by elimination of $\mathrm{Ph}_{3} \mathrm{PO}$ affords dihydroisoquinoline 31. One additional aromatization step is then required to produce the isoquinoline compound $\mathbf{3 2}$.
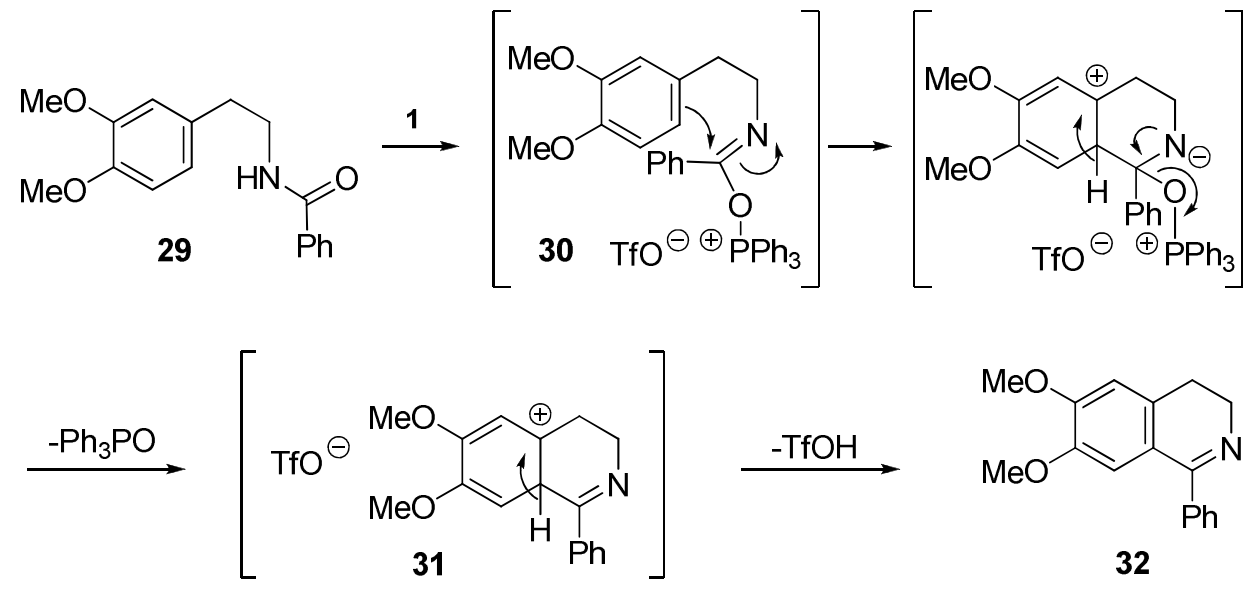

Scheme 8. Proposed mechanism for the formation of a dihydroisoquinoline triggered by Hendrickson reagent 1 
Indeed, after screening several oxidants and solvents, dihydroisoquinoline $\mathbf{3 2}$ was successfully oxidized with $\mathrm{MnO}_{2}$ by refluxing the reaction in chlorobenzene at $130{ }^{\circ} \mathrm{C}$ for $4 \mathrm{~h}$, affording the desired isoquinoline in $80 \%$ yield. Using the optimized conditions, different amides derived from 2-(3,4-dimethoxyphenyl)ethylamine were examined (Table 16). As shown, both electron-withdrawing $\left(4-\mathrm{NO}_{2}\right)$ (Entry 1) and electron-donating (4-OMe) (Entry 2) groups were tolerated, although the electron-withdrawing group appears more advantageous. Halo and other substituents were also compatible with the reaction (Entries 3-6), giving good yields of the desired isoquinolines. It is noted that the isoquinoline shown in Entry 6 is a naturally occurring alkaloid named nigellimine. $^{42}$

Using the above cascade reaction, the cyclization/oxidation sequence of different amides derived from tryptamine $\mathbf{3 5}$ was investigated under the same optimized conditions employed earlier. Surprisingly, no $\beta$-carboline products were detected. However, the cyclization step proceeded only after the reaction of the amides 35 with $\mathbf{1}$ was heated at $130{ }^{\circ} \mathrm{C}$ for about 30 minutes. Subsequent oxidation with $\mathrm{MnO}_{2}$ gave the corresponding $\beta$-carboline products 36 (Table 17) in yields ranging from 65 to $88 \%$. It is noted that the preceding process provides an effective route to prepare $\beta$-carboline natural products. For instance, the alkaloids shown in Entries 4 and 6 are $\beta$-carboline natural products known as vulcanine ${ }^{43}$ and harman, ${ }^{44}$ respectively.

Table 16. One-pot synthesis of isoquinolines

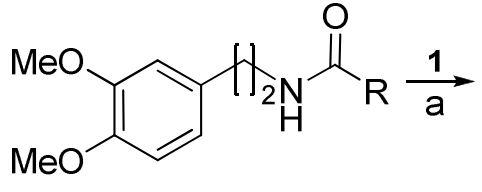

33<smiles>[R]c1nccc2cc(OC)c(OC)cc12</smiles>

34

\begin{tabular}{ccc}
\hline Entry & $\mathrm{R}$ & Product yield (\%) \\
\hline 1 & $\mathrm{Ph}-4-\mathrm{NO}_{2}$ & 86 \\
2 & $\mathrm{Ph}-4-\mathrm{OMe}$ & 61 \\
3 & $\mathrm{Ph}-2-\mathrm{I}$ & 85 \\
4 & $\mathrm{Ph}-3-\mathrm{Br}$ & 87 \\
5 & E-Styryl & 77 \\
6 & $\mathrm{Me}$ & 75 \\
\hline
\end{tabular}

Reagents and conditions: 1 (prepared from 1.5 equiv. $\mathrm{Tf}_{2} \mathrm{O}$ and 3 equiv. $\mathrm{Ph}_{3} \mathrm{PO}, \mathrm{PhCl}$, rt, 30 min; (a) $\mathrm{MnO}_{2}$ (3 equiv.), $130{ }^{\circ} \mathrm{C}, 4 \mathrm{~h}$. 
Table 17. One-pot synthesis of $\beta$-carbolines

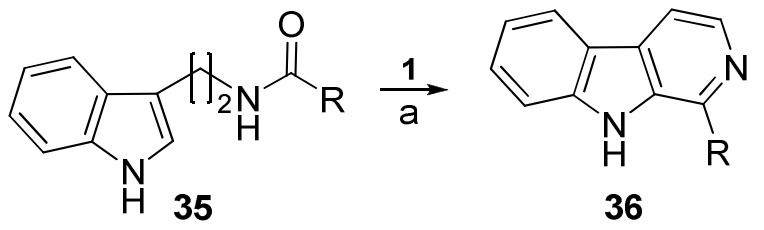

\begin{tabular}{ccc}
\hline Entry & $\mathrm{R}$ & Product yield (\%) \\
\hline 1 & $\mathrm{Ph}$ & 76 \\
2 & $\mathrm{Ph}-3-\mathrm{Br}$ & 88 \\
3 & $\mathrm{Ph}-2-\mathrm{NO}_{2}$ & 65 \\
4 & 2-methylprop-1-ene & 71 \\
5 & $\mathrm{Me}$ & 82 \\
6 & $\mathrm{Et}$ & 85 \\
\hline
\end{tabular}

Reagents and conditions: 1 (prepared from 1.5 equiv. $\mathrm{Tf}_{2} \mathrm{O}$ and 3 equiv. $\mathrm{Ph}_{3} \mathrm{PO}, \mathrm{PhCl}, \mathrm{rt}, 30$ min, then $130{ }^{\circ} \mathrm{C}, 30 \mathrm{~min}$; (a) $\mathrm{MnO}_{2}$ (3 equiv.), $130{ }^{\circ} \mathrm{C}, 4 \mathrm{~h}$.

2.3.7. Synthesis of phenanthridines. Substituted phenanthridines comprise an important class of heterocyclic compounds with applications in material science ${ }^{45}$ and in medicinal chemistry ${ }^{46}$ due to their pronounced biological activities. ${ }^{46}$ Among the many synthetic approaches reported in the past, the Bischler-Napieralski cyclization has been most extensively used to synthesize phenanthridine derivatives. It is usually performed under high temperature conditions in the presence of $\mathrm{P}_{4} \mathrm{O}_{10}, \mathrm{POCl}_{3}$, or $\mathrm{PCl}_{5}$. ${ }^{47}$ Such harsh conditions have created limitations as to the kind of functional groups that can be tolerated. More recently, several other synthetic routes to substituted phenanthridines have been disseminated, most of which involve multistep syntheses and require metal catalysts and elevated temperatures. ${ }^{48}$ Thus, there is a need for flexible and versatile synthetic protocols of constructing phenanthridines. In continuation of their early work involving the generation of imido carboniums with reagent $1,{ }^{34-37}$ Yao et al. envisaged that such reactive intermediates might undergo an intramolecular Friedel-Crafts reaction with electron-rich arenes, providing a novel approach to the synthesis of substituted phenanthridine derivatives. ${ }^{49}$ Thus, a number of biphenyl-2-amine amides $\mathbf{3 7}$ bearing a variable substituent $\mathrm{R}$ on ring $\mathrm{B}$ were subjected to the standard conditions of their previous work with Hendrickson's reagent (Table 18). All reactions proceeded smoothly under mild conditions $\left(0{ }^{\circ} \mathrm{C}-\mathrm{rt}\right)$ and in short duration $(5-$ $30 \mathrm{~min}$ ), affording phenanthridines 38 in good yields (Table 18, Entries 1-9). The amide containing a $\mathrm{NO}_{2}$ group (Entry 10) on phenyl ring $\mathrm{B}$ failed to undergo the cascade reaction presumably due to the strong electron-withdrawing effects of the nitro group, which render the final intramolecular Friedel-Crafts reaction unfavorable. Interestingly, several phenanthridines bearing halogen atoms were successfully prepared in satisfactory yields, rendering such derivatives amenable to further structural elaboration to improve their chemical and physical properties in various applications. Finally, poor regioselectivity was observed with the substrate 
bearing a methoxy group at the C-3 position of phenyl ring B (Entry 3), giving 7-methoxy-6methylphenanthridine and 9-methoxy-6-methylphenanthridine in a 1:2.5 ratio.

Table 18. Synthesis of phenanthridines with various substituents

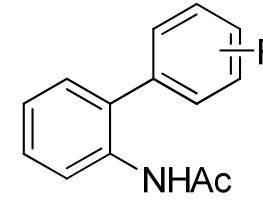

37

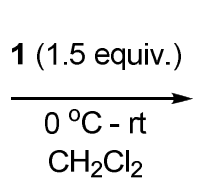

$\mathrm{CH}_{2} \mathrm{Cl}_{2}$<smiles>[R]c1cccc2c(C)nc3ccccc3c12</smiles>

38

\begin{tabular}{ccc}
\hline Entry & $\mathrm{R}$ & Product yield $(\%)$ \\
\hline 1 & $\mathrm{H}$ & 95 \\
2 & $4-\mathrm{MeO}$ & 95 \\
3 & $3-\mathrm{MeO}$ & 26,65 \\
4 & $4-\mathrm{Me}$ & 90 \\
5 & $3,4-\mathrm{di}-\mathrm{MeO}$ & 87 \\
6 & $2-\mathrm{MeO}$ & 91 \\
7 & $4-t \mathrm{Bu}$ & 89 \\
8 & $4-\mathrm{Ph}$ & 98 \\
9 & $4-\mathrm{Br}$ & 78 \\
10 & $3-\mathrm{NO} 2$ & n.r. \\
\hline
\end{tabular}

Reagents and conditions: 1 (prepared from 1.5 equiv. $\mathrm{Tf}_{2} \mathrm{O}$ and 3 equiv. $\mathrm{Ph}_{3} \mathrm{PO}, \mathrm{CH}_{2} \mathrm{Cl}_{2}, 0^{\circ} \mathrm{C}-\mathrm{rt}$, 5-30 min, ${ }^{\mathrm{a} a}$ mixture of regioisomers: 7-methoxy-6-methylphenanthridine: 9-methoxy-6methylphenanthridine $(1: 2.5)$.

\subsubsection{Proposed mechanism for Hendrickson reagent promoted intramolecular Friedel-} Crafts reaction in the synthesis of phenanthridines. Formation of the phenanthridine skeleton involves three consecutive reactions (Scheme 9): (a) in situ formation of an $N$-arylimidate 40 through activation of the precursor amide 39 with the highly-oxophilic reagent $\mathbf{1}$, accompanied by the elimination of 1 molecule of $\mathrm{Ph}_{3} \mathrm{PO}$ and triflic acid, and (b) subsequent elimination of $\mathrm{Ph}_{3} \mathrm{PO}$ with concomitant intramolecular Friedel-Crafts (F-C) cyclization to give 41, and (c) aromatization accompanied by the formation of triflic acid ( $\mathrm{TfOH})$. 


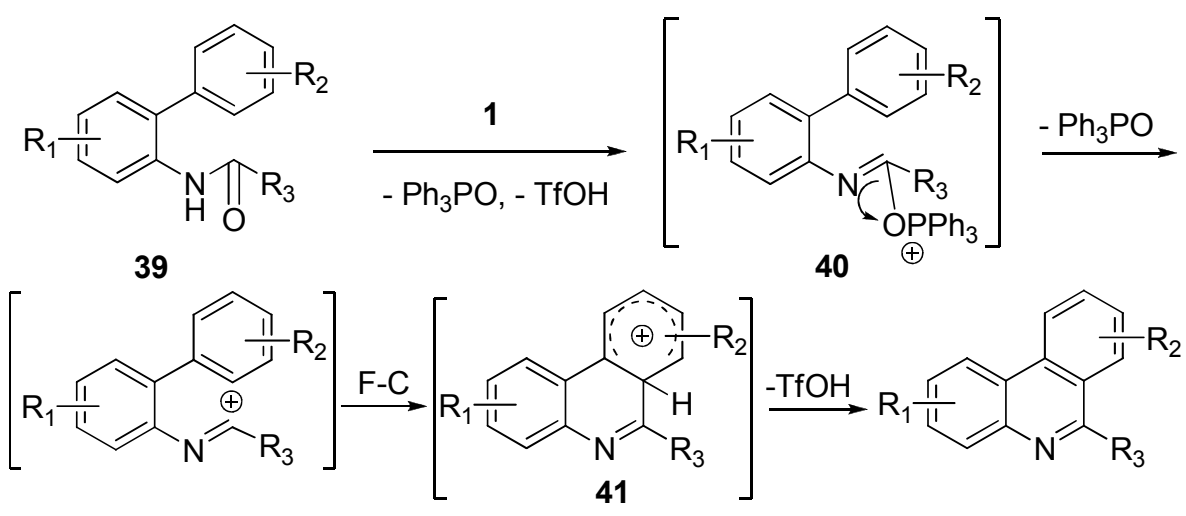

Scheme 9. Proposed mechanism for Hendrickson reagent promoted intramolecular FriedelCrafts reaction in the synthesis of phenanthridines

2.3.8. Synthesis of $\mathbf{1 1 H}$-indolo[3,2-c]quinolines. The $11 H$-indolo[3,2-c]quinoline scaffold occurs in many natural alkaloids, bestowing diverse and significant biological properties on such heterocylces. ${ }^{50}$ For instance, isocryptolepine, a methyl-substituted derivative isolated from Cryptolepis sanguinolenta, shows pronounced antiplasmodial activity, ${ }^{51}$ while related analogues display high cytotoxicity against certain cancer cell lines. ${ }^{52}$ Thus, motivated by the need to further investigate the structure-activity relationship, several strategies based on indole and quinoline formation have been developed to construct the tetracyclic skeleton. However, due to the limitations associated with availability of indole and quinoline starting materials, such strategies are relatively inflexible with respect to the introduction of different substituents on the ring. In order to address these drawbacks and to further develop a more efficient and flexible protocol, Wang et al. designed a two-step approach to assemble $11 H$-indolo[3,2-c]quinolines. ${ }^{53}$ The five- and six-membered nitrogen-containing rings in the skeleton were formed via a gold(III)-catalyzed 5-endo-dig-cyclization (step I), followed by a Hendrickson reagent promoted regioselective 6-endo-cyclization (step II). Under the action of Hendrickson reagent (1) (1.5 equiv.), a variety of benzamides $\mathbf{4 2}$ prepared from step 1 were converted to the anticipated tetracyclic products 43 in yields ranging from 60-95\% (Table 19). Apparently, the electronic properties of the substituent on the benzoyl group had a significant impact on the outcome of the cyclization. While the methoxy group facilitated the conversion, producing the methoxysubstituted indoloquinoline in $95 \%$ yield (Entry 4), the nitro group impeded the cyclization (Entry 5), giving the product in only $78 \%$ yield. 
Table 19. Synthesis of $11 H$-indolo[3,2-c]quinolines<smiles>[R]C(=O)Nc1ccccc1-c1cc2cc([R])ccc2[nH]1</smiles>

\begin{tabular}{llll}
\hline Entry & Starting material & Product & Yield (\%) \\
\hline 1 & $\mathrm{R}_{1}=\mathrm{H}, \mathrm{R}_{2}=\mathrm{Et}$ & $\mathrm{R}_{1}=\mathrm{H}, \mathrm{R}_{2}=\mathrm{Et}$ & 83 \\
2 & $\mathrm{R}_{1}=\mathrm{H}, \mathrm{R}_{2}=\mathrm{H}$ & $\mathrm{R}_{1}=\mathrm{H}, \mathrm{R}_{2}=\mathrm{H}$ & 75 \\
3 & $\mathrm{R}_{1}=\mathrm{H}, \mathrm{R}_{2}=\mathrm{Ph}$ & $\mathrm{R}_{1}=\mathrm{H}, \mathrm{R}_{2}=\mathrm{Ph}$ & 92 \\
4 & $\mathrm{R}_{1}=\mathrm{H}, \mathrm{R}_{2}=\mathrm{OMe}$ & $\mathrm{R}_{1}=\mathrm{H}, \mathrm{R}_{2}=\mathrm{OMe}$ & 95 \\
5 & $\mathrm{R}_{1}=\mathrm{H}, \mathrm{R}_{2}=\mathrm{NO}_{2}$ & $\mathrm{R}_{1}=\mathrm{H}, \mathrm{R}_{2}=\mathrm{NO}_{2}$ & 78 \\
6 & $\mathrm{R}_{1}=\mathrm{H}, \mathrm{R}_{2}=\mathrm{OEt}$ & $\mathrm{R}_{1}=\mathrm{H}, \mathrm{R}_{2}=\mathrm{OEt}$ & 60 \\
7 & $\mathrm{R}_{1}=\mathrm{Cl}, \mathrm{R}_{2}=\mathrm{Me}$ & $\mathrm{R}_{1}=\mathrm{Cl}, \mathrm{R}_{2}=\mathrm{Me}$ & 94 \\
8 & $\mathrm{R}_{1}=\mathrm{Me}, \mathrm{R}_{2}=\mathrm{Me}$ & $\mathrm{R}_{1}=\mathrm{Me}, \mathrm{R}_{2}=\mathrm{Me}$ & 84 \\
\hline
\end{tabular}

2.3.8.1. Proposed mechanism for Hendrickson reagent promoted 6-endo cyclization in the synthesis of $11 \mathrm{H}$-indolo[3,2-c]quinolines. Formation of the $11 \mathrm{H}$-indolo[3,2-c]quinoline skeleton involves three consecutive reactions (Scheme 10): (a) in situ formation of an $N$ arylimidate through selective activation of the corresponding amide with the highly-oxophilic reagent $\mathbf{1}$, and (b) subsequent intramolecular regioselective 6-endo cyclization with concomitant elimination of $\mathrm{Ph}_{3} \mathrm{PO}$, and (c) aromatization accompanied by the formation of triflic acid (TfOH).<smiles>[R]C(=O)Nc1ccccc1-c1cc2ccccc2[nH]1</smiles>

Scheme 10. Proposed mechanism for Hendrickson reagent promoted intramolecular regioselective 6-endo cyclization in the synthesis of $11 H$-indolo[3,2-c]quinolines 
2.3.9. Synthesis of quinoline-lactones and furoquinolinones. Furoquinolinones are useful synthetic intermediates and are key structural features in biologically interesting natural products, such as uncialamycin. ${ }^{54}$ Considerable effort has been invested in the past few decades to the construction of variously substituted quinoline-lactones. ${ }^{55}$ Among these, the intramolecular aza Diels-Alder reaction has been employed on several occasions, but has met limited success because of the involvement of unstable intermediates and low overall yields. ${ }^{54,55}$ Consequently, the further application of quinoline-lactones in the syntheses of many useful products bearing multiple functionalities has been severely constrained. Building on their early success in using reagent 1 to convert aniline-amides to the corresponding highly reactive imidates at ambient temperature, ${ }^{34-37,49-53}$ Yao et al. considered a similar strategy in the synthesis of furoquinolinone derivatives. Indeed, an efficient approach to this class of heterocycles was reported recently, where reagent $\mathbf{1}$ initiated a cascade aza Diels-Alder reaction, followed by eliminative aromatization to afford the tricyclic framework. ${ }^{56}$ Hence, following the preparation of several amides 44 with various substituents at $R_{1}, R_{2}$, and $R_{3}$, their reactions with 1 were examined under the standard conditions used in their previous work (Table 20). Pleasingly, the desired quinoline-lactone derivatives $\mathbf{4 5}$ were formed in high regioselectivity and almost quantitative yields (90-97\%), and the effects of the electronic properties of the substituents were negligible. The stereochemistry of the exo double bond in the products was confirmed by X-ray single crystal analysis. Finally, conversion of a representative tricyclic quinoline-lactone (product from Entry 7) to its corresponding furoquinolinone was achieved by oxidative cleavage of the exo double bond by $\mathrm{NaIO}_{4}$ oxidation in the presence of catalytic amount of $\mathrm{RuCl}_{3}$ at room temperature, affording the furoquinolinone in $88 \%$ yield.

Table 20. Synthesis of quinoline-lactone derivatives with various substituents<smiles>[R]C#CC([R3])O/C(=C\c1c(C)cccc1C#N)C(=O)Nc1cccc([R])c1</smiles><smiles>CC(C)[C@H](C)O</smiles><smiles>[R]C1=C2C(=NC3C=CC=CC13)C([R])O/C2=C\c1c(C#N)cccc1C#N</smiles>

\begin{tabular}{cccc}
\hline Entry & Starting material & Product & Yield (\%) \\
\hline 1 & $\mathrm{R}_{1}=\mathrm{R}_{2}=\mathrm{R}_{3}=\mathrm{H}$ & $\mathrm{R}_{1}=\mathrm{R}_{2}=\mathrm{R}_{3}=\mathrm{H}$ & 90 \\
2 & $\mathrm{R}_{1}=p-\mathrm{OMe} ; \mathrm{R}_{2}=$ & $\mathrm{R}_{1}=p-\mathrm{OMe} ; \mathrm{R}_{2}=\mathrm{R}_{3}$ & 91 \\
$\mathrm{R}_{3}=\mathrm{H}$ & $=\mathrm{H}$ & \\
& $\mathrm{R}_{1}=p-\mathrm{Br} ; \mathrm{R}_{2}=\mathrm{R}_{3}$ & $\mathrm{R}_{1}=p-\mathrm{Br} ; \mathrm{R}_{2}=\mathrm{R}_{3}=$ & 97 \\
$=\mathrm{H}$ & $\mathrm{H}$ & \\
& $\mathrm{R}_{1}=\mathrm{p}-\mathrm{F} ; \mathrm{R}_{2}=\mathrm{R}_{3}=$ & $\mathrm{R}_{1}=\mathrm{p}-\mathrm{F} ; \mathrm{R}_{2}=\mathrm{R}_{3}$ & 93 \\
4 & $\mathrm{H}$ & $\mathrm{H}$ & \\
& $\mathrm{R}_{1}=p-\mathrm{CO}_{2} \mathrm{Me} ; \mathrm{R}_{2}$ & $\mathrm{R}_{1}=p-\mathrm{CO}_{2} \mathrm{Me} ; \mathrm{R}_{2}=$ & 92 \\
& $=\mathrm{R}_{3}=\mathrm{H}$ & & \\
& & &
\end{tabular}


Table 20. Continued

\begin{tabular}{cccc}
\hline Entry & Starting material & Product & Yield (\%) \\
\hline 6 & $\mathrm{R}_{1}=o-\mathrm{Me} ; \mathrm{R}_{2}=\mathrm{R}_{3}$ & $\mathrm{R}_{1}=o-\mathrm{Me} ; \mathrm{R}_{2}=\mathrm{R}_{3}=$ & 96 \\
& $\mathrm{H}$ & \\
7 & $\mathrm{R}_{1}=p-\mathrm{Me} ; \mathrm{R}_{2}=\mathrm{R}_{3}$ & $\mathrm{R}_{1}=p-\mathrm{Me} ; \mathrm{R}_{2}=\mathrm{R}_{3}=$ & 95 \\
& $\mathrm{H}$ & $\mathrm{H}$ & \\
8 & $\mathrm{R}_{2}=\mathrm{Et} ; \mathrm{R}_{1}=\mathrm{R}_{3}=$ & $\mathrm{R}_{2}=\mathrm{Et} ; \mathrm{R}_{1}=\mathrm{R}_{3}=\mathrm{H}$ & 93 \\
& $\mathrm{H}$ & \\
9 & $\mathrm{R}_{3}=\mathrm{Me} ; \mathrm{R}_{1}=\mathrm{R}_{2}=$ & $\mathrm{R}_{3}=\mathrm{Me} ; \mathrm{R}_{1}=\mathrm{R}_{2}=$ & 94 \\
& $\mathrm{H}$ & $\mathrm{H}$ & \\
\hline
\end{tabular}

2.3.9.1. Proposed mechanism for Hendrickson reagent promoted cascade aza Diels-Alder reaction. The proposed mechanism for Hendrickson reagent promoted cascade aza Diels-Alder reaction involves three consecutive reactions: (a) in situ generation of an imidocarbonium intermediate 46 through activation of the corresponding amide with the highly-oxophilic reagent 1, accompanied by the elimination of 2 molecules of $\mathrm{Ph}_{3} \mathrm{PO}$ and triflic acid, (b) subsequent intramolecular aza Diels-Alder reaction with a nearby alkyne tether to give the tricyclic species 47, (c) and a subsequent eliminative aromatization to generate the tricyclic quinoline-lactone derivative readied for oxidative cleavage into the dihydrofuroquinoline.<smiles>[R][X]c1ccccc1NC(=O)/C(=C/c1c(C)cccc1C#N)OCC#C</smiles>

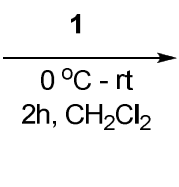

(a) $\downarrow \begin{aligned} & -2 \mathrm{Ph} \\ & -\mathrm{TFOH}\end{aligned}$<smiles>[R]c1cccc2cc3c(nc12)/C(=C/c1c(C#N)cccc1C#N)OC3</smiles>

(c) $\uparrow-\mathrm{TfOH}$

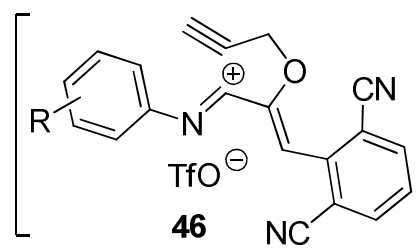

$\stackrel{\mathrm{IADA}}{\longrightarrow}$

(b)

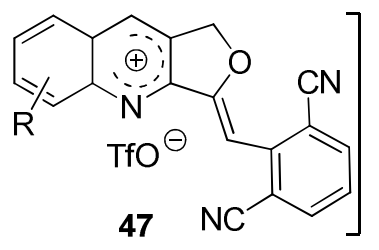

Scheme 11. Proposed mechanism for Hendrickson reagent promoted intramolecular aza DielsAlder cascade reaction in the synthesis of quinoline-lactone derivatives.

\subsection{Application of the Hendrickson reagent in total synthesis of natural products}

2.4.1. Total synthesis of dendroamide A. Dendroamide A (48) is a cyclic hexapeptide from the terrestrial blue-green alga (cyanobacterium) Stigonema dendroideum fremy. ${ }^{57}$ The natural product was isolated in 1996 on the basis of displaying multidrug-resistance (MDR) reversing activity in tumor cells. ${ }^{58}$ MDR refers to a situation whereby cancer cells develop resistance to 
drugs while undergoing chemotherapy and its development has been a major hurdle to successful cancer chemotherapy. Acquired resistance to anticancer drugs is thought to involve overexpression of the transport protein P-glycoprotein (Pgp) and related drug transporters in cancer cells. Pgp is a plasma membrane efflux pump that can effectively remove anticancer drugs out of the cell. Consequently, Pgp inhibitors comprise promising agents for cancer therapy and great synthetic targets. Because of the activity of dendroamide A, a convergent synthesis of this oxazole- and thiazole-containing peptide has been reported by Kelly et al. using oxodiphosphonium salt 1 to prepare the three key intermediates 52-54. ${ }^{59}$ Thus, as outlined in Scheme 12, retrosynthetic analysis of dendroamide A featured disconnection at three amide bonds to produce three thiazole- and oxazole-containing amino acids 52-54. While the thiazoles were prepared by treating the corresponding protected cysteine-containing dipeptides 49 and 50 with $\mathbf{1}$, followed by oxidation with activated manganese oxide ( 81 and $82 \%$ overall yield, respectively), the oxazole was synthesized in one step from the $\beta$-ketodipeptide $\mathbf{5 1}$ (84\% yield) without any racemization ( $98 \%$ ee). This was in striking contrast to the $\mathrm{PPh}_{3} \mathrm{P} / \mathrm{I}_{2}$ reagent which compromised the Ala-derived stereocenter due the presence of a base.

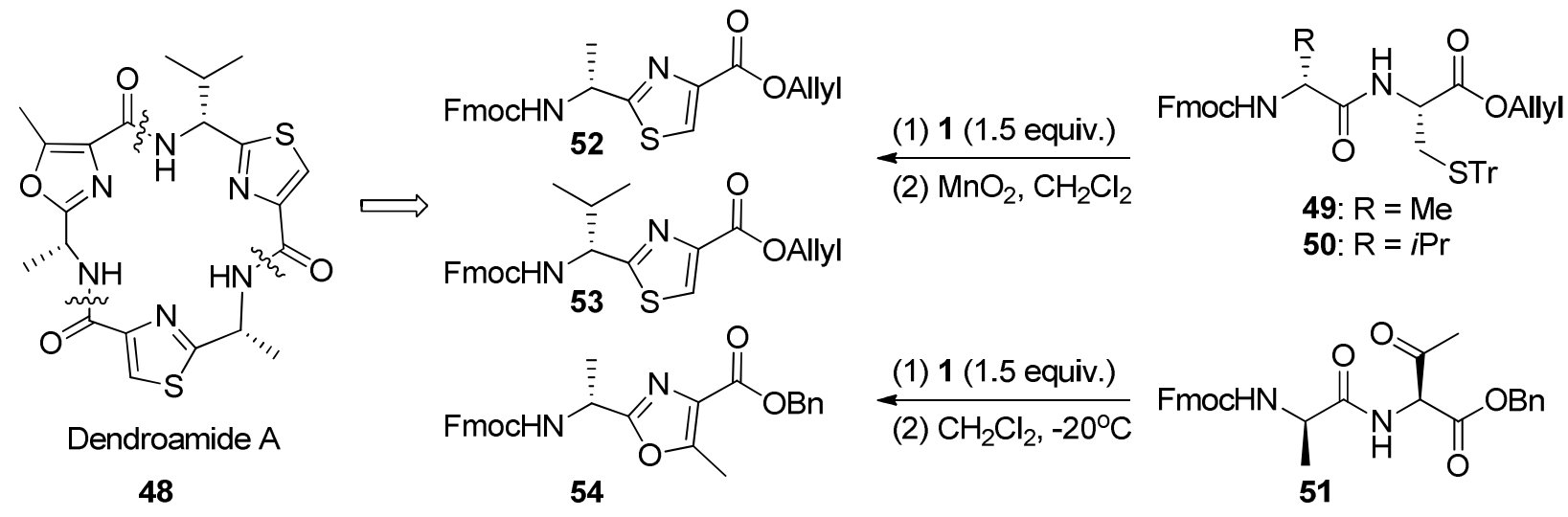

Scheme 12. Application of $\mathbf{1}$ in the total synthesis of dendroamide A.

2.4.2. Total synthesis of bistratamides E-J. As outlined earlier, oxazole- and thiazolecontaining natural products have attracted considerable attention due to their cytotoxic and metal binding capacity. Bistramides $\mathrm{E}$ (55) and $\mathbf{J}$ (56) are thiazole-oxazoline and thiazole containing macrocycles of peptide origin. ${ }^{60}$ Both were isolated from Lissoclinum bistratum in the southern Philippines and proved cytotoxic against a human colon tumor (HCT-116) cell line. ${ }^{61}$ Assembly of the thiazole rings is central to the total synthesis of these natural products. Thus as depicted in Scheme 13, bistramides $\mathrm{E}$ and $\mathrm{J}$ may be synthesized from the common bis-thiazole intermediate 57, which can be prepared from the coupling between thiazoles $\mathbf{5 8}$ and $\mathbf{5 9}$. Both, $\mathbf{5 8}$ and $\mathbf{5 9}$, may be derived from the same protected thiazole 62. Preparation of the key allyl-Fmoc-protected thiazole 62 started by converting the Val-Cys dipeptide 60 into thiazoline 61 by using the biomimetic approach developed earlier with diphosphonium 1. $^{7}$ Conversion of the trityl- 
protected cysteine residue of $\mathbf{6 0}$ proceeded in high yield ( $89 \%$ yield) at $-20{ }^{\circ} \mathrm{C}$ by using 1.5 equiv. of 1. Subsequent oxidation to the thiazole 62 was accomplished with activated $\mathrm{MnO}_{2}$ in 94\% yield and $96 \%$ ee. Having thiazole 62 in hand, the proposed synthetic scheme was successfully executed to afford the first total syntheses of bistratamides $\mathrm{E}$ and $\mathrm{J}$ in overall yields of 19 and 34\%, respectively. The total syntheses of the related bistratamides F-I have also been achieved by the same group, whereby the thiazole substructure was prepared utilizing a $\mathrm{MnO}_{2}$ oxidation of a thiazoline, synthesized from a Val-Cys dipeptide using oxodiphosphonium $\mathbf{1}^{60}$

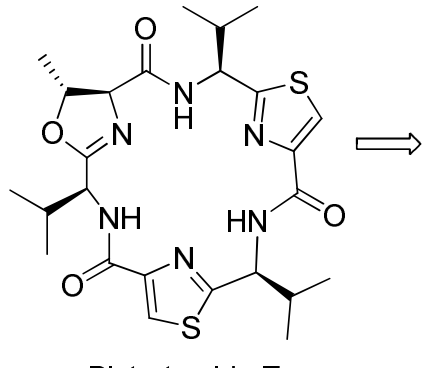

Bistratamide $\mathrm{E}$

55

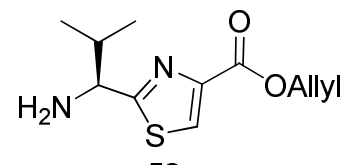

58<smiles>COC(=O)c1csc(C(NC(=O)c2csc(C(NC(F)F)C(C)C)n2)C(C)C)n1</smiles>

$\prod$<smiles>CC(C)[C@H](NC(F)F)c1nc(C(=O)O)cs1</smiles>

59

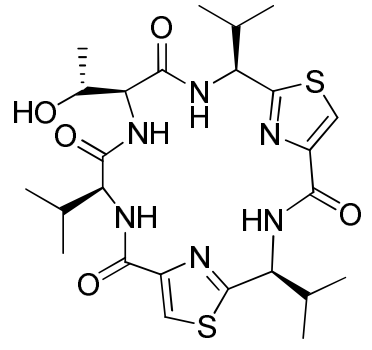

Bistratamide J

56<smiles>CC(C)[C@H](NC(F)F)C(=O)N[C@@H](C[Sn])C(=O)OCC(F)F</smiles>

Scheme 13. Application of $\mathbf{1}$ in the total synthesis of bistratamides E and J.

2.4.3. Total synthesis of didmolamides $A$ and $B$. The oxazoline and thiazole rings comprise an integral part of didmolamides A (69) and B (71) (Scheme 14 and 15). The two compounds are cyclic hexapeptides that were isolated from the marine ascidian Didemnum molle collected in Madagascar. ${ }^{62}$ Both heterocycles showed mild cytotoxicity with $\mathrm{IC}_{50}$ values of $10-20 \mu \mathrm{g} / \mathrm{mL}$. These properties have prompted wide interest to search for simple and efficient synthetic routes toward these species. The biomimetic synthesis of thiazolines ${ }^{7}$ reported by Kelly et al. and successfully used in the total synthesis of dendroamide A and bistratamides E-J appeared most suitable for the construction of the thiazole rings of didmolamides A and B. Thus, treating the appropriate $\mathrm{N}$-acylated cysteine substrate with $\mathbf{1}$, followed by oxidation of the resulting thiazoline should afford the corresponding thiazole. Indeed Kelly et al. took advantage of this methodology to synthesize didmolamides A (Scheme 14) and B (Scheme 15). ${ }^{63}$ Thus, preparation of the key thiazole-based amino acid building block 64 was accomplished in $92 \%$ yield by treating the $\mathrm{N}$-Fmoc-S-trityl-L-cysteine allyl ester dipeptide 63 with $\mathbf{1}$, followed by 
oxidation of the resulting thiazoline with activated manganese oxide and subsequent removal of the allyl ester protecting group employing a palladium catalyst. After attaching the thiazole to Wang resin utilizing HBTU and HOBt in the presence of DIEA, the Fmoc protecting group of the supported thiazole 65 was removed with $20 \%$ piperidine in DMF. Subsequent coupling between the resin-supported amine and the next thiazole-based amino acid residue $\mathbf{6 4}$ using HBTU/HOBt afforded the thiazole-containing dipeptide 66. Finally, sequential coupling of $N$ Fmoc-allo-threonine and $N$-Fmoc-L-phenylalanine (giving 67) using the same coupling conditions gave the complete skeleton and all the stereogenic centers of didmolamide A. Deprotection of the Fmoc group of $\mathbf{6 7}$ and cleavage of the resin with 95\% TFA afforded the thiazole-containing triamide which underwent macrolactamization into $\mathbf{6 8}$ by using a combination of PyBOP and DMAP. Treatment of the macrolactam 68 with Burgess reagent gave didmolamide $\mathrm{A}$ in $56 \%$ yield.

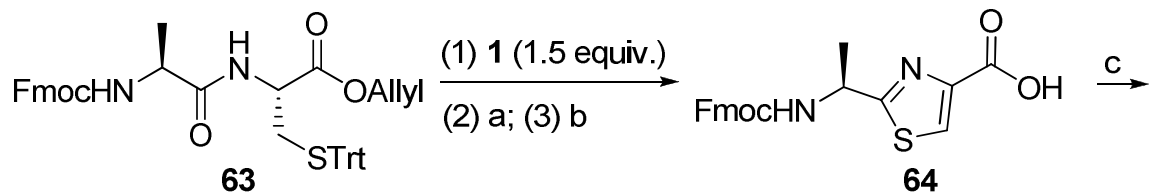

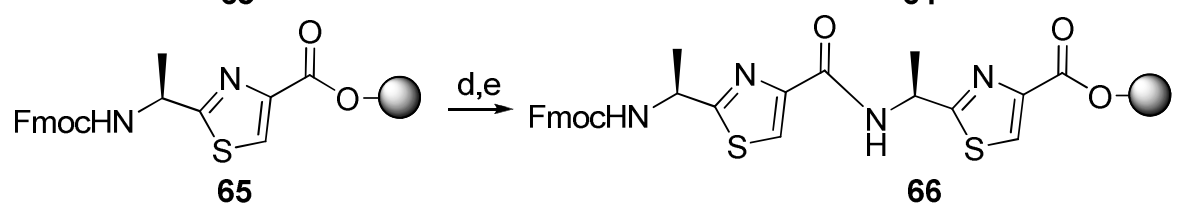
$\stackrel{\mathrm{d}, \mathrm{f}, \text { then } \mathrm{d}, \mathrm{g}}{\longrightarrow}$<smiles>CC(NC(=O)c1csc([18O])n1)c1nc(C(=O)NC(C)[C@H](NC(=O)C(Cc2ccccc2)NC(F)F)C(C)O)cs1</smiles>
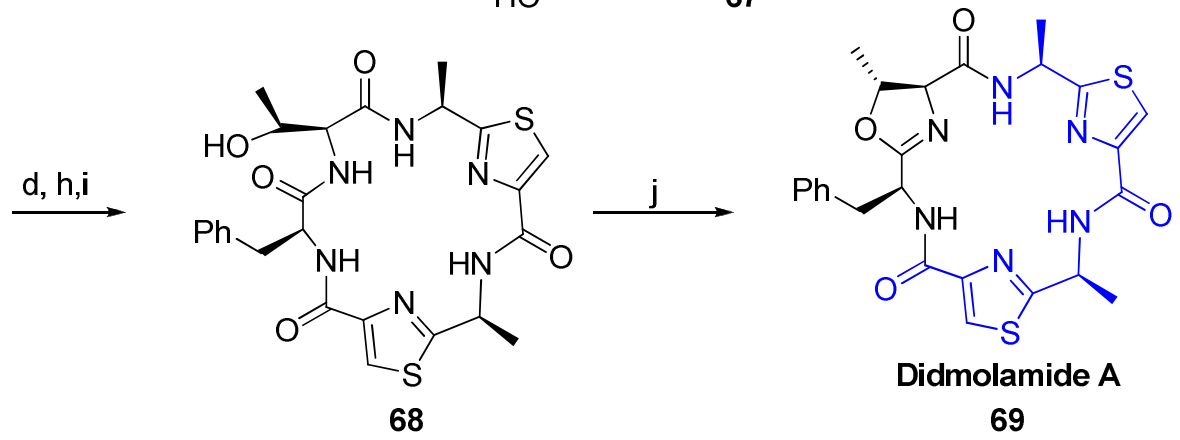

Scheme 14. Solid phase total synthesis of didmolamide A. Reagents and conditions: (a) activated $\mathrm{MnO}_{2}$; (b) $\mathrm{Pd}(\mathrm{OAc})_{2}, \mathrm{PS}-\mathrm{PPh}_{3}, \mathrm{PhSiH}_{3}, \mathrm{CH}_{2} \mathrm{Cl}_{2}$. (c) $\mathrm{HBTU}$ (2 equiv), $\mathrm{HOBt}$ (2 equiv), DIEA (3 equiv), 8-12 h. (d) 20\% piperidine in DMF, 1 h. (e) HBTU (2 equiv), HOBt (2 equiv), DIEA (3 equiv), 64 (2 equiv, $0.5 \mathrm{M}$ in DMF), 2 h. (f) HBTU (2 equiv), HOBt (2 equiv), DIEA (3 equiv), N-Fmoc-allo-Thr-OH (2 equiv, 0.5 M in DMF), $2 \mathrm{~h}$. (g) HBTU (2 equiv), HOBt (2 equiv), DIEA (3 equiv), N-Fmoc-Phe-OH (2 equiv, 0.5M in DMF), 2 h. (h) $95 \%$ TFA in $\mathrm{CH}_{2} \mathrm{Cl}_{2}$, 3 h. (i) PyBOP (2 equiv), DMAP (2 equiv), DIEA (2 equiv), $\mathrm{CH}_{2} \mathrm{Cl}_{2}$, DMF; (j) Burgess reagent, THF, reflux. 
Didmolamide B (71) was synthesized in much the same way as outlined above for didmolamide A, except for the last step involving oxazoline formation with the Burgess reagent (Scheme 15). Hence, starting from the common thiazole-containing dipeptide 66, the Fmoc was removed as before (20\% piperidine) and the resulting free amine was coupled sequentially with $N$-Fmoc-O-trityl-L-threonine and $N$-Fmoc-L-phenylalanine utilizing HBTU/HOBt/DIEA to give the triamide 70 in high yield. Next, removal of the Fmoc protecting group and cleavage of the peptide from the Wang resin using TFA, which also removed the $O$-trityl protecting group on the threonine residue, afforded the free triamide with unprotected amine and carboxylic acid moieties. Finally, macrolactamization under the standard conditions used earlier afforded didmolamide $\mathrm{B}$ in $51 \%$ yield.<smiles>CC(NC(=O)c1csc(C(C)NC(F)F)n1)c1csc(C(=O)O[Na])n1</smiles><smiles>CC(NC(=O)C(NC(=O)C(Cc1ccccc1)NC(F)F)C(C)O)c1nc(C(=O)N[C@@H](C)c2nc(C(=O)O[O-])cs2)cs1</smiles>

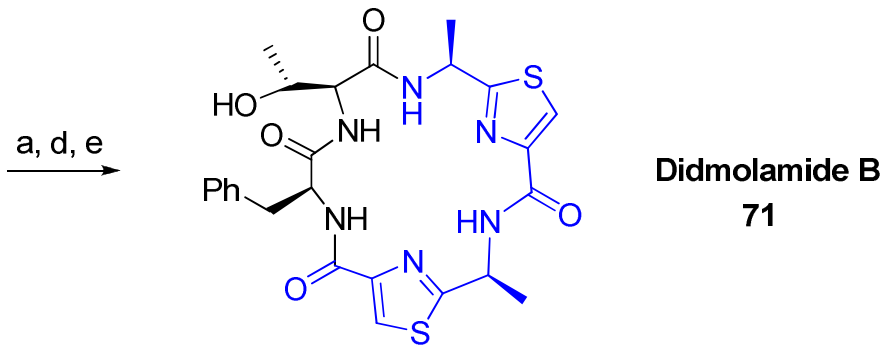

Scheme 15. Solid phase total synthesis of didmolamide A. Reagents and conditions: (a) $20 \%$ piperidine in DMF, $1 \mathrm{~h}$. (b) HBTU (2 equiv), HOBt (2 equiv), DIEA (3 equiv), N-FmocThr(Trt)-OH (2 equiv, $0.5 \mathrm{M}$ in DMF), 2 h. (c) HBTU (2 equiv), HOBt (2 equiv), DIEA (3 equiv), N-Fmoc-Phe-OH (2 equiv, $0.5 \mathrm{M}$ in DMF), $2 \mathrm{~h}$. (d) $\mathrm{PhSH}$ (1.1 equiv), 95\% TFA in $\mathrm{CH}_{2} \mathrm{Cl}_{2}, 3$ h. (e) PyBOP (2 equiv), DMAP (2 equiv), DIEA (2 equiv), $\mathrm{CH}_{2} \mathrm{Cl}_{2}, \mathrm{DMF}$.

2.4.4. Total synthesis of (+)-largazole. Largazole (72) is a 16-membered depsipeptide isolated from the marine cyanobacterium Symploca sp. collected in the Florida Keys (Scheme 16). ${ }^{64}$ The structure features an $\alpha$-methylcysteine-derived thiazoline connected to a thiazole and the presence of a caprylic acid-derived thioester. Largazole has shown potent antiproliferative activity against a number of cancer cell-lines including MDA-MB-231 mammary cells (GI 7.7 $\mathrm{nM})$, and IMR-32 neuroblastoma cells ( $\left.\mathrm{GI}_{50} 16 \mathrm{nM}\right)$. The molecular target of largazole has been determined as the histone deacetylase enzyme. ${ }^{65}$ Because of the potent biological activity of the 
cytotoxic natural product 72, Ghosh and Kulkarni described an enantioselective synthetic route ${ }^{66}$ whereby the key thiazoline-thiazole fragment $\mathbf{7 4}$ embedded in the macrocycle was prepared using the Hendrickson reagent 1 following the biomimetic procedure reported earlier by Kelly and coworkers (Scheme 16). ${ }^{7}$ Thus, reacting the advanced amide intermediate 73 with 1.5 equiv of 1 in $\mathrm{CH}_{2} \mathrm{Cl}_{2}$ at $0{ }^{\circ} \mathrm{C}$ for 10 minutes provided the thiazoline in $89 \%$ yield. Subsequent reduction of the azide group using $\mathrm{PPh}_{3}$ in refluxing methanol, and protection of the resulting amine using $\mathrm{Boc}_{2} \mathrm{O}$ furnished fragment $\mathbf{7 4}$ in $95 \%$ yield over two steps.

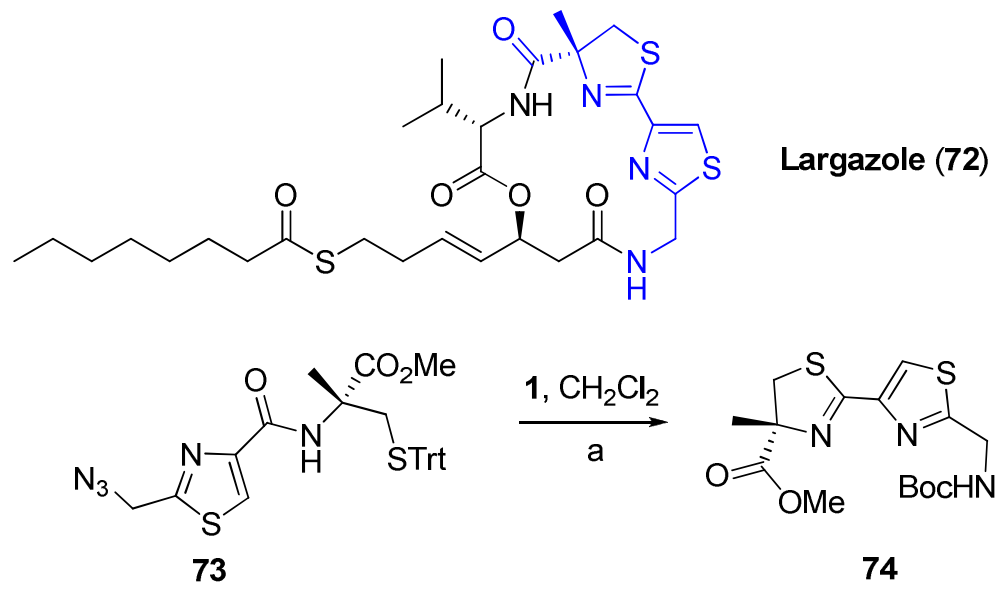

Scheme 16. Synthesis of a key fragment of (+)-largazole. Reagents and conditions: 1 (1.5 equiv.), $\mathrm{CH}_{2} \mathrm{Cl}_{2}, 0{ }^{\circ} \mathrm{C}, 10 \mathrm{~min}, 89 \%$. (a) $\mathrm{Ph}_{3} \mathrm{P}, \mathrm{MeOH}$, then $\mathrm{Boc}_{2} \mathrm{O}, \mathrm{CH}_{2} \mathrm{Cl}_{2}, 95 \%$.

2.4.5. Total synthesis of apratoxin A. Apratoxin A (78) is a potent cytotoxic marine natural product isolated from the cyanobacterium Lyngbya majuscule (Scheme 17). ${ }^{67}$ It is a 25 membered cyclic depsipeptide of mixed peptide-polyketide biogenesis and consists of a thiazoline, proline, three methylated amino acids ( $N$-methylisoleucine, $N$-methylalanine, $O$ methyltyrosine), and a dihydroxylated fatty acid moiety with an unusual methylation pattern. Thesecondary metabolite and derivative of the apratoxin family of cytotoxins is known for inducing G1-phase cell cycle arrest and apoptosis. ${ }^{68}$ The $\mathrm{IC}_{50}$ values for in vitro cytotoxicity against human tumor cell lines range from 0.36 to $0.52 \mathrm{nM}$. Such promising bioactivity has made it a popular synthetic target for developing anticancer derivatives. A very elegant and convergent total synthesis of apratoxin A was achieved by Doi et al. in which thiazoline formation was accomplished with $\mathrm{PPh}_{3} \mathrm{O} / \mathrm{Tf}_{2} \mathrm{O}(\mathbf{1})$ in $\mathrm{CH}_{2} \mathrm{Cl}_{2}$ at $0{ }^{\circ} \mathrm{C}$. ${ }^{69}$ All other attempted methods to effect this transformation proved problematic. In the former case, the annulation of $\mathbf{7 5}$ proceeded cleanly and the resulting product was immediately treated with $\mathrm{Zn}-\mathrm{NH}_{4} \mathrm{OAc}$ to cleave the Troc protecting group, producing thiazoline 76 in an overall yield of 90\% (Scheme 17). The acidsensitive thiazoline group which is prone to acid hydrolysis was not affected under these conditions and no epimerization at the chiral center attached to the 2-position was observed. Cleavage of the $O$-allyl ester of this fragment with $\mathrm{Pd}\left(\mathrm{PPh}_{3}\right)_{4} / N$-methylaniline provided the 
carboxylic acid 77 in $95 \%$ yield readied for amide coupling with the remaining tripeptide fragment (not shown). Hence, amide coupling, removal of the remaining protecting groups, and finally macrolactamization between the proline and $N$-methylisoleucine residues afforded apratoxin A (78).

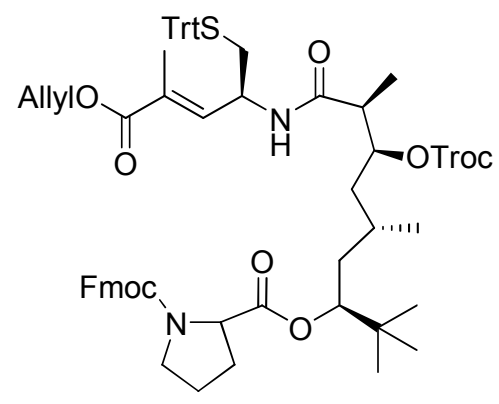

75 $\frac{(1) 1, \mathrm{CH}_{2} \mathrm{Cl}_{2}}{\text { (2) } \mathrm{Zn}, \mathrm{NH}_{4} \mathrm{OAc}}$

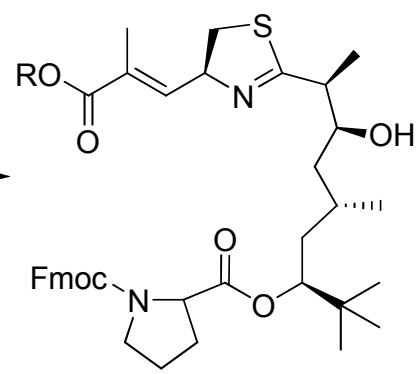

$\mathrm{Pd}\left(\mathrm{PPh}_{3}\right)_{4} /$ $N$-methylaniline

76: $R=$ Allyl

77: $\mathrm{R}=\mathrm{H}$

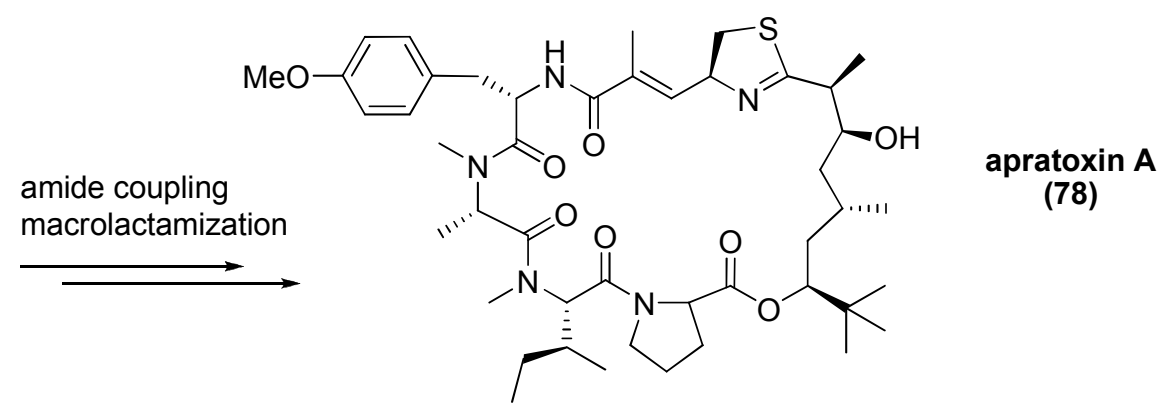

Scheme 17. Total synthesis of apratoxin A.

2.4.6. Total synthesis of camptothecin. Camptothecin (CPT, 84) is a cytotoxic pentacyclic quinoline alkaloid that was discovered in 1966 by Wani and Wall in systematic screening of natural products for anticancer activity. ${ }^{70}$ The natural product was isolated from the bark and stem of Camptotheca acuminata, a tree native to China. CPT showed remarkable anticancer activity in preliminary clinical trials and has been shown to target and stabilize the covalent binary complex formed between DNA and topoisomerase I (topo I) during DNA relaxation, leading to aptosis. ${ }^{33-71}$ Because of the promising bioactivity, synthetic and medicinal chemists have developed numerous syntheses of camptothecin and various derivatives. ${ }^{72}$ Although several impressive syntheses of CPT have been disclosed, involvement of difficult operations and long steps render most syntheses impractical for large scale preparation. The development and application of cascade reactions to generate multiple $\mathrm{C}-\mathrm{C}$ bonds in one operation is particularly attractive strategy in the synthesis of complex molecular architectures. Fortunately, the very short and efficient cascade route developed earlier by Yao et al. is generally applicable to this class of alkaloids and analogues thereof. In this regard, a mild Hendrickson-reagent-promoted cascade reaction consisting of an imidate formation, an intramolecular aza-Diels-Alder reaction, 
and an eliminative aromatization is anticipated to construct the common tetracyclic A/B/C/Dring core of CPT-family alkaloids in high yield. Thus, the total synthesis of CPT (84) started from the known chloropyridine 79 (Scheme 18) which was carbonylated under CO atmosphere, affording the methyl ester $\mathbf{8 0}$ in $97 \%$ yield. $^{73}$ Selective $O$-demethylation of $\mathbf{8 0}$ with iodotrimethylsilane, followed by $N$-propargylation of the resulting pyridone $\mathbf{8 1}$ with propargyl bromide, $\mathrm{K}_{2} \mathrm{CO}_{3}$, tetrabutylammonium bromide, and $\mathrm{LiBr}$ in toluene generated the $N$-propargyl pyridone in an overall yield of $67 \%$. Conversion of the methyl ester $\mathbf{8 2}$ into the corresponding acyl chloride, followed by coupling with aniline afforded the key amide precursor $\mathbf{8 3}$ readied for the cascade reaction ( $90 \%$ overall). With the newly developed cascade annulation methodology in hand, the advanced intermediate containing the A/B/C/D-ring core of CPT was obtained in $96 \%$ yield by simple treatment of amide $\mathbf{8 3}$ with reagent $\mathbf{1}$ at room temperature. To complete the synthesis, a highly enantioselective Sharpless asymmetric dihydroxylation and an $\mathrm{I}_{2} / \mathrm{CaCO}_{3}$ based hemiacetal oxidation afforded camptothecin (84) in $83 \%$ yield (2 steps) and $95 \%$ ee.

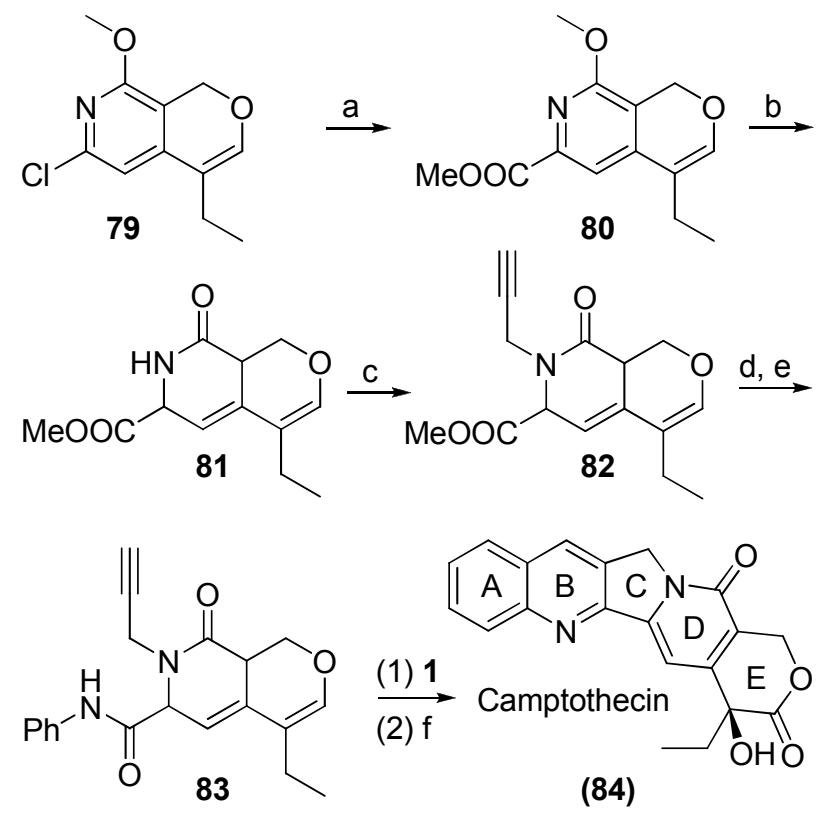

Scheme 18. Application of 1 in the total synthesis of camptothecin. Reagents and conditions: (a) $\mathrm{CO}$ (120 psig), $2 \mathrm{~mol} \% \mathrm{PdCl}_{2}\left(\mathrm{CH}_{2} \mathrm{Cl}_{2}\right)$ dppf, $\mathrm{Et}_{3} \mathrm{~N}, \mathrm{MeOH}, 97 \%$. (b) TMSCl, $\mathrm{NaI}, \mathrm{CH}_{3} \mathrm{CN}, \mathrm{H}_{2} \mathrm{O}$, 5h, 96\%. (c) propargyl bromide, $\mathrm{K}_{2} \mathrm{CO}_{3}, \mathrm{LiBr}, \mathrm{Bu}_{4} \mathrm{NBr}$, toluene, $\mathrm{H}_{2} \mathrm{O}, 70 \%$. (d) $\mathrm{LiOH}$, THF$\mathrm{H}_{2} \mathrm{O}$, 94\%. (e) $(\mathrm{COCl})_{2}, \mathrm{CH}_{2} \mathrm{Cl}_{2}$, then aniline, rt, 96\%. 1 (1.5 equiv.), $0{ }^{\circ} \mathrm{C}-\mathrm{rt}$, 96\%. (f) $\mathrm{K}_{2} \mathrm{OsO}_{2}(\mathrm{OH})_{4},(\mathrm{DHQD})_{2}-\mathrm{PYR}, \mathrm{K}_{3} \mathrm{Fe}(\mathrm{CN})_{6}, \mathrm{~K}_{2} \mathrm{CO}_{3}, \mathrm{MeSO}_{2} \mathrm{NH}_{2}, t \mathrm{BuOH}-\mathrm{H}_{2} \mathrm{O}, 0{ }^{\circ} \mathrm{C}$, then $\mathrm{I}_{2}$, $\mathrm{CaCO}_{3}, 40{ }^{\circ} \mathrm{C}, 83 \%$ for two steps, $95 \%$ ee.

2.4.7. Total synthesis of 22-hydroxyacuminatine and luotonin A. 22-Hydroxyacuminatine (85) and luotonin $\mathrm{A}(\mathbf{8 6})$ are quinoline alkaloids and are derivatives of camptothecin. 22Hydroxyacuminatine was isolated from a Chinese medicinal plant (Camptotheca acuminate) in 
1989 in a minute quantity and displayed cytotoxic activity against the murine leukemia P-388 cells $\left(\mathrm{ED}_{50} 1.32 \mu \mathrm{g} / \mathrm{mL}\right)$ and $\mathrm{KB}\left(\mathrm{ED}_{50} 0.61 \mu \mathrm{g} / \mathrm{mL}\right)$ in vitro. ${ }^{74}$ The benz[6,7]indolizino[1,2$b$ ]quinolin-11(13H)-one core is a notable structural feature unique to 22-hydroxyacuminatine and has drawn special attention. The related derivative luotonin A was also isolated from a Chinese medicinal plant (Peganum nigellastrum) in 1997 and demonstrated potent cytotoxicity against P388 cells $\left(\mathrm{IC}_{50} 1.8 \mu \mathrm{g} / \mathrm{mL}\right.$ ). ${ }^{75}$ In addition, luotonin A was recently shown to target and stabilize the binary complex formed between human DNA and topoisomerase I during DNA relaxation and to mediate topoisomerase I-dependent cytotoxicity in intact cells ( $\mathrm{IC}_{50}$ 5.7-12.6 $\mu \mathrm{M}$ ).

Building on the highly efficient cascade methodology to construct variously substituted indolizino[1,2-b]quinolin-9(11H)-ones, which represent the tetracyclic A/B/C/D-ring core of camptothecin-family alkaloids, Yao et al. applied the same common cascade strategy that gained success earlier in total synthesis of camptothecin to prepare luotonin A and 22hydroxyacuminatine. ${ }^{76}$ Both targets, which share identical A-C rings with camptothecin, were successfully synthesized in a few steps and high overall yields. Thus, as shown in Scheme 19, retrosynthetic analysis called for the preparation of two aniline amide precursors (87 and 88) which are expected to undergo a cascade reaction triggered by reagent $\mathbf{1}$ under mild conditions. Thus, starting from 2,6-dicyanotoluene, the aniline amide precursor 87 to 22hydroxyacuminatine was prepared in five short steps in an overall yield of $35 \%$. The amide was subsequently treated with 1 (1.5 equiv.) at room temperature for $30 \mathrm{~min}$. The expected intramolecular aza Diels-Alder reaction was efficiently triggered ensuing the formation of the imidate, giving a known advanced tetracyclic intermediate with the entire skeleton of 22hydroxyacuminatine in $91 \%$ yield. Finally, reduction of the nitrile to the corresponding alcohol to generate 22-hydroxyacuminatine (85) has been previously reported by Cushman $(51 \%$ yield). ${ }^{77}$ Thus, this represents a formal synthesis of 22-hydroxyacuminatine (85) in eight steps and $16 \%$ overall yield. Using the same strategy, total synthesis of luotonin A was achieved in five steps and $47 \%$ overall yield starting from commercial materials. Hence, starting from commercial anthranilamide, the structural skeleton was elaborated to the aniline amide precursor $\mathbf{8 8}$ in four simple steps in an overall yield of $48 \%$. Finally, the cascade annulation was carried out by simple treatment of $\mathbf{8 8}$ with $\mathbf{1}$ (1.5 equiv.) at room temperature for $1 \mathrm{~h}$, affording luotonin A (86) in an impressive yield of $99 \%$. 

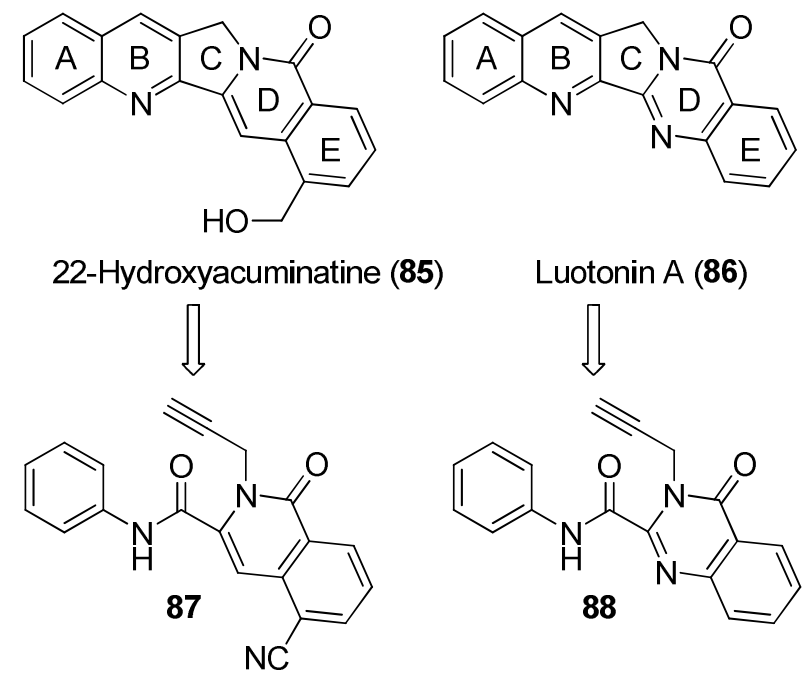

Scheme 19. Application of $\mathbf{1}$ in the total synthesis of luotonin A and 22-hydroxyacuminatine

2.4.8. Total synthesis of 14 -azacamptothecin. The anticancer activity of camptothecin and unique mechanism of action by which it reversibly binds to DNA topoisomerase have made it a target lead for drug discovery and development. As shown earlier, other natural alkaloids in this family, including 22- hydroxyacuminatine and luotonin A, have also been found to inhibit the same enzyme. Unfortunately, camptothecin itself suffers from several drawbacks including poor water solubility and high toxicity, rendering its application unsuitable in clinical treatments. Preliminary clinical trials of CPT were carried out with its more toxic and less potent sodium salt. 14-Azacamptothecin (89) is a water-soluble CPT analogue in which the C-14 carbon atom of camptothecin has been replaced with a nitrogen atom, enhancing water solubility. ${ }^{7}$ Further, the aza analogue has been shown to stabilize the topoisomerase I-DNA complex in much the same way as natural CPT, with the added advantage of achieving a higher level of potency as demonstrated by its superior $\mathrm{IC}_{50}$ value. Although the synthesis of 14-azacamptothecin has been previously reported, the relatively low overall yield $(0.6 \%$ yield in 10 total steps) called for the development of a more efficient total synthesis. ${ }^{79}$ Hence, encouraged by their previous successful application of Hendrickson reagent-triggered mild cascade reaction in the total syntheses of camptothecin (84), 22- hydroxyacuminatine (85), and luotonin A (86), Yao extended this route to the synthesis of 14-azacamptothecin. ${ }^{80}$ In their retrosynthetic analysis (Scheme 20), formation of the lactone moiety and C-20 stereogenic center was envisaged to occur via a Sharpless asymmetric dihydroxylation (Sharpless AD) of the cyclic enol ether $\mathbf{9 0}$, followed by oxidation of the resulting hemiacetal to the lactone using $\mathrm{I}_{2}-\mathrm{CaCO}_{3}$. The $\mathrm{B}$ and $\mathrm{C}$ rings of the cyclic enol ether 90 may be constructed via an intramolecular aza-Diels-Alder reaction of imidate 91 formed by the reaction of 1 with the key $N$-propargyl aryl amide 92. Thus, starting from 2-chloro-8-ethyl-4methoxy-5H-pyrano[4,3- $d$ ]pyrimidine, the desired amide 92 was prepared in just a few short steps, albeit as a 1.9:1 inseparable mixture of $N$ - and $O$-propargylated products. The mixture was directly used and treated with 1 (1.5 equiv.) for 30 minutes at room temperature, affording the 
pentacyclic enol ether in $56 \%$ overall yield for the last two steps. Finally, Sharpless asymmetric dihydroxylation, followed by oxidation with iodine gave rac-14-azacamptothecin in $85 \%$ overall yield from the enol ether.

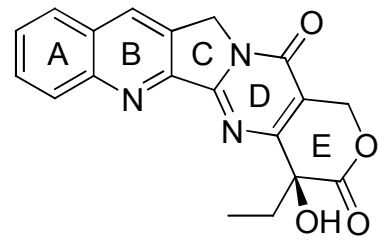

14-azacamptothecin (89)

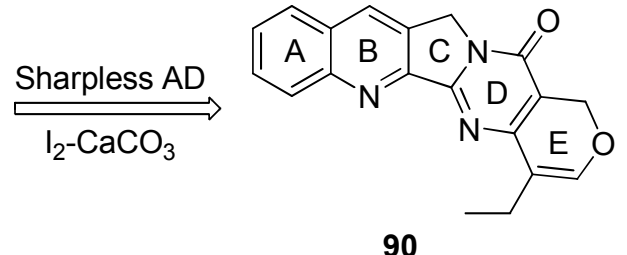

90

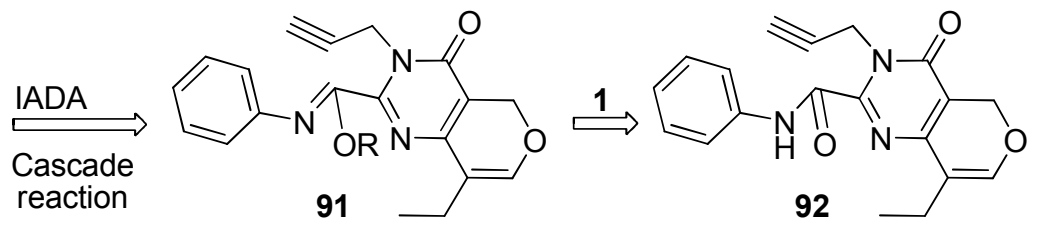

Scheme 20. Application of 1 in the total synthesis of 14-azacamptothecin.

2.4.9. Enantioselective total synthesis of 14-azacamptothecin. Although 14-azacamptothecin (89) was successfully synthesized, unfortunately no asymmetric induction was achieved under the Sharpless asymmetric dihydroxylation conditions, affording only the racemic product. Employing other commonly used chiral ligands like (DHQD) $)_{2}$-PHAL also provided the same result. It has been suggested that the two proximal nitrogen atoms $(\mathrm{N}-14$ and $\mathrm{N}-1)$ in the rigid cyclic enol ether might disrupt coordination of osmium with the chiral ligand during the AD reaction. As an alternative, the enantioselective dihydroxylation was carried out early in the synthesis (Scheme 21) to provide the oxygenated stereogenic center in $94 \%$ ee $(\mathbf{9 3} \rightarrow \mathbf{9 4})$.

Because of the poor regioselectivity obtained in the $N$ - and $O$-propargylation step, it was decided to prepare the $N$ - and $O$-allyl mixture (95 and 96) and perform a $\mathrm{Pd}$-catalyzed rearrangement of $O$-allyl to $N$-allyl derivative. Indeed, the rearrangement was successful, producing the key $\mathrm{N}$-allyl amide 96 in a remarkable yield of 100\%. It is noted that such allyl amides have not been previously used in the aza-Diels-Alder cascade reaction designed earlier with alkyne tethers. Pleasingly, treating the allyl amide 96 with 1 (1.5 equiv.) at $0{ }^{\circ} \mathrm{C}$, followed by oxidation with freshly prepared $\mathrm{MnO}_{2}$ provided the pentacyclic intermediate 97 in $89 \%$ yield. This transformation represents a novel application of the Hendrickson reagent in which an allyl group successfully underwent a highly efficient aza-Diels-Alder cascade reaction. To complete the enantioselective synthesis, deacetylation of 97 with concentrated $\mathrm{HCl}$ in ethanol gave $(S)-14-$ azacamptothecin (89) in $95 \%$ yield and $>99 \%$ ee. 
<smiles>CCC1=COCc2c1cc(C(=O)Nc1ccccc1)nc2OC</smiles>

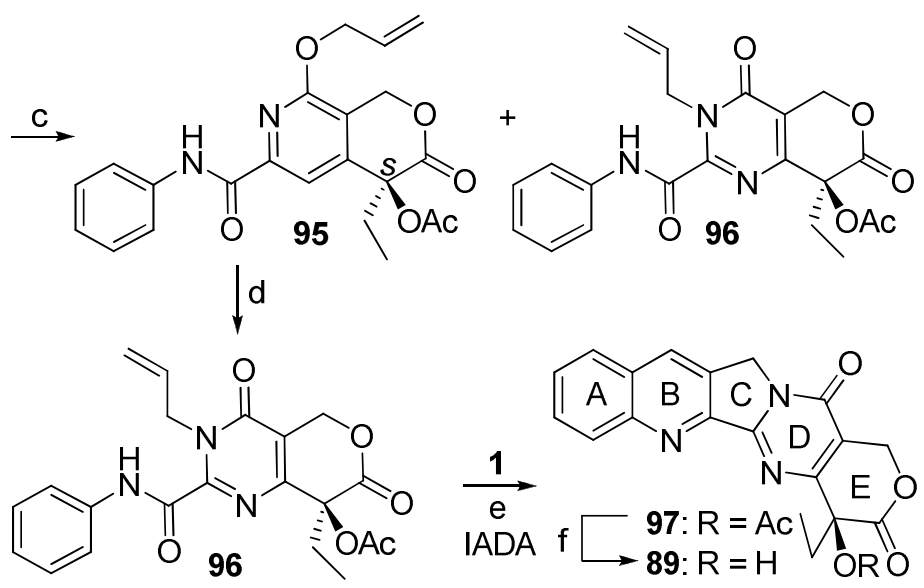

Scheme 21. Application of $\mathbf{1}$ in the enantioselective total synthesis of 14-azacamptothecin. Reagents and conditions: (a) $\mathrm{K}_{2} \mathrm{OsO}_{4}$, (DHQD) 2 -PYR, $\mathrm{K}_{3} \mathrm{Fe}(\mathrm{CN})_{6}, \mathrm{~K}_{2} \mathrm{CO}_{3}, \mathrm{MeSO}_{2} \mathrm{NH}_{2}, t \mathrm{BuOH}-$ $\mathrm{H}_{2} \mathrm{O}$, rt, $20 \mathrm{~h}$, then $\mathrm{I}_{2}, \mathrm{CaCO}_{3}, 91 \%$, 94\% ee. (b) TMSCl, $\mathrm{NaI}, \mathrm{CH}_{3} \mathrm{CN}, \mathrm{H}_{2} \mathrm{O}, 98 \%$. (c) allyl methanesulfonate, $\mathrm{K}_{2} \mathrm{CO}_{3}, \mathrm{LiBr}, \mathrm{Bu}_{4} \mathrm{NBr}$, toluene, $\mathrm{H}_{2} \mathrm{O}, 70 \%$, (d) $\mathrm{PdCl}_{2}\left(\mathrm{PhCN}_{2}, \mathrm{CH}_{2} \mathrm{Cl}_{2}, \mathrm{rt}\right.$, $100 \%, 1$ (1.5 equiv.), $\mathrm{CH}_{2} \mathrm{Cl}_{2}$, rt. (e) $\mathrm{MnO}_{2}, \mathrm{CH}_{2} \mathrm{Cl}_{2}, 89 \%$ for 2 steps. (f) con. $\mathrm{HCl}, \mathrm{EtOH}, 95 \%$, $99 \%$ ee.

\section{Analogues of the Hendrickson reagent}

\subsection{Jenkins' cyclic analogues of the Hendrickson reagent}

The aforementioned synthetic applications associated with the Hendrickson's reagent provided the impetus for the Jenkins' group to develop five-, six-, and seven-membered cyclic bisphosphine analogs 98-100 of the "POP" reagent which had the advantage of liberating one mole of the phosphine oxide byproduct per dehydration reaction. ${ }^{81}$ With the latter reagent, the release of two moles of triphenylphosphine oxide exacerbates the problem of separation of the product by chromatography. On the other hand, the bisphosphine oxide byproducts produced from the cyclic analogues are considerably more polar than triphenylphosphine oxide because of the two phosphine oxide moieties, thus rendering purification much more facile. The three cyclic phosphonium anhydrides 98-100 were synthesized from the corresponding bis-phosphine precursors by oxidation with excess $\mathrm{H}_{2} \mathrm{O}_{2}$ (Scheme 22), followed by triflation of the resulting phosphine oxides with triflic anhydride. The analogues precipitated immediately as white solids following mixing of reagents. 

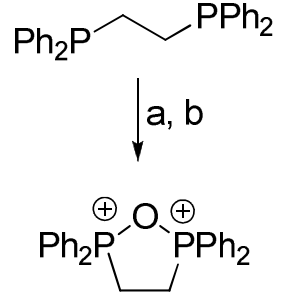

$2 \mathrm{CF}_{3} \mathrm{SO}_{2} \mathrm{O}^{\ominus}$

98
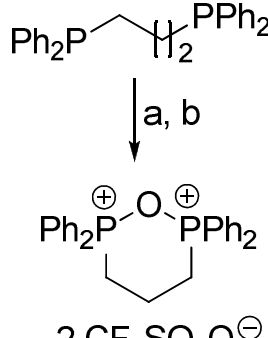

99
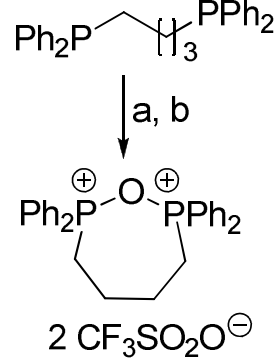

100

Scheme 22. Cyclic analogues of the Hendrickson reagent. Reagents and conditions: (a) excess $\mathrm{H}_{2} \mathrm{O}_{2}$ (30\%), 5 min, rt, $\mathrm{CH}_{2} \mathrm{Cl}_{2}, 98 \%$. (b) $\mathrm{Tf}_{2} \mathrm{O}$ (1 equiv.), $-20{ }^{\circ} \mathrm{C}, 24 \mathrm{~h}, \mathrm{CD}_{2} \mathrm{Cl}_{2}$.

3.1.1. Application of Jenkins' cyclic reagents in the synthesis of esters and amides. The three cyclic analogues 98-100 proved very effective in the esterifications of primary alcohols and the synthesis of amides from primary amines (Table 21). For ester (Entries 1-3) and amide (Entries 4-6) synthesis, addition of the substrates and diisopropylethylamine to a prepared solution of reagent 1 produced 4-nitrobenzyl 4-nitrobenzoate and $\mathrm{N}$-phenyl-4-toluamide in high yields.

Table 21. Ester and amide synthesis with cyclic analogues 98-100

\begin{tabular}{|c|c|c|c|c|c|}
\hline Entry & Reagent & Acid & Alcohol/amine & Product & $\begin{array}{c}\text { Yield } \\
(\%)\end{array}$ \\
\hline 1 & 98 & $4-\mathrm{NO}_{2}-\mathrm{C}_{6} \mathrm{H}_{4} \mathrm{CO}_{2} \mathrm{H}$ & $\begin{array}{c}4-\mathrm{NO}_{2-} \\
\mathrm{C}_{6} \mathrm{H}_{4} \mathrm{CH}_{2} \mathrm{OH}\end{array}$ & $\begin{array}{l}\text { 4-Nitrobenzyl 4- } \\
\text { nitrobenzoate }\end{array}$ & 93 \\
\hline 2 & 99 & $4-\mathrm{NO}_{2}-\mathrm{C}_{6} \mathrm{H}_{4} \mathrm{CO}_{2} \mathrm{H}$ & $\begin{array}{c}4-\mathrm{NO}_{2-}^{-} \\
\mathrm{C}_{6} \mathrm{H}_{4} \mathrm{CH}_{2} \mathrm{OH}\end{array}$ & $\begin{array}{l}\text { 4-Nitrobenzyl 4- } \\
\text { nitrobenzoate }\end{array}$ & 94 \\
\hline 3 & 100 & $4-\mathrm{NO}_{2}-\mathrm{C}_{6} \mathrm{H}_{4} \mathrm{CO}_{2} \mathrm{H}$ & $\begin{array}{c}4-\mathrm{NO}_{2-}^{-} \\
\mathrm{C}_{6} \mathrm{H}_{4} \mathrm{CH}_{2} \mathrm{OH}\end{array}$ & $\begin{array}{l}\text { 4-Nitrobenzyl 4- } \\
\text { nitrobenzoate }\end{array}$ & 83 \\
\hline 4 & 98 & $4-\mathrm{Me}-\mathrm{C}_{6} \mathrm{H}_{4} \mathrm{CO}_{2} \mathrm{H}$ & $\mathrm{C}_{6} \mathrm{H}_{5} \mathrm{NH}_{2}$ & N-phenyl-4-toluamide & 81 \\
\hline 5 & 99 & $4-\mathrm{Me}-\mathrm{C}_{6} \mathrm{H}_{4} \mathrm{CO}_{2} \mathrm{H}$ & $\mathrm{C}_{6} \mathrm{H}_{5} \mathrm{NH}_{2}$ & N-phenyl-4-toluamide & 90 \\
\hline 6 & 100 & 4- $\mathrm{Me}-\mathrm{C}_{6} \mathrm{H}_{4} \mathrm{CO}_{2} \mathrm{H}$ & $\mathrm{C}_{6} \mathrm{H}_{5} \mathrm{NH}_{2}$ & N-phenyl-4-toluamide & 85 \\
\hline
\end{tabular}

3.1.2. Application of Jenkins' cyclic reagents in the synthesis of 2-oxazolines, 2-thiazolines, and related derivatives. Jenkins demonstrated that the "POP" cyclic analogue 98 reacts with $\beta$ hydroxy amides to generate 2-oxazolines under mild conditions in 50-52\% yield. ${ }^{82}$ 
Table 22. The synthesis of 2-oxazolines, 2-thiazolines, and related derivatives using cyclic analogue 98

Entry

The reaction was optimized by utilizing $O$ - and $S$-trityl protected amides in order to circumvent reaction at the hydroxyl or thiol group of the starting material. Further, a detailed investigation on the number of equivalents of reagent $\mathbf{1}$ and base required, as well as the effects of manipulating reaction time, temperature, concentration, solvent, and addition rate was performed. As shown in Table 22, reagent 1 proved highly efficient in the cyclodehydration of a range of trityl derivatives to afford oxazolines (85-94\%), thiazolines (88-95\%), dihydro-1,3oxazine (99\%), and tetrahydro-1,3-oxazepine (31\%). A possible mechanism for these cyclodehydrations would involve the formation of an oxophosphonium complex, elimination of $\mathrm{Ph}_{3} \mathrm{PO}$ to generate a nitrilium intermediate, in situ detritylation, and lastly a 5-endo-dig cyclization.

\subsection{Jenkins' polymer-supported analogues of the Hendrickson reagent}

There has been a recent surge in the development of polymer-supported reagents, which has been driven by the special requirements of both combinatorial and green chemistry to obtain clean 
products without time consuming work-up and purification protocols. ${ }^{83}$ Desirable features of such systems include short and high-yielding preparation sequences from simple commercial materials, recyclability where applicable, and versatility. In addition, they must tolerate a wide range of functionalities and offer generally good and consistent yields. In continuation of his work on analogues of the Hendrickson reagent, Jenkins further modified the 5-membered ring cyclic analogue 98 by attachment on polymer (101) to avoid tedious chromatography in removing the phosphine oxide byproduct (Scheme 23). ${ }^{84}$ In this case, the phosphine oxide moieties are tethered to the polymer support and remain attached after the reaction, whereas with Hendrickson's reagent the release of two moles of triphenylphosphine oxide exacerbates the problem of separation of the product by chromatography. In the former case, removal of the phosphine oxide is performed simply by filtration of the polymer beads which may be recycled back into the phosphonium anhydride by treatment with triflic anhydride. The synthesis of 101 started from brominated poly(styrene-co-divinylbenzene) which was used to prepare polymersupported 1,2-bis(diphenylphosphinyl)ethane. The reaction of the latter with triflic anhydride yielded the polymer-supported cyclic 'POP' species 101. The reagent was only explored in the esterification of a primary alcohol and the formation of an amide from a primary amine. Jenkins also reported the preparation, dehydration properties, ${ }^{85}$ and structure of polymer-supported triphenylphosphine ditriflate version $\mathbf{1 0 2}$ of the Hendrickson reagent. ${ }^{86}$ The polymer-supported triphenylphosphine ditriflate reagent $\mathbf{1 0 2}$ was synthesized from the oxidized form of commercial polymer-supported triphenylphosphine with triflic anhydride. The leap into the realm of polymer support has truly revolutionized Hendrickson's reagent, bestowing several advantages on the polymer-bound analogues, which demonstrated high success in a wide range of coupling/dehydration-type reactions, such as ester, amide, anhydride, peptide, ether, and nitrile formation.

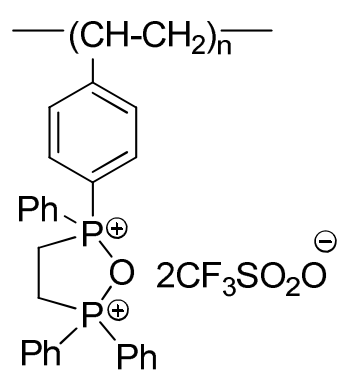

101

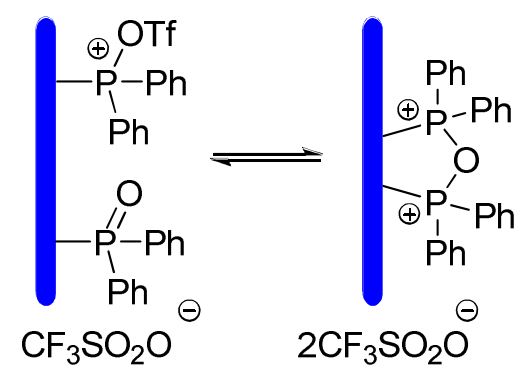

102

Scheme 23. Jenkins' polymer-supported analogues of the Hendrickson reagent.

3.2.1. Synthetic transformations using Jenkins' polymer-supported triphenylphosphine ditriflate 102. The efficiency of the polymer-supported triphenylphosphine ditriflate $\mathbf{1 0 2}$ as a general dehydrating reagent/activating agent was shown by the synthesis of esters from primary and secondary alcohols, an anhydride, thioacetate, amide, ether, azide, and a nitrile. A selection 
of these transformations is shown in Table 23. The advantage of the polymer-supported triphenylphosphine ditriflate $\mathbf{1 0 2}$ lies in the fact that the phosphine oxide by-product remains attached to the polymer-support. All products were obtained cleanly following filtration of the polymer beads and a sodium hydrogen carbonate wash of the filtrate to remove the diisopropylethylammonium triflate. An additional advantage of reagent $\mathbf{1 0 2}$ is that at the end of the reaction, the polymer is recycled as its oxide, ready for reconversion to $\mathbf{1 0 2}$. The recovered polymer could be recycled at least three times without loss of efficiency.

Table 23. A selection of synthetic transformations with Jenkins' polymer-supported triphenylphosphine ditriflate $\mathbf{1 0 2}$

\begin{tabular}{|c|c|c|c|c|}
\hline Entry & Substrate & Nucleophile & Product & Yield (\%) \\
\hline 1 & $4-\mathrm{NO}_{2}-\mathrm{C}_{6} \mathrm{H}_{4} \mathrm{CH}_{2} \mathrm{OH}$ & $\begin{array}{c}4-\mathrm{NO}_{2-} \\
\mathrm{C}_{6} \mathrm{H}_{4} \mathrm{CO}_{2} \mathrm{H}\end{array}$ & $\begin{array}{l}\text { 4-Nitrobenzyl 4- } \\
\text { nitrobenzoate }\end{array}$ & 95 \\
\hline 2 & 4-Me- $\mathrm{C}_{6} \mathrm{H}_{4} \mathrm{CO}_{2} \mathrm{H}$ & $\begin{array}{c}\text { 4-Me- } \\
\mathrm{C}_{6} \mathrm{H}_{4} \mathrm{CO}_{2} \mathrm{H}\end{array}$ & 4-Toluic anhydride & 95 \\
\hline 3 & 4- $\mathrm{Cl}-\mathrm{C}_{6} \mathrm{H}_{4} \mathrm{CH}_{2} \mathrm{OH}$ & $\mathrm{CH}_{3}-\mathrm{C}(\mathrm{O})-\mathrm{SH}$ & $\begin{array}{l}\text { 4-Chlorobenzyl } \\
\text { thioacetate }\end{array}$ & 91 \\
\hline 4 & $4-\mathrm{NO}_{2}-\mathrm{C}_{6} \mathrm{H}_{4} \mathrm{CO}_{2} \mathrm{H}$ & $\mathrm{C}_{6} \mathrm{H}_{5} \mathrm{CH}_{2} \mathrm{NH}_{2}$ & $\begin{array}{c}N \text {-Benzyl 4- } \\
\text { nitrobenzamide }\end{array}$ & 96 \\
\hline 5 & 4-NO2-C6H4CH2OH & $\begin{array}{l}\text { 4-MeO- } \\
\mathrm{C} 6 \mathrm{H} 4 \mathrm{OH}\end{array}$ & $\begin{array}{l}\text { o-(4-Nitrobenzyl)- } \\
\text { 4-methoxyphenol }\end{array}$ & 88 \\
\hline 6 & $4-\mathrm{Cl}-\mathrm{C}_{6} \mathrm{H}_{4} \mathrm{CH}_{2} \mathrm{OH}$ & $\mathrm{NaN}_{3}$ & $\begin{array}{l}\text { 4-Chlorobenzyl } \\
\text { azide }\end{array}$ & 89 \\
\hline 7 & $\mathrm{C}_{6} \mathrm{H}_{4}-\mathrm{C}(\mathrm{O})-\mathrm{NH}_{2}$ & - & Benzonitrile & 88 \\
\hline
\end{tabular}

Reagents and conditions: polymer-supported triphenylphosphine oxide 102 (1.35 equiv), triflic anhydride (1.0 equiv), substrate (1.0 equiv), nucleophile (1.0 equiv), diisopropylethylamine (3.5 equiv), $\mathrm{CH}_{2} \mathrm{Cl}_{2}(10 \mathrm{~mL})$.

\subsection{Mahdavi's polymer-supported analogue of the Hendrickson reagent}

Mahdavi and Amani reported the synthesis of triphenylphosphine oxide supported on non-crosslinked maleimide-styrene and the application of the corresponding triphenylphosphine ditriflate in several types of dehydration reactions. ${ }^{87}$

3.3.1. Synthesis. The synthesis of the non-cross-linked maleimide-styrene copolymer 107 was achieved in four steps from triphenylphosphine oxide (103) (Scheme 24). Hence, nitration of the latter using sulfuric acid and fuming nitric acid gave 3-nitrophenyldiphenylphosphine oxide (NPDPPO) (104) as white crystals in $75 \%$ yield. A subsequent reduction of NPDPPO with hydrazine hydrate and palladium over activated carbon afforded 3aminophenyldiphenylphosphine oxide (APDPPO) (105) in $87 \%$ yield. Reaction of the amine (APDPPO) with maleic anhydride produced 3-maleimidophenyldiphenylphosphine oxide (MPDPPO) (106) as a yellowish solid in 79\% yield. Next, copolymer 107 was prepared by the radical copolymerization of the maleimide (MPDPPO) (106) with styrene in the presence of 2,2'- 
azobisisobutyronitrile (AIBN) as a radical initiator.The copolymer $\mathbf{1 0 7}$ was obtained by precipitation from $n$-hexane and was purified by re-precipitation from dichloromethane into $n$ hexane and dried in vacuo. The composition of the copolymer was calculated from elemental analysis of phosphorus. The percentage of phosphorus content in the copolymer was approximately 5.6\%. Finally, the polymer-supported phosphine oxide reagent $\mathbf{1 0 7}$ was treated with triflic anhydride in dry dichloromethane to produce a non-cross-linked polymer-supported triphenylphosphine ditriflate $\mathbf{1 0 8}$.

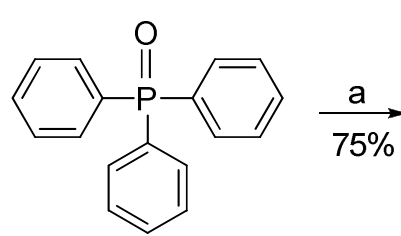

103

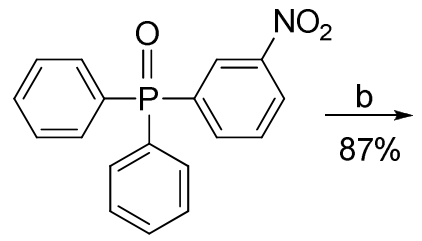

104

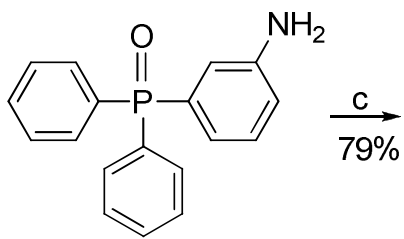

105

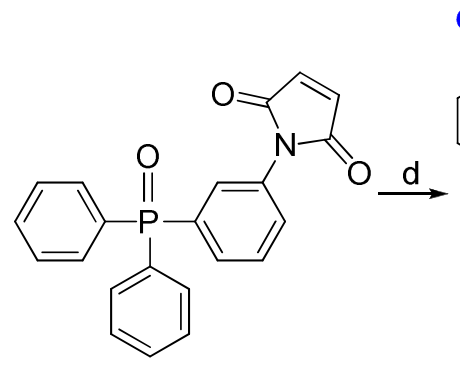

106

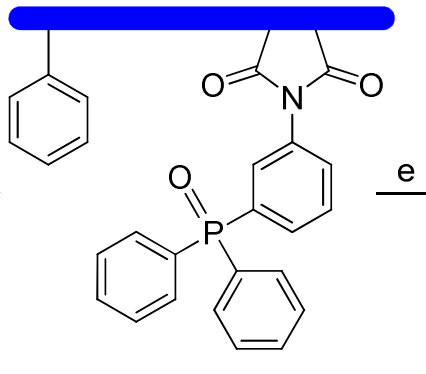

107

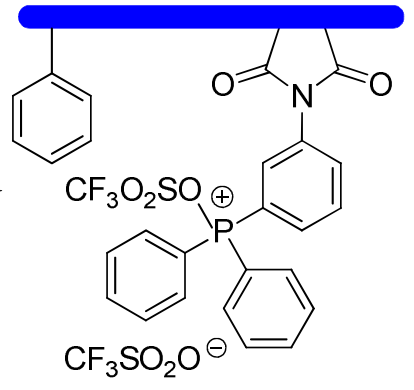

108

Scheme 24. Reagents and conditions: (a) $\mathrm{H}_{2} \mathrm{SO}_{4}$, fuming $\mathrm{HNO}_{3},-25{ }^{\circ} \mathrm{C}$. (b) hydrazine hydrate, $\mathrm{Pd} / \mathrm{C}$. (c) (i) maleic anhydride, acetone, $0{ }^{\circ} \mathrm{C}, 4$ h. (ii) $\mathrm{CH}_{3} \mathrm{COONa}, \mathrm{Ac}_{2} \mathrm{O}, 60{ }^{\circ} \mathrm{C}, 6 \mathrm{~h}$. (d) styrene, AIBN, $60{ }^{\circ} \mathrm{C}$. (e) $\mathrm{Tf}_{2} \mathrm{O}, \mathrm{CH}_{2} \mathrm{Cl}_{2}, 0.5$ h.

\subsubsection{Dehydration reactions with Mahdavi's polymer-supported analogue of the} Hendrickson reagent. Polymer-supported triphenylphosphine ditriflate 108 was employed in a series of dehydration reactions as shown in Table 24 . Thus, a variety of substituted aromatic carboxylic acids and other nucleophiles (benzylamine, ethanethioic $S$-acid, and sodium azide) were successfully coupled to alcohols and acids to afford ester, amide, anhydride, thioacetate, and azide products in yields ranging from 83-97\%. Complete removal of the triphenylphosphine oxide byproduct was accomplished by precipitation from THF and subsequent removal of the polymer suspension by filtration. The filtered polymeric catalyst could be recovered several times and used without any loss in reactivity. Concentration of the remaining phosphine-oxidefree filtrate (as indicated by the absence of a signal in the ${ }^{31} \mathrm{P}$ NMR spectrum of the crude products) and purification of the residue by flash chromatography afforded the coupled products in the yields indicated in the Table. 
Table 24. Dehydration reactions with Mahdavi's polymer-supported triphenylphosphine ditriflate $^{\mathrm{a}}$

\begin{tabular}{|c|c|c|c|c|}
\hline Entry & Substrate & Nucleophile & Product & $\begin{array}{l}\text { Yield } \\
(\%)\end{array}$ \\
\hline 1 & $4-\mathrm{NO}_{2}-\mathrm{C}_{6} \mathrm{H}_{4} \mathrm{CH}_{2} \mathrm{OH}$ & $\begin{array}{c}4-\mathrm{NO}_{2-}^{-} \\
\mathrm{C}_{6} \mathrm{H}_{4} \mathrm{CO}_{2} \mathrm{H}\end{array}$ & $\begin{array}{l}\text { 4-Nitrobenzyl 4- } \\
\text { nitrobenzoate }\end{array}$ & 96 \\
\hline 2 & 4- $\mathrm{NO}_{2}-\mathrm{C}_{6} \mathrm{H}_{4} \mathrm{CO}_{2} \mathrm{H}$ & $\mathrm{C}_{6} \mathrm{H}_{5} \mathrm{CH}_{2} \mathrm{NH}_{2}$ & N-Benzyl-4-nitrobenzamide & 97 \\
\hline 3 & $4-\mathrm{Me}-\mathrm{C}_{6} \mathrm{H}_{4} \mathrm{CO}_{2} \mathrm{H}$ & $\begin{array}{c}4-\mathrm{Me}- \\
\mathrm{C}_{6} \mathrm{H}_{4} \mathrm{CO}_{2} \mathrm{H}\end{array}$ & 4-Toluic anhydride & 94 \\
\hline 4 & $4-\mathrm{Cl}-\mathrm{C}_{6} \mathrm{H}_{4} \mathrm{CH}_{2} \mathrm{OH}$ & $\mathrm{CH}_{3}-\mathrm{C}(\mathrm{O})-\mathrm{SH}$ & 4-Chlorobenzyl thioacetate & 92 \\
\hline 5 & $4-\mathrm{NO}_{2}-\mathrm{C}_{6} \mathrm{H}_{4} \mathrm{CH}_{2} \mathrm{OH}$ & $\begin{array}{l}4-\mathrm{MeO}- \\
\mathrm{C}_{6} \mathrm{H}_{4} \mathrm{OH}\end{array}$ & $\begin{array}{l}o \text {-(4-Nitrobenzyl)-4- } \\
\text { methoxyphenol }\end{array}$ & 90 \\
\hline 6 & $4-\mathrm{Cl}-\mathrm{C}_{6} \mathrm{H}_{4} \mathrm{CH}_{2} \mathrm{OH}$ & $\mathrm{NaN}_{3}$ & 4-Chlorobenzyl azide & 90 \\
\hline 7 & Cyclohexanol & $\begin{array}{c}4-\mathrm{NO}_{2-}^{-} \\
\mathrm{C}_{6} \mathrm{H}_{4} \mathrm{CO}_{2} \mathrm{H}\end{array}$ & Cyclohexyl 4-nitrobenzoate & 83 \\
\hline
\end{tabular}

${ }^{\mathrm{a}}$ Reagents and conditions: 108 (1.35 equiv), nucleophile (1.0 equiv), diisopropylethylamine (3.5 equiv), $\mathrm{CH}_{2} \mathrm{Cl}_{2}(10 \mathrm{~mL})$.

\subsection{Moussa's analogues of the Hendrickson reagent}

3.4.1. Moussa's triphenylphosphine /triflic anhydride dehydrating system. In an attempt to modify the preparation of the Hendrickson reagent and eliminate the use of 2 equivalents of $\mathrm{Ph}_{3} \mathrm{PO}$, Moussa et al. became interested in using triphenyl(trifluoromethylsulfonyloxy) phosphonium trifluoromethanesulfinate (109) (Scheme 25) as an alternative oxygen activator and dehydrating reagent. ${ }^{88}$ They envisaged that 109 could be directly prepared from $\mathrm{Ph}_{3} \mathrm{P}$ and $\mathrm{Tf}_{2} \mathrm{O}$ by mixing them in a $1: 1$ stoichiometric ratio. In principle, 109 may be formed by attack of the phosphorus atom of triphenylphosphine on the anhydride oxygen of triflic anhydride via path a of Scheme 25, releasing a trifluoromethanesulfinate ion as the leaving group. Interestingly, the trifluoromethanesulfonate analogue of $\mathbf{1 0 9}$ is the first intermediate produced during the formation of $\mathbf{1}$, where ensuing attack by a second molecule of $\mathrm{Ph}_{3} \mathrm{PO}$ forms the latter oxodiphosphonium dimer. However, dimerization of $\mathbf{1 0 9}$ by reacting with a second molecule of $\mathrm{Ph}_{3} \mathrm{P}$ appeared unlikely. Alternatively $\mathrm{Ph}_{3} \mathrm{P}$ may react via path $\mathrm{b}$ of Scheme 25 with the triflyl group to give an electrophilic triphenyl( trifluoromethylsulfonyl)phosphonium complex (110) and a negative triflate ion (Scheme 25). Complex 110 may then act as a triflyl source, extinguishing the role of triphenylphosphine. Fortunately, this was not the case as was demonstrated by the reaction of $\mathrm{Ph}_{3} \mathrm{P}$ with $\mathrm{PhNTf}_{2}$. The latter reagent is a source of a triflyl group and a very strong triflating agent. Thus, when an equimolar amount of $\mathrm{Ph}_{3} \mathrm{P}$ and $\mathrm{PhNTf}_{2}$ was reacted in $\mathrm{CH}_{2} \mathrm{Cl}_{2}$ at $0{ }^{\circ} \mathrm{C}$, the former failed to react as was demonstrated by ${ }^{1} \mathrm{H},{ }^{13} \mathrm{C},{ }^{19} \mathrm{~F}$ and ${ }^{31} \mathrm{P}$ NMR spectroscopy. 


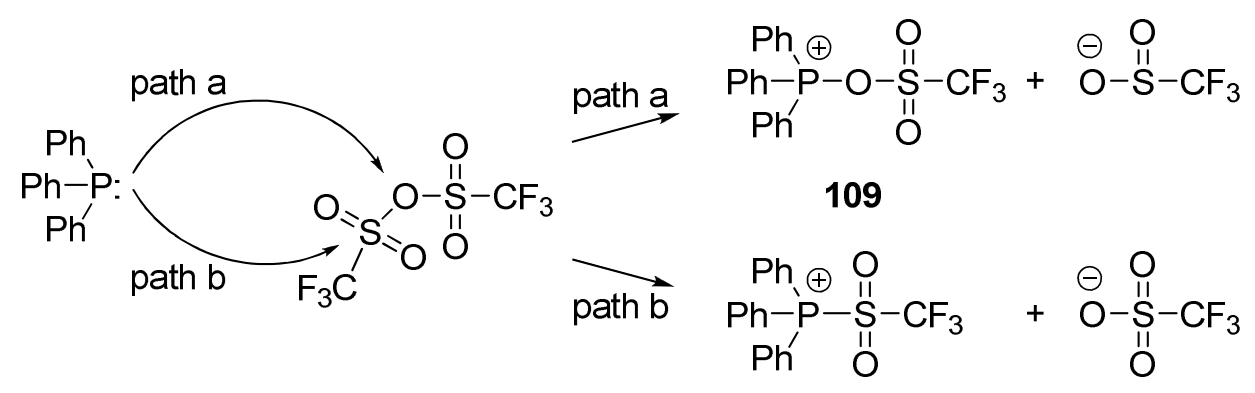

110

Scheme 25. Envisaged pathways for the reaction of $\mathrm{Ph}_{3} \mathrm{P}$ with $\mathrm{Tf}_{2} \mathrm{O}$.

To test the above hypothesis, an investigation was conducted to determine the appropriate stoichiometry of $\mathrm{Ph}_{3} \mathrm{P}$ to $\mathrm{Tf}_{2} \mathrm{O}$ required to produce the electrophilic triphenylphosphonium salt 109 and whether any dimerization to complex 111 would occur (Scheme 26). This is critical as triflic anhydride itself is an indiscriminate electrophile and any remaining unreacted excess obscures the identity of the electrophilic species responsible for dehydration. Thus, the study revealed that $\mathrm{Ph}_{3} \mathrm{P}$ and $\mathrm{Tf}_{2} \mathrm{O}$ react in a 1.3:1 stoichiometric ratio, respectively. NMR studies indicated that the reaction produces an equilibrium mixture consisting mainly of $\mathbf{1 0 9}$ and the corresponding bis(triphenyl)oxodiphosphonium trifluoromethanesulfinate dimer 111. It is noted, though, that both reacted readily and cleanly at $0{ }^{\circ} \mathrm{C}$ to effect instantaneous dehydration of aldoximes into nitriles (Table 25). The main advantages of this reagent is that it avoids the formation of a double stoichiometric amount of $\mathrm{Ph}_{3} \mathrm{PO}$ and does not require the extra unnecessary step of oxidizing the phosphine into the corresponding oxide prior to triflation, as often done in the preparation of known phosphine-based dehydrating agents.

$$
\begin{aligned}
& \mathrm{Ph}_{3} \mathrm{P}+\mathrm{Tf}_{2} \mathrm{O} \stackrel{\mathrm{a}}{\longrightarrow}\left(\mathrm{Ph}_{3} \mathrm{P}^{+}\right) \mathrm{OTf} \mathrm{Tf}^{-}+\left(\mathrm{Ph}_{3} \mathrm{P}^{+}\right)_{2} \mathrm{O} .2 \mathrm{Tf}^{-} \\
& 109 \\
& 111
\end{aligned}
$$

Scheme 26. Reagents and conditions: (a) $\mathrm{Ph}_{3} \mathrm{P}: \mathrm{Tf}_{2} \mathrm{O} ; 1.3$ : 1 stoichiometry, ${ }^{\circ} \mathrm{C}, \mathrm{CH}_{2} \mathrm{Cl}_{2}$.

3.4.2. Moussa's cyclic aromatic analogues of the Hendrickson reagent. In addition to the above analogues, Moussa reported the preparation of two novel aromatic cyclic bisphosphine analogues, 1,1,3,3-tetraphenyl-1,3-dihydro-2,1,3-benzoxadiphosphole-1,3-diium bis(trifluoromethanesulfinate) (113) and 1,1,3,3-tetraphenyl-1,3-dihydro-2,1,3-benzoxadiphosphole-1,3-diium bis (trifluoromethanesulfonate) (115) of the Hendrickson 'POP' reagent (Scheme 27). ${ }^{89}$ The advantage of these analogues over the Hendrickson reagent is that they liberate one mole of the phosphine oxide byproduct per dehydration reaction. With the latter reagent, the release of two moles of triphenylphosphine oxide exacerbates the problem of separation of the product by chromatography. On the other hand, the bisphosphine oxide by-product produced from the cyclic 
analogues is considerably more polar than $\mathrm{Ph}_{3} \mathrm{PO}$ because of the two phosphine oxide moieties, thus rendering purification much more facile. For instance, the retention factor values in a solvent system of ethyl acetate/diethyl ether (1:1) for 1,2-bis(diphenylphosphinyl)benzene and triphenylphosphine oxide were 0.04 and 0.33 , respectively.

3.4.2.1. Synthesis and electrophilic properties. The cyclic phosphonium anhydride 115 was synthesized from commercial 1,2 bis(diphenylphosphino)benzene (112) by oxidation with excess hydrogen peroxide and subsequent triflation of the resulting 1,2-bis(diphenylphosphoryl)benzene (114) with triflic anhydride (Scheme 27). Preliminary studies were carried out to determine the appropriate stoichiometry of $\mathbf{1 1 4}$ to $\mathrm{Tf}_{2} \mathrm{O}$ required to produce the electrophilic phosphonium anhydride salt 115 and whether any double triflation of 114 would occur. In principle, the bisphosphine oxide 114 may react with up to two equivalents of $\mathrm{Tf}_{2} \mathrm{O}$ to afford a mixture of 115 and 116. Thus, when 1,2-bis(diphenylphosphoryl)benzene (114) was first treated with two molar equivalents of $\mathrm{Tf}_{2} \mathrm{O}$ at $0{ }^{\circ} \mathrm{C}$, one molar equivalent of $\mathrm{Tf}_{2} \mathrm{O}$ remained unreacted and the reaction produced exclusively the cyclic anhydride 115, which proved more favorable over the alternative bis-triflated non-cyclic analogue 116. Indeed, when 1,2-bis(diphenylphosphoryl)benzene (114) was treated with one molar equivalent of $\mathrm{Tf}_{2} \mathrm{O}$ under the preceding conditions, the same product (115) formed instantaneously and promptly precipitated as a white solid within the first 10 minutes following mixing of the two reagents. It is noted, though, that 1.3 molar equivalent of 114 was required to completely consume the $\mathrm{Tf}_{2} \mathrm{O}$. Unlike the latter complex (115) which formed as the sole product, ${ }^{31} \mathrm{P}$ and ${ }^{19} \mathrm{~F}$ NMR studies have shown that species $\mathbf{1 1 3}$, formed by mixing $\mathrm{Ph}_{3} \mathrm{P}$ and $\mathrm{Tf}_{2} \mathrm{O}$ in a 1:1 molar ratio, was a predominant component in equilibrium with 1(diphenylphosphino)-2-[diphenyl(trifluoromethylsulfonyloxy)phosphonio]benzene

trifluoromethanesulfinate and 1,2-bis[diphenyl(trifluoromethylsulfonyloxy)phosphonio]benzene bis(trifluoromethanesulfinate). The dehydrating 'POP' systems were exploited in the conversion of aldoximes into nitriles (Table 25). The dehydration occurred rapidly at room temperature and produced high yields with a variety of alkyl- and arylaldoximes, tolerating a wide range of substrates and functional groups.

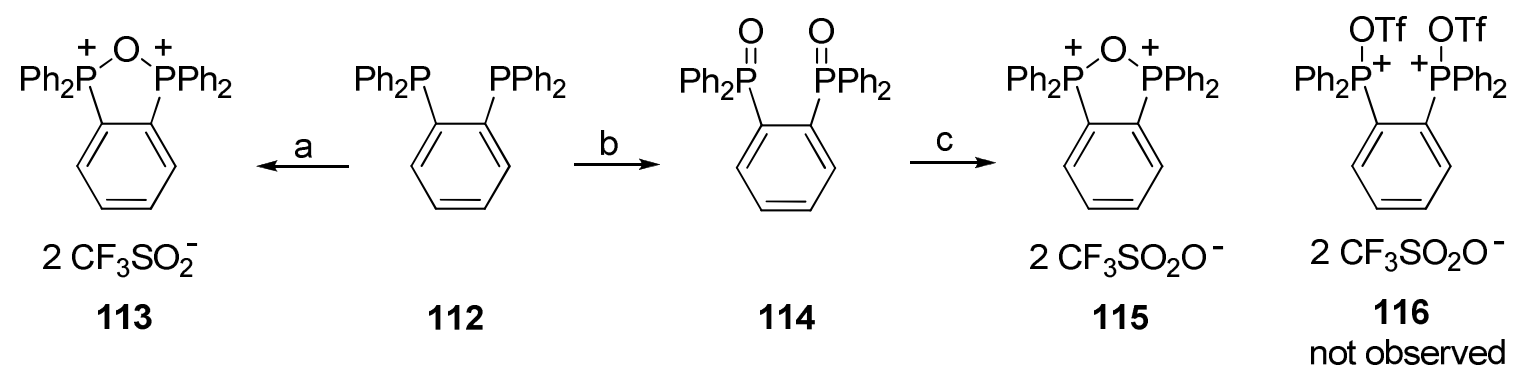

Scheme 27. Reagents and conditions: preparation of 113. (a) 112: $\mathrm{Tf}_{2} \mathrm{O}$ (1:1 stoichiometry), rt, 20 min, $\mathrm{CH}_{2} \mathrm{Cl}_{2}$; preparation of 115. (b) excess $\mathrm{H}_{2} \mathrm{O}_{2}$ (30\%), 30 min, rt, $\mathrm{CH}_{2} \mathrm{Cl}_{2}, 99 \%$. (c) 114: $\mathrm{Tf}_{2} \mathrm{O}$ (1.3:1) stoichiometry, rt, $10 \mathrm{~min}, \mathrm{CH}_{2} \mathrm{Cl}_{2}$. 
Table 25. Dehydration of aldoximes into nitriles

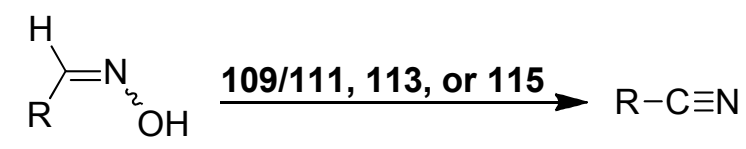

\begin{tabular}{l} 
Yield (\%) \\
115 \\
\hline
\end{tabular}


Table 25. Continued

Entry Substrate 34 \begin{tabular}{c} 
Yield (\%) \\
\cline { 3 - 5 }
\end{tabular}

\section{Conclusions}

In the past few years, the Hendrickson "POP" reagent $\mathbf{1}$ has demonstrated wide applicability as an effective dehydrating agent and its many proven applications have been well documented. The dehydrating system has since been successfully used for the preparation of 2arylbenzimidazoles directly from the acid and diamine, and for the conversion of amides and aldoximes into nitriles. Furthermore, cyclodehydration of alcohols, conversion of carboxylic acids to anhydrides and amidines, and ester and amide formation from the reaction of carboxylic acids with alcohols and amines, respectively, have been demonstrated. Others have also used it for the direct synthesis of sulfonamides and activated sulfonate esters from sulfonic acids. Recently, the synthetic utility of Hendrickson's reagent as a mediator of thiazoline and imidazoline ring formation has been demonstrated by You and Kelly and elegantly applied in the total synthesis of dendromide A, didmolamides A and B, bistratamides E-J, apratoxin A, largazole, and the preparation of $(R)$ - and $(S)$ - $\alpha$-alkylcysteines, and thiazole-based peptides. Lately, Hendrickson's reagent has emerged as a powerful activating reagent to convert an amide to its corresponding imidate under mild conditions. In one instance, this strategy triggered a mild and efficient cascade reaction, where imidate formation promoted a subsequent intramolecular aza-Diels-Alder annulation, converting the aniline-amide precursors into variously substituted indolizino[1,2-b]quinolin-9(11H)-ones. The preceding domino reaction was successfully utilized in total synthesis of camptothecin and related alkaloids, 22-hydroxyacuminatine, and luotonin A. In a related reaction, Yao et al. developed a cascade annulation comprising dehydration of an amide precursor to a highly reactive imido-carbonium intermediate and a subsequent 
intramolecular Friedel-Crafts reaction or an intramolecular aza Diels-Alder reaction to afford phenanthridines, or furo[3,4-b]quinolin-3(1H)-one derivatives, respectively. Furthermore, they developed an expedient approach to construct $11 H$-indolo[3,2-c]quinoline scaffold from acyclic alkynes via a Hendrickson reagent-promoted regioselective 6-endo cyclization. In addition, the reagent has been reported to induce the intramolecular cyclization of $\beta$-arylethylamides to access isoquinolines and $\beta$-carbolines, acting as an alternative to the Pictet-Gams reaction. Finally, several analogues of $\mathbf{1}$, including cyclic and polymer-supported versions, were developed by the Jenkins, Mahdavi, and Moussa groups. These reagents demonstrated high success in a wide range of coupling/dehydration-type reactions and rendered the purification process much more facile because they liberated a lesser amount of the phosphine oxide byproduct, which also remained attached to the resin in the case of the polymer-supported analogues.

\section{Acknowledgements}

The author would like to thank Lena Moussa for helpful discussions during the preparation of this manuscript. This work was supported by the Deanship of Scientific Research of Taibah University (project number: 162). Dr. Ziad Moussa greatly acknowledges this generous financial support.

\section{References}

1. Appel, A. Angew. Chem., Int. Ed. Engl. 1975, 14, 801.

2. Mitsunobu, O. Synthesis 1981, 1.

3. Swamy, K. C. K.; Kumar, N. N. B.; Balaraman, E.; Kumar, K. V. P. P. Chem. Rev. 2009, 109, 2551.

4. Hendrickson, J. B.; Schwartzman, S. M. Tetrahedron Lett. 1975, 277.

5. Aaberg, A.; Gramstad, T.; Husebye, S. Tetrahedron Lett. 1979, 2263.

6. Hendrickson, J. B.; Hussoin, Md. S. J. Org. Chem. 1987, 52, 4137.

7. You, S.-L.; Razavi, H.; Kelly, J. W. Angew. Chem. Int. Ed. 2003, 42, 83.

8. Hendrickson, J. B.; Hussoin, Md. S. J. Org. Chem. 1989, 54, 1144.

9. Hendrickson, J. B.; Hussoin, Md. S. Synthesis 1989, 217.

10. Hendrickson, J. B.; Hussoin, Md. S. Synlett. 1990, 423.

11. Hendrickson, J. B.; Walker, M.A.; Varvak, A., Hussoin, M.S. Synlett, 1996, 661.

12. Navia, M. A. Science 2000, 288, 2132.

13. Roush, W. R.; Gwaltney, S. L., II.; Cheng, J.; Scheidt, K. A.; McKerrow, J. H.; Hansell, E. J. Am. Chem. Soc. 1998, 120, 10994.

14. Caddick, S.; Wilden, J. D.; Judd, D. B. J. Am. Chem. Soc. 2004, 126, 1024.

15. Dwek, R. A. Chem. Rev. 1996, 96, 683. 
16. Garcia, B. A.; Gin, D. Y. J. Am. Chem. Soc. 2000, 122, 4269.

17. Shingu, Y.; Miyachi, A.; Miura, Y.; Kobayashi, K.; Nishida, Y. Carbohydr. Res. 2004, 340, 2236.

18. Mossotti, M.; Panza, L. J. Org. Chem. 2011, 76, 9122.

19. Wipf, P. Chem. Rev. 1995, 95, 2115.

20. Roy, R. S.; Gehring, A. M.; Milne, J. C.; Belshaw, P. J.; Walsh, C. T. Nat. Prod. Rep. 1999, 16, 249.

21. Kim, T.-S.; Lee, Y.-J.; Jeong, B-S.; Park, H.-G.; Jew, S.-S. J. Org. Chem. 2006, 71, 8276.

22. Jung, M. E.; Huang, A. Org. Lett. 2000, 2, 2659.

23. Langlois; Y.; Dalko, P. I. J. Org. Chem. 1998, 63, 8107.

24. Corey, E. J.; Grogan, M. J. Org. Lett. 1999, 1, 157.

25. Menges, F.; Neuburger, M.; Pfaltz, A. Org. Lett. 2002, 4, 4713.

26. Gust, R.; Keilitz, R.; Schmidt, K.; von Rauch, M. J. Med. Chem. 2002, 45, 3356.

27. You, S.-L.; Kelly, J. W. Org. Lett. 2004, 6, 1681.

28. Du, X.; Liu, H.; Du, D-M. Eur. J. Org. Chem. 2011, 786.

29. Mei, L.-Y.; Yuan, Z.-L.; Shi, M. Organometallics, 2011, 30, 6466.

30. Borst, P. Ann. Oncol. 1999, 10, 162.

31. Christensen, C.; Schiodt, C. B.; Foged, N. T.; Meldal, M. QSAR Comb. Sci. 2003, 22, 754.

32. Biron, E.; Chatterjee, J.; Kessler, H. Org. Lett. 2006, 8, 2417.

33. Staker, B. L.; Hjerrild, K.; Feese, M. D.; Behnke, C. A.; Burgin, A. B., Jr.; Stewart, L. Proc. Natl. Acad. Sci. 2002, 99, 15387.

34. Zhou, H.-B.; Liu, G.-S.; Yao, Z.-J. Org. Lett. 2007, 9, 2003.

35. Liang, Y.; Jiang, X; Yu, Z.-X. Org. Lett. 2009, 11, 5302.

36. (a) Michael, J. P. Nat. Prod. Rep. 2001, 18, 543. (b) Funayama, S.; Murata, K.; Noshita, T. Heterocycles 2001, 54, 1139. (c) Abass, M. Heterocycles 2005, 65, 901. (d) Henry, G. D. Tetrahedron 2004, 60, 6043. (e) Jones, G. In Comprehensive Heterocyclic Chemistry II; Katritzky, A. R., Rees, C. W., Scriven, E. F. V., McKillop, A., Eds.; Pergamon: Oxford, 1996. Vol. 5, p 167.

37. Dong, Q.-L.; Liu, S.-G.; Zhou, H.-B.; Chen, L.; Yao, Z.-J. Tetrahedron Lett. 2008, 49, 1636.

38. (a) Bentley, K. W. Nat. Prod. Rep. 1992, 9, 365. (b) Bentley, K. W. Nat. Prod. Rep. 2000, 17, 247. (c) Bentley, K. W. Nat. Prod. Rep. 2001, 18, 148. (d) Bentley, K. W. Nat. Prod. Rep. 2002, 19, 332. (e) Bentley, K. W. Nat. Prod. Rep. 2003, 20, 342. (f) Bentley, K. W. Nat. Prod. Rep. 2004, 21, 395.

39. Love, B. E. Org. Prep. Proced. Int. 1996, 28, 1. (b) Cox, E. D.; Cook, J. M. Chem. Rev. 1995, 95, 1797.

40. Pictet, A.; Gams, A. Ber. Dtsch. Chem. Ges. 1909, 42, 1973.; Pictet, A.; Spengler, T. Ber. Dtsch. Chem. Ges. 1911, 44, 2030.

41. Wu, M.; Wang, S. Synthesis 2010, 4, 587.

42. Rahman, A.; Malik, S.; Zaman, K. J. Nat. Prod. 1992, 55, 676. 
43. Gozler, T.; Gozler, B.; Linden, A.; Hesse, M. Phytochemistry 1996, 43, 1425.

44. Blackman, A. J.; Matthews, D. J.; Narkowicz, C. K. J. Nat. Prod. 1987, 50, 494.

45. Bondarev, S. L.; Knyukshto, V. N.; Tikhomirov, S. A.; Pyrko, A. N. Opt. Spectrosc. 2006, $100,386$.

46. Korth, C.; May, B. C.; Cohen, F. E.; Prusiner, S. B. Proc. Natl. Acad. Sci. U.S.A. 2001, 98, 9836.

47. Mamalis, P.; Petrow, V. J. Chem. Soc. 1950, 703. (b) Buu-Hoï, N. P.; Jaquignon, P.; Long, C. T. J. Chem. Soc. 1957, 505.

48. For recent syntheses of phenanthridines, see: (a) Patra, P. K.; Suresh, J. R.; Ila, H.; Junjappa, H. Tetrahedron 1998, 54, 10167. (b) Gug, F.; Bach, S.; Blondel, M.; Vierfond, J.-M.; Martin, A.-S.; Galons, H. Tetrahedron 2004, 60, 4705. (c) Pawlas, J.; Begtrup, M. Org. Lett. 2002, 4, 2687. (d) Banwell, M. G.; Lupton, D. W.; Ma, X. H.; Renner, J.; Sydnes, M. O. Org. Lett. 2004, 6, 2741. (e) Mehta, B. K.; Yanagisawa, K.; Shiro, M.; Kotsuki, H. Org. Lett. 2003, 5, 1605. (f) Li, D.; Zhao, B.; LaVoie, E. J. J. Org. Chem. 2000, 65, 2802. (g) Hilt, G.; Hess, W.; Schmidt, F. Eur. J. Org. Chem. 2005, 2526. (h) Liepa, A. J.; Nearn, R. N.; Wright, D. M. J. Aust. J. Chem. 2004, 57, 473. (i) Lysén, M.; Kristensen, J. L.; Vedsø, P.; Begtrup, M. Org. Lett. 2002, 4, 257. (j) Shabashov, D.; Daugulis, O. J. Org. Chem. 2007, 72, 7720. (k) Appukkuttan, P.; Dehaen, W.; Van Der Eycken, E. Chem. Eur. J. 2007, 13, 6452. (1) Bowman, W. R.; Lyon, J. E.; Pritchard, G. J. Synlett 2008, 2169. (m) Portela- Cubillo, F.; Scott, J. S.; Walton, J. C. J. Org. Chem. 2008, 73, 5558. (n) Gerfaud, T.; Neuville, L.; Zhu, J. Angew. Chem. Int. Ed. 2009, 48, 572. (o) Youn, S. W.; Bihn, J. H. Tetrahedron Lett. 2009, 50, 4598.

49. Xi, J.; Dong, Q.-L.; Liu, G.-S.; Wang, D.; Yao, Z. J. Synlett. $2010,1674$.

50. For a review, see: Lavrado, J.; Moreira, R.; Paulo, A. Curr. Med. Chem. 2010, 17, 2348.

51. (a) Pousset, J.-L.; Martin, M.-T.; Jossang, A.; Bodo, B. Phytochemistry 1995, 39, 735. (b) Van Miert, S.; Hostyn, S.; Maes, B. U. W.; Cimanga, K.; Brun, R.; Kaiser, M.; Matyus, P.; Dommisse, R.; Lemiere, G.; Vlietinck, A.; Pieters, L. J. Nat. Prod. 2005, 68, 674.

52. (a) Lu, C.-M.; Chen, Y.-L.; Chen, H.-L.; Chen, C.-A.; Lu, P.-J.; Yang, C.-N.; Tzeng, C.-C. Bioorg. Med. Chem. 2010, 18, 1948. (b) He, L.; Chang, H.-X.; Chou, T.-C.; Savaraj, N.; Cheng, C.-C. Eur. J. Med. Chem. 2003, 38, 101. (c) Chen, Y.-L.; Chung, C.-H.; Chen, I.L.; Chen, P. H.; Jeng, H.-Y. Bioorg. Med. Chem. 2002, 10, 2705.

53. Xu, M.; Hou, Q.; Wang, S.; Wang, H.; Yao, Z. J. Synthesis 2011, 626.

54. Desrat, S.; van de Weghe, P. J. Org. Chem. 2009, 74, 6728.

55. (a) Desrat, S.; van de Weghe, P. J. Org. Chem. 2009, 74, 6728. (b) Sagi, M.; Sato, O.; Konno, S. Heterocycles 1989, 29, 2253. (c) Townsend, N. O.; Jackson, Y. A.; Yamanaka, H. Heterocycles 2007, 71, 669. (d) Haddadin, M. J.; Zahr, G. E.; Rawdah, T. N.; Chelhot, N. C.; Issidorides, C. H. Tetrahedron 1974, 30, 659. (e) Anzini, M.; Cappelli, A.; Vomero, S. Heterocycles 1994, 38, 103.

56. Xu, P.; Liu, S.-G.; Xi, J.; Wang, S.; Yao, Z. J. Tetrahedron, 2011, 65, 5455.

57. Ogino, J.; Moore, R. E.; Patterson, G. M. L.; Smith, C. D. J. Nat. Prod. 1996, 59, 581. 
58. (a) Borst, P. Ann. Oncol. 1999, 10, Suppl. 4, 162-164. (b) Kaye, S. B. Curr. Opin. Oncol. 1998, 10, Suppl. 1, S15. (c) Leith, C. Curr. Opin. Oncol. Hematol. 1998, 5, 287. (d) Lawrence, D. S.; Copper, J. E.; Smith, C. D. J. Med. Chem. 2001, 44, 594.

59. You, S.-L.; Kelly, J. W. J. Org. Chem. 2003, 68, 9506.

60. (a) You, S.-L.; Kelly, J. W. Chem. Eur. J. 2004, 10, 71. (b) You, S.-L.; Kelly, J. W. Tetrahedron, 2005, 61, 241.

61. J. Perez, D. J. Faulkner, J. Nat. Prod. 2003, 66, 247.

62. Rudi, A.; Chill, L.; Aknin, M.; Kashman, Y. J. Nat. Prod. 2003, 66, 575.

63. You, S.-L.; Kelly, J. W. Tetrahedron Lett. 2005, 46, 2567.

64. Taori, K.; Paul, V. J.; Luesch, H. J. Am. Chem. Soc. 2008, 130, 1806.

65. Ying, Y.; Taori, K.; Kim, H.; Hong, J.; Luesch, H. J. Am. Chem. Soc. 2008, 130, 8455.

66. Ghosh, A.K.; Kulkarni, S. Org. Lett. 2008, 10, 3907.

67. (a) Luesch, H.; Yoshida, W. Y.; Moore, R. E.; Paul, V. J.; Corbett, T. H. J. Am. Chem. Soc. 2001, 123, 5418. (b) Luesch, H.; Yoshida, W. Y.; Moore, R. E.; Paul, V. J. Bioorg. Med. Chem. 2002, 10, 1973.

68. Luesch, H.; Chanda, S. K; Raya, R. M; Dejesus, P. D; Orth, A. P; Walker, J. R; Belmonte, J. C. I; Schultz, P. G. Nat. Chem. Biol. 2006, 2, 158.

69. (a) Doi, T.; Numajiri, Y.; Munakata, A.; Takahashi, T. Org. Lett. 2006, 8, 531. (b) Numajiri, Y.; Takahashi, T.; Doi. T. Chem. Asian J. 2009, 4, 111.

70. Wall, M. E.; Wani, M. C.; Cook, C. E.; Palmer, K. H.; McPhail, A. T.; Sim, G. A. J. Am. Chem. Soc. 1966, 88, 3888.

71. (a) Hsiang, Y. H.; Hertzberg, R.; Hecht, S. M.; Liu, L. F. J. Biol. Chem. 1985, 260, 14873.

(b) Kohn, K. W.; Pommier, Y. Ann. N.Y. Acad. Sci. 2000, 922, 11. (c) Staker, B. L.; Hjerrild, K.; Feese, M. D.; Behnke, C. A.; Burgin, A. B., Jr.; Stewart, L. Proc. Natl. Acad. Sci. 2002, 99, 15387.

72. For reviews on camptothecin and its derivatives, see: (a) Du, W. Tetrahedron 2003, 59, 8649. (b) Wall, M. E.; Wani, M. C. In The Alkaloids; Cordell, G. A., Ed.; Academic Press: San Diego, CA, 1998; Vol. 50, Chapter 13, pp 509-520. (c) Hutchinson, C. R. Tetrahedron 1981, 37, 1047.

73. Zhou, H.-B.; Liu, G.-S.; Yao, Z.-J. Org. Lett. 2007, 9, 2003.

74. Lin, L. Z.; Cordell, G. A. Phytochemistry 1989, 28, 1295.

75. Ma, Z. Z.; Hano, Y.; Nomura, T.; Chen, Y.-J. Heterocycles 1997, 46, 541.

76. Zhou, H.-B.; Liu, G.-S.; Yao, Z.-J. J. Org. Chem. 2007, 72, 6270.

77. Xiao, X.; Antony, S.; Pommier, Y.; Cushman, M. J. Med. Chem. 2006, 49, 1408.

78. Cheng, K. J.; Rahier, N. J.;. Eisenhauer, B. M.; Gao, R.; Thomas, S. J.; Hecht, S. M. J. Am. Chem. Soc. 2005, 127, 838.

79. N. J. Rahier, K. J. Cheng, R. Gao, B. M. Eisenhauer, S. M. Hecht, Org. Lett. 2005, 7, 835.

80. Liu, G.-S.; Yao, Y.-S.; Xu, P.; Wang, S.-Z.; Yao, Z.-J. Chem. Asian J. 2010, 5, 1382.

81. Elson, K. E.; Jenkins, I. D.; Loughlin, W. A. Aust. J. Chem., 2004, 57, 371.

82. Petersson, M. J.; Jenkins, I. D.; Loughlin, W. A. Org. Biomol. Chem. 2009, 7, 739. 
83. For example see (a) Shuttleworth, S. J.; Allin, S. M.; Sharma, P. K. Synthesis 1997, 1217. (b) Ley, S. V.; Baxendale, I. R.; Bream, R. N.; Jackson, P. S.; Leach, A. G.; Longbottom, D. A.; Nesi, J. S.; Storer, R. I.; Taylor, S. J. J. Chem. Soc., Perkin Trans. 1 2000, 3815. (c) Ley, S. V.; Baxendale, I. R. The Chemical Record 2002, 2, 377.

84. Fairfull-Smith (nee Elson), K. E.; M. J.; Jenkins, I. D.; Loughlin, W. A. Org. Biomol. Chem. 2004, 2, 1979.

85. Elson, K. E.; Jenkins, I. D.; Loughlin, W. A. Tetrahedron Lett. 2004, 45, 2491.

86. Petersson, M. J.; Jenkins, I. D.; Loughlin, W. A. J. Org. Chem. 2008, 73, 4691.

87. Mahdavi, H.; Amani, J. Tetrahedron Lett. 2008, 49, 2204.

88. Moussa, Z.; Ahmed, S. A.; ElDouhaibi, A. S.; Al-Raqa, S. Y. Tetrahedron Lett. 2010, 51, 1826.

89. Moussa, Z. Synthesis 2012, 44, 460.

\section{Author's Biography}

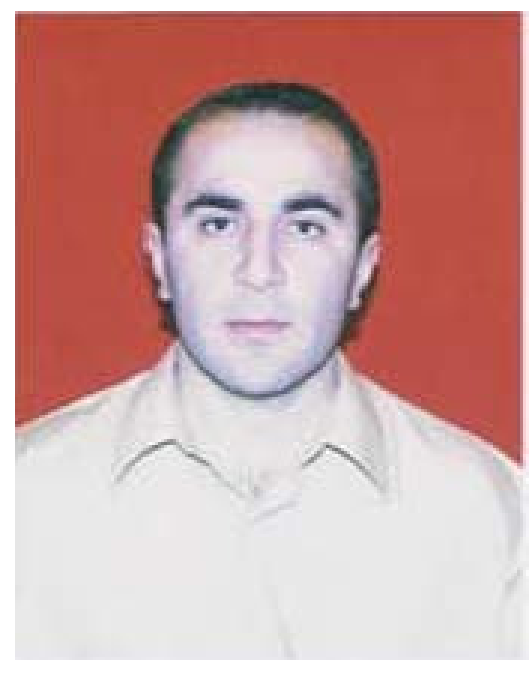

Dr. Ziad Moussa, Taibah University

Ziad Moussa was born in Lebanon in 1976 and grew up in Calgary, Canada where he undertook undergraduate and postgraduate studies in chemistry at University of Calgary (B.Sc. 1998, Ph.D. 2003). His Ph.D. research was conducted under the supervision of prof. Thomas G. Back and focused on the synthesis and evaluation of some novel selenium-based chiral auxiliaries and glutathione peroxidase mimetics. Following postdoctoral research at Texas A\&M University (2003-2006) in the laboratories of Prof. Daniel Romo, he joined the department of chemistry at Taibah University as an assistant professor (2006-present). His main research interests include the development of synthetic methodologies and the synthesis and characterization of novel 
bioactive organic/heterocyclic compounds with anticancer, antiviral, and antimicrobial activities. Dr. Ziad is married to Lena Moussa (nee Hammoud) with two kids, Ali and Nadine. 